Portland State University

PDXScholar

$1-1-1981$

\title{
Organizational innovation in a professional school: a case study
}

Marie Streng Berger

Portland State University

Follow this and additional works at: https://pdxscholar.library.pdx.edu/open_access_etds Let us know how access to this document benefits you.

Recommended Citation

Berger, Marie Streng, "Organizational innovation in a professional school: a case study" (1981).

Dissertations and Theses. Paper 778.

https://doi.org/10.15760/etd.778

This Dissertation is brought to you for free and open access. It has been accepted for inclusion in Dissertations and Theses by an authorized administrator of PDXScholar. Please contact us if we can make this document more accessible: pdxscholar@pdx.edu. 


\section{ORGANIZATIONAL INNOVATION IN A PROFESSIONAL \\ SCHOOL: A CASE STUDY}

by

MARIE STRENG BERGER

A dissertation submitted to the faculty of the School of Urban Affairs in partial fulfillment of the requirements for the degree of

\section{DOCTOR OF PHILOSOPHY}

Portland State University

1981 
TO THE OFFICE OF GRADUATE STUDIES AND RESEARCH:

The members of the Committee approve the dissertation of Marie Streng Berger presented on February 17, 1981.
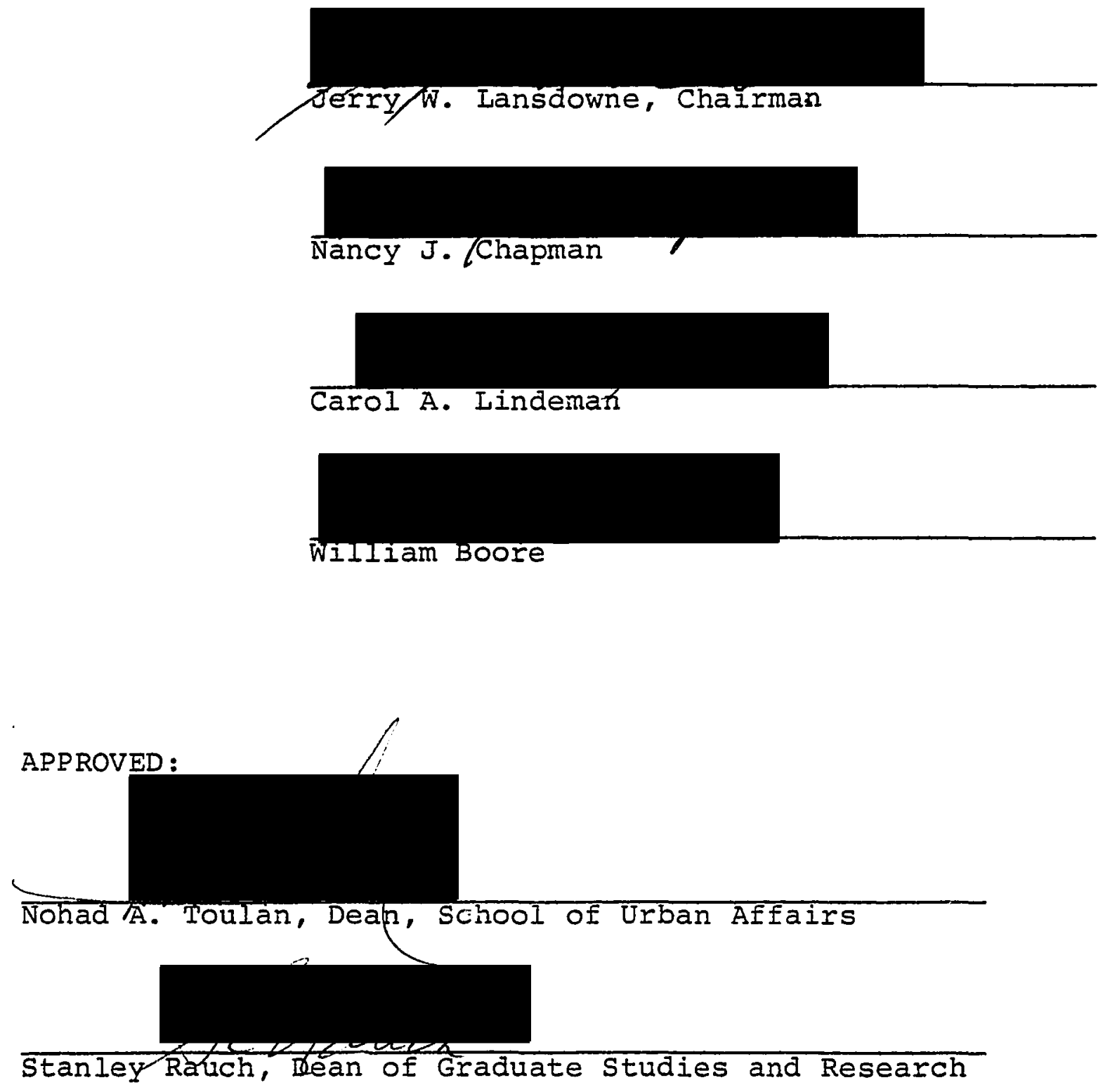
AN ABSTRACT OF THE DISSERTATION OF Marie streng Berger for the Doctor of Philosophy in Urban Studies presented February $17,1981$.

Title: Organizational Innovation in a Professional School: A case Study.

APPROVED BY MEMBERS OF THE DISSERTATION COMMITTEE:
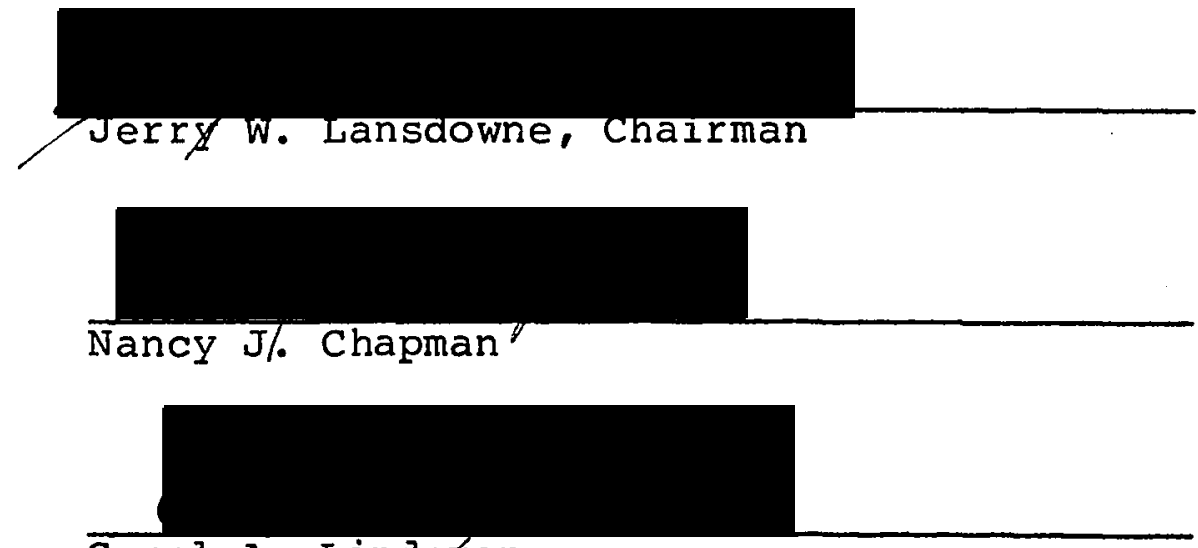

Carol A. Lindernan

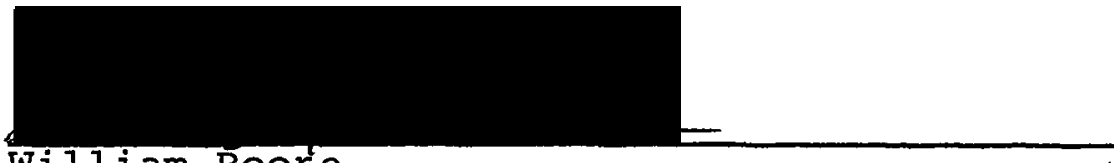

William Boore

The purpose of this research was to apply specific organization development strategies in a professional school to test the applicability of Argyris' Theory and Method Model for this setting. The research was designed to determine the effectiveness of group decision-making processes before and after intervention. In order to accomplish 
this, the research included two phases. The purpose of Phase one was to involve all members in the organization development program so valid information could be collected about strengths, limitations, and problems of the organization.

Data for this phase were collected by individual and group interviews. These interviews, while unstructured, were designed to accomplish four objectives: (I) to provide information about perceived strengths and limitations, (2) to ascertain the direction participants wanted the organization to take, (3) to identify specific problem areas, and (4) to ascertain the perceived need for change. In addition, participants were asked to complete a questionnaire designed to elicit perceptions of emphasis given to four missions of the school and the adequacy of the support services and personnel.

As a result of the data collected, a new organizational structure was developed by the participants and the researcher. Problem areas were also identified.

Phase Two of the research was an experimental study of impact of three interventions on the effectiveness of a group. Effectiveness was measured by a positive change in (1) the degree of collaboration used in problem solving, (2) the effectiveness of communication, (3) role clarity, and (4) the level of trust, concern, and individuality behaviors. 
The two larger departments were selected for this phase, one serving as the experimental group and the other as the control group. Two data collection methods were employed, the Meetings Questionnaire and nonparticipant observation.

The Meetings Questionnaire, a 36-item instrument, measures perceived collaboration, communication, and role clarity. Participants were asked to complete this questionnaire before and after intervention.

Nonparticipant observation data were collected by trained observers using Argyris' system of categories. Baseline information on the percent of trust, individuality, and concern behaviors were collected for three weeks before intervention. Post-intervention data were collected for three weeks by the same observers.

The organization development strategies employed in the three-week intervention period were survey feedback, process consultation, and coaching/modeling. In the survey feedback, data collected from both the questionnaire and the observations were reported to the experimental group during the first week at a two-hour department meeting. The observational categories were also explained and discussed. During the next two weeks, the researcher served as process consultant at the experimental group department meetings, using coaching and modeling of facilitative behaviors as a teaching method. 
Post-treatment data indicated no significant change in collaboration, communication, role clarity, or trust, concern, and individuality behaviors. The conclusions drawn were that the organization development strategies had little impact on improving organizational effectiveness. The fact that none of the hypotheses were supported does not mean that OD has no value for professional schools, but may be due to the inadequacy of the instruments used. It was further suggested that the time actually spent on intervention may have been too short and the intervention too mild to effect a change in the numerous dependent variables of the research. 


\section{ACKNOWLEDGMENTS}

Thanks to my Eamily, Eriends, and colleagues who gave me the love, emotional support, and pragmatic suggestions I needed to accomplish this task.

My appreciation and thanks are also given to Jerry Lansdowne for believing in me, and to my Committee members for "sticking with me" through the process.

Special appreciation goes to Nancy Chapman for her helpful comments and assistance, and for the many hours she spent critically reviewing this dissertation.

I also appreciate the helpful suggestions from Carol Iindeman and Bill Boore. 
TABLE OF CONTENTS

PAGE

ACKNOWLEDGMENTS . . • . . . . . . . . . . . . . . . i ii

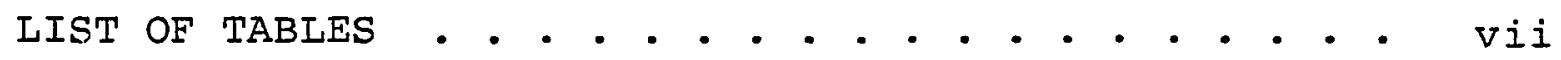

LIST OF FIGURES • • • • • • • • • • • • • • • • • • • viii

\section{CHAPTER}

I INTRODUCTION

Purpose of the Study . . . . . . . . 3

Assumptions of the Study . . . . . . 4

Organization Development Defined . . . 5

The Role of the Consultant/Change

Agent . . . . . . . . . . . . 9

Need for the Study ........... . . 18

Organization Development in the

Measuring the Impact of Organization
Development . . . . . . . . 27

Summary . . . . . . . . . . . . 28

Organization of the Dissertation . . . 30

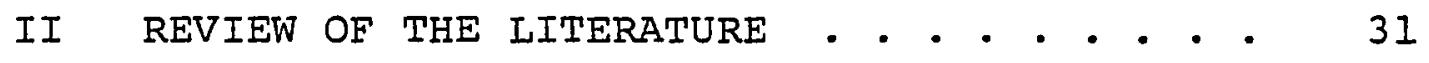

Modern Organizations . . . . . . 31

Trust, Concern, and Individuality . . 47 


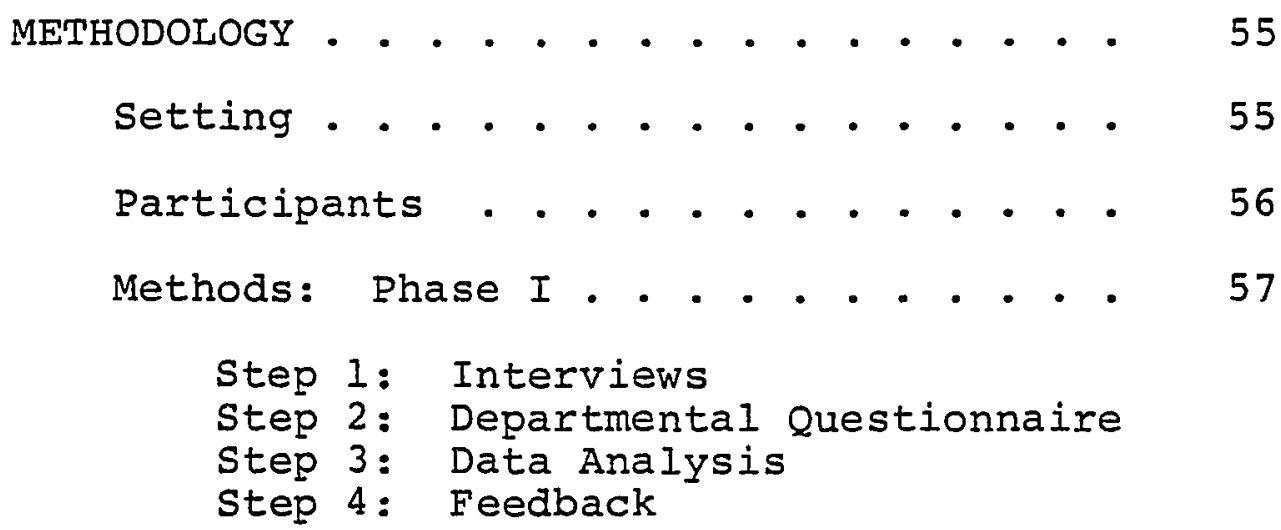

Methods: Phase II ......... . 59

Pre-test/post-test Control Group Design

Time Series Design

Dependent and Independent Variables

Intervention

Data Analysis . . . . . . . . . . 76

IV RESULTS AND DISCUSSION: PHASE I • . . . . 78

Individual and Group Interviews . . . 78

Question I

Question II

Question III

Question IV

Question V

Missions of the School . . . . . . . 91

Teaching

Community Service

Research

Practice

Summary

Support Services . . . . . . . . . 94

Summary 
V RESULTS AND DISCUSSION: PHASE II . . . . . 96

Hypothesis I . . . . . . . . . . 97

Hypothesis II . . . . . . . . . 102

Hypothesis III . . . . . . . . 106

Hypotheses IV, V, and VI . . . . . 107

\section{Hypothesis IV}

Hypothesis V

Hypothesis VI

Summary . . . . . . . . . . . . 127

VI SUMMARY, CONCIUSIONS, AND RECOMMENDATIONS • 128

Introduction . . . . . . . . . 128

Summary of Phase I . . . . . . . 129

Summary of Phase II . . . . . . . 132

Conclusions . . . . . . . . . . 133

Recommendations for Future Research . . 137

REFERENCES • . . . . . . . . . . . . . . . . . . 139

APPENDICES . . . . . . . . . . . . . . . . . . . 146

A DEPARTMENTAL ANALYSIS QUESTIONNAIRE . . . 147

B STAFF MEETINGS . . . . . . . . . . . 149 


\section{LIST OF TABLES}

TABLE

PAGE

I Roles of Change Agents . . . . . . . . 14

II Organizational Value systems . . . . . . . . 34

III System of Categories: Interpersonal

Effectiveness . . ... . . . . . . 54

IV Mean Responses: Perceived Emphasis on

Missions of the School . . . . . . . . 91

$\mathrm{V}$ Mean Responses: Perceived Adequacy of

Support Services . . . . . . . . . 94

VI Pre-test and Post-test Mean Responses of

Experimental and Control Group to the

Meetings Questionnaire--Collaboration . .

VII Pre-test and Post-test Mean Responses of

Experimental and Control Group to the

Meetings Quesionnaire--Communication . .

VIII Pre-test and Post-test Mean Responses of

Experimental and Control' Group to the

Meetings Questionnaire--Role Clarity . .

IX Frequency and Percentage of Norms Observed

in Experimental Group Meetings . . . . 110

$X$ Frequency and Percentage of Norms Observed

in Control Group Meetings . . . . . . 114 


\section{LIST OF FIGURES}

FIGURE

PAGE

1. Some Relationships of Trust, Opennness,

Adaptation, and Effectiveness . . . . . 51

2. Current organizational Structure, 1977 . . . 83

3. Model A . . . . . . . . . . . . . 85

4. Model B . . . . . . . . . . . . . . 86

5. Model C . . . . . . . . . . . . . . 87

6. Model D . . . . . . . . . . . . 88

7. Model E . . . . . . . . . . . . . 90

8.- Model F . . . . . . . . . . . . . . . 92

9. Frequency of Individuality: Ideas . . . . . 117

10. Frequency of Individuality: Feelings . . . 119

11. Frequency of Concern: Ideas . . . . . . . 121

12. Frequency of Concern: Feelings . . . . . . 122

13. Frequency of Trust: Ideas . . . . . . . 125

14. Frequency of Trust: Feelings . . . . . . . 126

15. Intermediate Model--1978-1981 . . . . . 131 


\section{CHAPTER I}

\section{INTRODUCTION}

There are a number of ways in which organizational effectiveness can be improved, and organization development (OD) represents one such method. As a field, OD has its roots in the movement toward humanistic theories of management which began in the late 1940 s and 1950s. It has emerged from the demands of a rapidly changing society for more flexible institutions, and has been given impetus by the growing body of knowledge provided by the applied behavioral sciences. Many social transformations occurring in our society have also contributed to the emergence of organization development as a field. The dramatic changes in life styles, needs, and values that have occurred in recent years have necessitated a new approach to the worker. For example, increase in professionalization, educational level, and mobility have decreased organizational loyalty and dependency (Friedlander \& Brown, 1974). In management literature there has also been a gradual shift from organizational relevance to personal relevance. As Varney suggests:

- - the entire field of organizational development (OD) has emerged in direct response to the problems managers face in keeping up with the changes in our society and in the highly technical and ever-changing environment in which they find themselves (1977, p. 4). 
The strategies of organization development emphasize the use of behavioral sciences theory and research to help an organization improve the porcesses it utilizes to do its work. Such processes include decision making, problem solving, communication patterns, as well as work relationships and transactions which occur among organizational members. In general, organization development can be described as a tool with which an organization assesses its functioning; that is, what is working wely and what is not. Through the use of organization development technology, managers can learn how to evaluate and make appropriate changes in behavior, processes, or structures, so that the organization functions more effectively.

Organization development has been used frequently in the private, for-profit sector, but has been used infrequently in public sector settings such as large government organizations, academic settings, and professional schools. Furthermore, evaluation of organization development programs is infrequently done, perhaps because such evaluation is a complicated and difficult task. As French and Bell suggest," . . teasing out the effects of specific interventions or even a large OD program is an inherently formidable task" (1978, p. 226). Whereas there is evidence that $O D$ is a successful strategy for improving individual and organizational effectiveness in the private sector 
organization, there is no evidence with respect to its effects in the public sector.

\section{PURPOSE OF THE STUDY}

The purpose of this research was to test the applicability of Argyris' Theory and Method model to a professional school. Testing of this organization development model required two phases. The first phase was an assessment of the strengths and limitations of the organizational structure and support services, and the emphasis given to the four missions of the school (teaching, research, clinical practice, and community service) as perceived by all members of the organization. This assessment phase was designed to involve members of the organization in the OD process and to provide an initial diagnosis of the organization.

The second phase. was measurement of the impact of specific OD strategies on effectiveness of a group as measured by change in:

(a) The degree of collaboration utilized for problem solving and decision making

(b) The effectiveness of communication

(c) Role clarity

(d) The level of trust, concern, and individuality behaviors 
The research reported here fills a major gap in a Iiterature characterized by a scarcity of organization development evaluations and complete lack of reports of organization development applied in public sector organizations, including professional schools. Its contribution is enhanced by the use of two methodological improvements over the majority of organization development research: a control group research design and pre-treatment and posttreatment measures, neither of which is typically found in studies of organization development.

\section{ASSUMPTIONS OF THE STUDY}

This research paper was based on the following assumptions :

1. Collaboration, effective communication, and behaviors defined as trust, concern, and individuality are factors that contribute to organizational effectiveness.

2. The behaviors of organizational members are learned behaviors and can be changed when, during the process of $O D$, opportunities to learn alternative behaviors are presented.

In addition to these assumptions of the present study, there are assumptions and values which underlie most organization development activities. These assumptions are humanistic, developmental, and optimistic and relate to people as individuals, as members of a group, and as 
members in the larger organizational system. The basic tenets of $O D$ can be described as follows:

1. Most individuals have drives toward personal growth and development if provided an environment that is both supportive and challenging.

2. Most people desire to make, and are capable of making, a higher level of contribution to the attainment of organizational goals than most organizational environments will permit.

3. One of the most psychologically relevant reference groups for most people is the work group, including peers and the superior.

4. Most people wish to be accepted and to interact cooperative $\bar{y}$ with at least one small reference group, . and usually with more than one group.

5. For a group to optimize its effectiveness, the formal leader cannot perform all the leadership and maintenance functions in all circumstances.

6 . Suppressed feelings and attitudes adversely affect problem solving, personal growth, and job satisfaction.

7. The level of interpersonal trust, support, and cooperation is much lower in most groups and organizations than is either necessary or desirable.

8. Solutions to most attitudinal and motivational problems in organizations are transactional. That is, such problems have the greatest chance of constructive solution if all parties in the system. . . alter their mutual relationships.

9. . . the leadership style and the climate of the higher team [in the organization] tends to get transmitted to the lower team.

10. "Win-lose" conflict strategies between people and groups . . . are not optimal in the long run to the solution of most organizational problems. (French $\checkmark$ Bell, 1978, pp. 30-34)

\section{ORGANIZATION DEVELOPMENT DEFINED}

Although the term "organization development" could be used to refer to a wide range of strategies for improving an organization, the phrase has come to imply a set of fairly specific meanings. French and Bell comment that the meanings can only be called "fairly" specific because 
". . the boundaries are not entirely clear, perceptions of different authors and practitioners vary somewhat, and the field is evolving" (1978, p. 14). Consistent with its continuing development, organization development has been defined, redefined, and discussed by social scientists and practitioners in a variety of publications. In the behavioral sciences, and as French and Bell state, ". . perhaps [the] ideal, sense of the term...", OD is a "long range effort to improve an organization's problem solving and renewal processes. . with special emphasis on the culture of formal work teams..." (1978, p. 14).

A number of authors have attempted to define OD in more operational terms. Warren Bennis, for example, describes it as:

- a response to change, a complex educational
strategy intended to change the beliefs, attitudes,
values, and structure of organizations so that they
can better adapt to new technologies, markets, and
challenges, and the dizzying rate of change
itself. . (1968, p. 2)
When $O D$ is seen as an educational strategy, its practice generally involves the use of laboratory methods, essentially unstructured small group experiences during which members learn from their own interactions and the group's dynamics.

A somewhat broader view is presented by Beckhard, who states that $O D$ is a change strategy which is:

- . 1. planned, 2. organization wide, 3. managed from the top, to 4. increase organizational effectiveness and health through 5. planned interventions 
in the organizaion's processes, using behavioral science knowledge. (1969, p. 9)

Such planned interventions, regardless of the technology used, generally use an action research process which includes generation and collection of data, their feedback to the client system, and sound organizational diagnosis.

According to Argyris, $O D$ is a combination of inquiring, collecting valid data, generating options and choices from the data, and exercising free choices (1973). Successful change efforts begin with measurement of the way in which the organization is presently functioning. These measurements provide the information for the diagnosis and the diagnosis forms the basis for the design of a program of change activity, if change is needed.

Clarifying the subsequent process of organizational change, Goodstein states that:

- . OD covers all those attempts to change an organization's culture from one in which there is avoidance of any examination of social processes, such as communication, planning, and decision-making, to one that institutionalizes and legitimizes this kind of self-examination. Further, OD involves the changing of an organization from one that resists change to one that promotes the planning and use of procedures to adapting to needed changes on a regular basis. (1978, p. 47)

Clearly, there are:

- . as many theories of organizational behavior as there are theorists... . the personal predilections of the consultant appear to be the most common basis for accepting one over any other. (Goodstein, 1978, p. 59).

Because of this lack of a unified theory of organizational 
behavior, a consultant may view an organization from a variety of theoretical perspectives. The particular aspect of organizational life on which the consultant chooses to focus and the outcomes she/he selects as measures of success will necessarily differ with her/his own individual theoretical orientation. As Goodstein notes:

While the goals of $O D$ remain general, humanization of organizations through an optimizing of process or task or some combination of these, there is no longer any single technology, approach, or method by which such goals are to be achieved . . (1978, p. 122)

Despite the diversity of OD theory, there are three basic components of the OD process, including elements of diagnosis, action, and process-maintenance. The first step of any $O D$ process is to diagnose the state of the organization, specifically, its strengths, limitations, and its problem areas. The importance of gathering information about the status quo of the organization is emphasized by Beckhard who argues that:

The development of a strategy for systematic improvement of an organization demands an examination of the present state of things. Such an analysis usually looks at two broad areas. One is a diagnosis of the various subsystems that make up the total organization. These subsystems may be natural "teams" such as top management, . . or they may be levels such as top management, middle management, of the wcrk force. The second area of diagnosis is the organizational processes that are occurring. These include decision-making processes, communication patterns and styles, relationships. . . the management of conflict . . (1969, p. 26)

The second element, the action/feedback component, includes measures taken to correct problem areas discovered 
in the diagnostic phase. Such corrective action is achieved through activities called interventions, which are a set of structured activities involving the target group(s).

The third element, the process-maintenance component, is designed to model self-analysis and reflection as a means of self-improvement and hence organizational improvement. The OD practitioner actively works with the client system so that behaviors learned during the oD program can be maintained by the clients when the formal program is completed.

The definition of OD adopted by the present investigator was derived from the literature and was as follows: the process of diagnosis, data collection, data feedback, action planning, action, and evaluation which occurs in an organization with the help of a change agent, for the purpose of improving organizational effectiveness by altering processes or structures of the organization.

\section{THE ROLE OF THE CONSULTANT/CHANGE AGENT}

The OD consultant fulfills a variety of roles in the $O D$ process. According to French and Bell, these roles include: helping the client system develop its own resources; utilizing a developmental, collaborative approach with organizational members; suggesting and facilitating appropriate interventions given the organizational diagnosis; providing a model for behavior in the organization in terms of 
openness, risk taking, exploring errors as a means of learning and improving the organization; being an educator by teaching new behaviors to the organization's members; providing the expertise necessary to help the members learn; and conducting active research (1978).

The specific ways in which the consultant fulfills her/his roles is largely dependent on the theoretical orientation to which she/he subscribes. As suggested earlier, there are different models for assessing or inducing change in an organization, each of which implies a different set of strategies for the consultant. In order to clarify the possible roles a consultant might play and the techniques she/he might use, it will be helpful to review the major models characterizing the field of $O D$.

The models that are concerned with producing specific changes can be labeled adoptive models; others oriented toward producing a general climate conducive to change may be called adaptive models. The differences between the two are reflected in answers to the following questions: Is the aim to get the client to change in specific ways, to adopt certain new prctices, to use new technological devices? If the answer is "yes," an adoptive model is appropriate (Sashkin, 1977).

On the other hand, if the aim is to help the client become more adaptable, more open to change and able to change in needed ways, whatever the specifics as defined by 
the client might be, an adaptive model of change is appropriate. It is these latter models which will be reviewed in some detail here.

Adaptivity is the focus of any model concerned with producing long-range, survival-facilitating change. Three such models will be examined: the Intervention Theory Method (ITM), Planned Change (PC), and Action Research (AR).

All are oriented toward the development of adaptive capacity in a client system, that is, the ability to become aware of needs for change and to plan, implement, and evaluate changes. Secondly, all stress client participation in specific change efforts. The client learns to use the change model by applying it to a specific problem with the help of a change agent. Third, all three are based, to differing degrees, on Kurt Lewin's action research model. (Sashkin, 1977, p. 161)

Intervention Theory Method (ITM), a model developed by Argyris (1970), differs from the Planned Change (PC) and Action Research (AR) models in the following ways. First, it is oriented exclusively toward changes in the internal processes of the organization. The interventionist is relatively unconcerned with technological or structural change. The assumption of this model is that the necessary data are present within the organization. Secondly, there is less emphasis, in practice, on generation of research knowledge about the change process. Although there is considerable emphasis on collecting and analyzing data within the client system and on monitoring effects of actions, the goal is to provide the client with skills so that they can continue to accomplish effective, adaptive internal changes 
after the consultant leaves the organization. "There is no aim to generate experimental knowledge on the process of change or to build better behavioral science theories about the change processes" (Sashkin, 1977, p. 161). The emphasis is primarily on the internal processes of the client system and thus the interventionist is primarily a trainer, who teaches the client how to use the ITM approach to identify and solve problems.

The second model, Planned Change (PC) (Lippitt, Watson \& Westley, 1955), differs substantially from ITM in two ways: first, change resources outside the client system, as well as within, receive attention. Furthermore, the model is not criented solely toward the process of change, although this aspect does receive most of the attention. Secondly, more specific attention is given to evaluating changes and planning. However, as in the ITM model, generation of behavioral science knowledge on the change process is not emphasized in practice. The basic principles underlying the PC model are that all information must be translated into action. There is greater emphasis on immediate change and problem solving than on research about the results.

The Action Research (AR) model has, in addition to the attributes of ITM and PC models, the generation of new, useful knowledge about the process of change. Furthermore, specific change methods and strategies relating to technical, 
structural, or process changes are addressed. The AR model, then, creates specific changes which develop the client's own resources for change and future adaptability. These changes could include training in research methods, in problem identification, and in evaluation of change attempts. The results are increased knowledge about behavior change.

In all three models, the change agent fulfills three roles: that of trainer, consultant, and researcher. Following is a brief examination and comparison of these roles as they are employed or omitted in the three adaptive change models discussed above.

In ITM, the interventionist is primarily a trainer, showing the client how to use the ITM approach to alter system processes. Part of this role is training the client in data gathering and analysis methods. The AR model includes both consultant and trainer roles, plus that of researcher. Table I outlines the roles of the consultant in the three models. While all of the adaptive models emphasize consultation and training roles, the nature of these roles differ somewhat. ITM includes consultation on process issues, not on specific content problems. PC and AC emphasize process consultation, but often include consultation around content problems. All train the client in the use of the model to produce change. For ITM, this training is the primary emphasis; $\mathrm{PC}$ and $\mathrm{AC}$ are more balanced in focus. 
TABLE I

ROLES OF CHANGE AGENTS

\begin{tabular}{|c|c|c|c|}
\hline $\begin{array}{l}\text { Adaptive } \\
\text { Change } \\
\text { Models }\end{array}$ & Consultant & Trainer & Researcher \\
\hline$I T M$ & $\begin{array}{l}\text { Consultation on process } \\
\text { only, not on content prob- } \\
\text { lems; however, the inter- } \\
\text { ventionist dces introduce } \\
\text { the client to new methods } \\
\text { of data gathering, analy- } \\
\text { sis, decision making. }\end{array}$ & $\begin{array}{l}\text { Primary emphasis on train- } \\
\text { ing the client in new } \\
\text { skills and methods (pro- } \\
\text { cess oriented). }\end{array}$ & $\begin{array}{l}\text { Emphasized to the extent that research } \\
\text { skills needed for generation of valid } \\
\text { information prior to and during the } \\
\text { process; research for development of } \\
\text { new behavioral science knowledge is em- } \\
\text { phasized conceptually, but does not } \\
\text { seem an integral part of the model. }\end{array}$ \\
\hline PC & $\begin{array}{l}\text { Consultation on process } \\
\text { primarily, but also on } \\
\text { content; for example, the } \\
\text { derivation-utilization } \\
\text { conference introduces the } \\
\text { client to new content } \\
\text { knowledge resources. }\end{array}$ & $\begin{array}{l}\text { Major emphasis on training } \\
\text { the client in skills and } \\
\text { methods for creating adap- } \\
\text { tive changes. }\end{array}$ & $\begin{array}{l}\text { Emphasized mostly in evaluation of ef- } \\
\text { fects of specific changes and client } \\
\text { training in certain research skills } \\
\text { needed for data collection and diagno- } \\
\text { sis; the importance of the generation } \\
\text { of new behavioral science knowledge is } \\
\text { noted, but it is not an operational } \\
\text { part of the model. }\end{array}$ \\
\hline AR & $\begin{array}{l}\text { Consultation on process } \\
\text { is emphasized, but content } \\
\text { consultation also occurs. }\end{array}$ & $\begin{array}{l}\text { Major emphasis on training } \\
\text { for development of internal } \\
\text { resources for change. }\end{array}$ & $\begin{array}{l}\text { Major emphasis on research as the basis } \\
\text { for action, an important area of client } \\
\text { training, and the source of new knowl- } \\
\text { edge about change which can be used by } \\
\text { behavioral science practitioners and } \\
\text { theorists. }\end{array}$ \\
\hline
\end{tabular}

(Sashkin, 1977, p. 164) 
Bowers and Franklin summarize the role of the change agent as encompassing the following:

Iinks knowledge to action, resources to users;

Works from, and knows well, a model of organizational functioning and change that is a reasonably comprehensive portrait of what occurs in real world;

knows the body of empirical evidence that undergirds the model;

Knows measurement, its techniques, assumptions, and limitations, is aware of the difference between a controlled and an uncontrolled observation, between a hunch and a fact;

Has group and interpersonal process skills that he views as means, not as ends in themselves. . . . in order to make knowledge available in a supportive, not a demeaning manner. (1977, p. 89).

Overall, the role of the OD consultant is to apply behavioral science theory and related skills to help the organization to assess and improve its own work-related processes. The consultant "models" learning behaviors and provides experiences for organizational members to learn how to assess their own processes and be able to make appropriate change in response to that assessment. As can be seen, the differences between the three models presented are small. The present research adheres most closely to Argyris Intervention Theory and Method Model. A more detailed description of Argyris' model will be presented.

Argyris states that there are three primary intervention tasks of a change agent or interventionist. They are: generation of valid information, free and informed choice, and internal commitment. Valid information is that information which describes factors that can be publicly verified and which are problematic to the organization. He advocates 
a collaborative diagnosis in which a consultant and the clients generate the data. In the present study this was accomplished by interviewing members of the organization and asking members to complete a questionnaire. It is important that such information be obtained from representatives of the total system, not from any specific subgroups.

Free choice, the second task, implies that members of the client system are able to explore a variety of alternative solutions to the perceived problems. The interventionists avoid giving "pat answers" to problems. Free choice also implies voluntary as opposed to automatic action; therefore, the focus of decision making remains in the client system rather than with the interventionist.

Internal commitment means that each client has internalized the choice or course of action decided upon and by so doing feels a high degree of ownership and responsibility. The individual so committed is acting under the influence of her/his own will, not under duress of external forces.

The basic concept of the intervention theory and method model is that because of behaviors inherent in hierarchical organizations, members do not know how to generate valid information relevant to their problems. Because of this, Argyris maintains that there is difficulty in developing alternative solutions and in making decisions that will increase effectiveness. The purpose of the "interventionist" (consultant) operating within Argyris' theoretical 
framework, then, is to gather valid information so that the basic processes of information flow, data gathering, and decision making can be altered within the organization, if need be. Use of this model also assumes that the necessary data are present within the organization but that communication blockages and dysfunctional interpersonal relationships prevent adequate dissemination. Argyris uses the term "interventionist" rather than change agent or consultant because implicit in the definition of change agent is the notion that change is ipso facto necessary, whereas in intervention theory and method, change is not presumed to be needed.

Whereas Argyris believes that descriptions of the formal organization are vital for information about tasks to be performed, the flow of communication, and power relationships, he also believes that to focus exclusively on these variables provides a limited basis for organizational diagnosis. The living system or informal organization must also be used as a basis for diagnosis. Because use of the formal organization as the primary basis for diagnosis is such a common practice, Argyris makes the limitations and problems involved in this practice quite explicit. He states:

1. Many diagnoses based on the formal organization view the formal system as the ideal one and the living system as the deviant one.

2. Formal organization by itself provides no explanation for the informal activities. Formal organization theory is helpful where the dysfunctional behavior is 
due to poorly defined formal structure, but without a behavioral theory, it is difficult to ascertain when the causes of dysfunction lie in the design of the system and when they lie in the incompatibility of individual capabilities and organizational demands.

3. Looking at the formal organization alone does not lead to a picture of the total organization.

4. The formal organizational chart and all the related documents actually contain too much information, more often than not, useless. (Argyris, 1973, p. 21)

In summary, the Intervention Theory Method is primarily concerned with process consultation rather than content. It is a behaviorally anchored model, in that the focus is on the actual observed behavior of the individuals in the organization. Unlike the Action Research and Planned Change models, need for change is not an ipso facto idea and the interventionist does not become involved in the content issues of organization.

NEED FOR THE STUDY

A review of the literature revealed no reports of OD which had been conducted in a professional school. Although there were suggestions that Argyris' model be tested in professional schools, no reports of this could be found in the 1iterature. Furthermore, of the twenty-six reports of oD reviewed by Morrison (1978), none had taken place in the academic setting and only a few had taken place in other public sector settings. Preliminary evidence provided by studies conducted in secondary schools by Schmuck and Miles (1971) suggests that OD interventions lead to a positive change in the behavior of faculty. Also Boyer (1974). 
strongly urges the use of $O D$ in both universities and professional schools to improve the quality of life for faculty, students, and administrators.

When contrasting professional schools with private sector organizations, it becomes clear that they can be classified as public sector organizations. The differences between public and private sector organizations are such that $O D$ in one cannot and should not be generalized to the other. While such differences have not been well documented in the literature, Goodstein (1978) and Morrison (1978) have suggested some which are pertinent to the present research. First of all, the fact that public sector organizations are accountable for expenditure of public money causes them to be more open to public scrutiny. Both Goodstein and Morrison suggest that this fact leads the public sector administrator to be less willing to spend money for management consultants. The infrequent use of such consultants in the public sector also suggests that the administrator fears being perceived as having problems and calling to question her/his competence in the public's eyes. Additionally, Schmuck and Miles (1971) point out that nonprofit public sector organizations, such as schools, do not ordinarily contribute heavily in research and development funds to improve their organizational effectiveness. Indeed, recommendations of the Carnegie Commission on Higher Education 
that 3 percent of an institution's operating budget be used for "self-renewal" is rarely followed (Boyer, 1975).

A second difference is that in most private sector organizations a profit motive exists which encourages selfimprovement and self-analysis designed to increase organizational efficiency and hence profits. In public sector organizations, the profit motive seldom exists. In fact, there is little incentive for public sector organizations to improve efficiency, for to do so usually means a decrease in funding. It has been said that public sector organizations or programs are seldom abolished even if their usefulness or efficacy has been shown to be nonexistent. The lack of the profit motive in such organizations leads to a relative absence of $s$ stimulus for improving efficiency.

The third major difference between public and private sector organizations is that managerial levels of public sector organizations are typically composed of professionals who identify more closely with their profession than with the organization (Ikenberry, 1972). On the other hand, private sector organizations have a greater proportion of nonprofessionals who identify more closely with the organization. It has been found that in organizations managed by professional managers ". . . rather than professionalsmade-managers, there is a greater likelihood that attention will be given to the effective management of the system" (Morrison, 1978, p. 49). 
The ultimate goal or output of public versus private sector organizations presents the fourth difference between the two. Whereas public sector organizations are more often in the business of providing services, private sector organizations more frequently provide goods. In serviceproviding organizations, the relationship of input to output is not as easily measured as is the relationship in the production of goods. Thus a problem in the production process will be less noticeable where services rather than goods are produced. Since such breakdowns are more noticeable in private sector organizations which produce goods, $O D$ is more likely to be used. Morrison (1978) suggests that because of this unclear relationship of input and output in the provision of services, the impact of $O D$ will be more difficult to determine.

A fifth difference is related to the organizational environment of the two sectors. The environment of a public sector organization is a more turbulent one than that of a private sector organization. Changes in the administration governing the public sector organization occur more frequently than in private sector organizations. There are multiple systems which have an impact on a public sector organization but typically do not play a large role in the private sector. These include federal, state, and local accrediting agencies, and legislative regulatory bodies. Some change in public sector organizations is constantly 
occurring in response to such outside influences. Because of this difference in the organizational environments, change which does occur in the public sector organization as a result of $O D$ efforts will be more difficult to attribute directly to OD efforts.

The final difference is specific to academic settings in contrast to industrial or privace sector settings. According to Boyer and Crockett, participants in higher education "tend to value ideas, thoughts, and concepts over feelings" (1973, p. 344). They go on to say that this value seems to be more true than is the case in industrial settings and suggests". . . an underlying source of resistance to a number of OD values..." (1973, p. 344).

Given the significant differences between private and public sector organizations outlined above, it is imperative that results of organization development in the private sector not be generalized to the public sector. Instead, there is a need for research addressed directly to a variety of questions about the applicability of OD models and intervention strategies in public sector organizations in general and in higher education settings in particular.

\section{ORGANIZATION DEVELOPMENT IN}

THE PUBLIC SECTOR

Among the few reported OD programs conducted in the public sector, most were intended to affect the attitudes 
and behavior of individuals rather than the processes or work flow of the organization. The first use of oD in government, for example, was done in the California state Personnel Board in 1954 (cited in Morrison, 1978) and was reported to have had a major impact upon the behavior of the target group.

Another use of $O D$ in government was the installation of participative management in the form of Management by objectives in a newly-formed county probation project. In this case, managers were trained by the consultant in the Management by objectives technique and in objective writing. Finally, Morrison cites two programs with city governments, one with a City Council and one with New York City's reorganization of fifty agencies. In neither case was the success or failure of these efforts documented.

While application of OD strategies in private sector business organizations is increasingly well documented, practice in public sector organizations, including higher education, are not well developed. One example of OD work in a university is illustrated in the efforts of Boyer and Crockett at the University of Cincinnati. Although results of this long-range OD program have not been reported in the literature, preliminary reports of their experience with several departments were presented at a national conference of the American Association of Higher Education in 1975. Work with departments involved a four-phase process: 
(1) consultant's relationship to the organization, (2) data collection, (3) feedback and discussion, and (4) follow-up. As a result of their departmental efforts, Bolton and Boyer developed a set of instruments which deal with departmental priorities, decision-making structure, the climate, and decision process of departmental meetings. Data are typically collected by both questionnaire and interviews. The authors state that the interviews precede the questionnaire administration and are used to build trust and to get commitment of the participants.

After data collection, the institute staff analyze and summarize the data in a report which is sent to each participant. Data are summarized around key issues and reported without interpretation or suggestions by the consultants. Generally no specific conclusions are drawn. Feedback is given in department meetings after distribution of the consultant's report. These meetings provide an opportunity for the participants to discuss the report and to ask questions about the data and to add data that are not in the report. The second function of the meeting is to discover what participants want to do about the data, i.e., do they want follow-up?

Follow-up has taken a variety of forms at the University of Cincinnati. In several departments, the staff has worked with the department head to improve leadership style and managerial ability. In others, follow-up has been 
geared to the total faculty in an effort to improve their meetings and problem-solving effectiveness.

The length of the $O D$ efforts at the University of Cincinnati thus far have varied from six months to five years. Bolton and Boyer believe that there are factors in higher education which limit lengthy follow-up activities to a greater extent than is usual in business organizations. Scheduling of time and space, for instance, is a much greater problem in higher education than in business. The large size of some academic departments is unwieldy for most of $O D$ strategies or interventions and therefore most activity takes place with subgroups. Most OD practitioners acknowledge some inherent difficulties with $O D$ efforts using subgroups rather than the total group.

Even though their experience with the application of $O D$ in a university setting is limited, the University of Cincinnati's Institute represents a viable approach to departmental improvement. A summary of their approach follows.

1. Entry--Consultant's Relationship to the Organization.

- Institute approached by department head.

- Begin developing trust and role expectations.

- Establish ground rule that data will not be shared with central administration but will be public within department.

- Determine the initial willingness of the department head to entertain changes which may alter his role or behavior.

- Begin a process of leadership education. 
2. Data Collection.

- Meet with department faculty to review discussions from (I) above and entertain questions about the consultation process.

- Establish ground rules that before any data is collected faculty must agree to meet for three hours to discuss the results and action implications.

- Faculty vote to proceed or not on the consulting relationship.

- Identify issues about which the department wishes more information.

- Modify standard Departmental Analysis Questionnaire and interview schedule to fit the department's needs.

- Conduct 1-1/2 hour individual interviews (est. 10-20 per dept.).

- Request completion of questionnaire $120-50 \mathrm{~min}$. per individual).

- Prepare summary report of results without interpretations and conclusions.

3. Feedback and Discussion of Priorities and Alternatives.

- Distribute departmental report to all faculty and the department head.

- Meet with the department head to continue process of leadership education begun at entry, to facilitate his thinking about the results and the department, and to plan agenda for the faculty meeting.

- Meet with faculty ( 3 hours) to help the faculty validate the results and to test what the department wants to do.

- Facilitate the setting of priorities and preparation for action.

4. Follow-up--Implementation and Evaluation.

- Implementation depends on the issues and the priorities assigned by the department. Some typical examples are: (a) work with department head on improving leadership, (b) assist in improving departmental meetings, (c) assist in the revision of the undergraduate curriculum, (d) conduct teaching effectiveness workshops, (e) consult on developing new means of involving graduate students in departmental teaching and research activities, (f) assist department committees in developing policy statements and processes regarding By-Iaws, promotion and tenure, and program requirements, (g) assist in the design of studies of market needs for students from a particular discipline, (h) consult on long range planning, and (i) help develop new programs in career planning and development for faculty. 
- Evaiuation of follow-up activities is made mutually by the client and consultant. There is periodic review of the consulting relationship. (Boyer, 1975, p. 7).

\section{MEASURING THE IMPACT OF ORGANIZATION \\ DEVELOPMENT}

While there has been very little evaluation of frequently used OD strategies, there is evidence that identifiable patterns of "successful" change for organizations do exist. These patterns were identified by Greiner (1967) after conducting a survey to answer two specific questions: Do patterns of planned change exist? and if so, do they have implications for the "success" or "failure" of a change program? From the eighteen empirical investigations reviewed, he delineated a potential "success" pattern. The eight primary characteristics of the "successful" change program were as follows:

1. The organization, and especially top management, is under considerable external and internal pressure for improvement long before an explicit organizational change is contemplated. Performance and/or morale are low. Top management seems to be groping for a solution to its problems.

2. A new person, known for (her/his) ability to introduce improvements, enters the organization, either as the official head of the organization, or as a consultant who deals directly with head of the organization.

3. An initial act of the new (woman/man) is to encourage a re-examination of past practices and current problems within the organization.

4. The head of the organization, her/his immediate subordinate assumes a direct and highly involved role in conducting this re-examination.

5. The new woman/man, with top management support, engages several levels of the organization in 
collaborative, fact-finding, problem-solving discussions to identify and diagnose current organizational problems.

6. The new woman/man provides others with new ideas and new methods for developing solutions to problems, again, at many levels of the organization.

7. The solutions and decisions are developed, tested, and found credible for solving problems on a small scale before an attempt is made to widen the scope of change to large problems and entire organization.

8. The change effort spreads with each success experience, and as management grows, it is gradually absorbed permanently into the organization's way of Iife. (1967, pp. 124-25)

Greiner was quite explicit about the fact that in the eighteen empirical studies he reviewed a redistribution of power was considered an essential part of a successful change experience. For example, with high subordinate power and delegated authority, a moderately successful change program could be instituted. However, the most successful change efforts were those in which there was equal management and subordinate powers and shared authority. In addition, the more successful programs of planned change utilized members of the organizations to a greater extent.

\section{SUMMARY}

Research on organization development efforts suggests that positive results occur in the organizations as an outcome of such programs. However, the extant literature can only be seen as suggestive since it includes few evaluations of the public sector and none in the professional school. of those studies including an evaluation component, virtually none were evaluated with any degree of control. Until 
organization development is tested further, particularly in the public sector, no conclusions can be drawn as to its general value as a means of improving organizational effectiveness.

The present research was designed to address these deficiencies in the organization development literature by conducting the first systematic, controlled organization development program with an evaluation component in a professional school. The purpose was to ascertain if a specific organization development model could be implemented and evaluated in a professional school setting.

The general purpose of this research was to apply certain theoretical perspectives and intervention strategies of organization development in a professional school, as one type of public sector organization. Specifically, this research involved the assessment of the present state of an organization relative to the strengths and limitations of its structure and support services, the perceived emphasis on the four missions of the school, and the evaluation of a specific intervention on the effectiveness of members in departmental meetings.

In this research, OD was defined as the process of diagnosis, data collection, data feedback, action planning, action, and evaluation which occurs in an organization with the help of a change agent, for the purpose of improving the effectiveness of the organization. Specific details 
of this intervention will be described in a subsequent section.

\section{ORGANIZATION OF THE DISSERTATION}

This chapter presented an introduction to the research and described the necessity for the study. Chapter II will present a review of the literature relevant to organizations in general and to the specific variables under consideration in this study. The methodology will be presented in Chapter III. The analysis of the data, interpretation, and discussion are presented in Chapters IV and V. More specifically, data relevant to the strengths and limitations of the structure and support services as perceived by the organizational members are presented in Chapter IV. Analysis and discussion of the data concerning the effectiveness of problem solving and interactions are presented in chapter $V$. The summary, conclusions, and recommendations for further research are in Chapter VI. 


\section{CHAPTER II}

\section{REVIEW OF THE LITERATURE}

Among the studies of organization development reported in the literature, only a few concern programs in the public sector and none are found reporting on OD in professional schools.

The purpose of this chapter is to examine the issue of organizational innovation and to present a brief summary of some related, but more general, topics. A review of the literature concerning OD in the public sector and evaluation of $O D$ interventions will also be presented. Finally, the gap in the OD literature which forms the rationale for this research will be identified.

\section{MODERN ORGANIZATIONS}

It is an accepted fact that organizations are an integral part of modern society. There is almost no way to avoid working for, dealing with, or being affected by them. They are an inevitable outgrowth of attempting to solve complex problems; that is, when any problem requires the effort of more than one person, some kind of organization is necessary to get the work done. Although organizations are ubiquitous in modern society, the average individual rarely 
recognizes the impact they have on her/his life and there is a curious ambivalence in attitudes toward them. While on the one hand, organizations are accepted as necessary, there is, on the other hand, rebellion against them.

Concern, in both the general society and within organizations, regarding the obsolescence of organizations has led to a growing and systematic use of planned change strategies. It has become increasingly obvious that in order to bring about long-lasting changes in institutions and in their management, new values, skills, and concepts of individual and organizational effectiveness must be developed (Argyris, 1976). Modern organizations may not survive unless they are able to introduce innovation by developing new organizational forms and new ways of operating. While there is agreement that large-scale organizations are here to stay, criticism of their impersonal character as well as recognition of their limitations and of the urgent need for organizational change is growing. Argyris states that ". - the older and more complex organizations in our society, business firms, government bureaus, hospitals, schools, and universities appear to be deteriorating . . ." He goes on to say that "organizations are becoming increasingly rigid and difficult to change" (1973, p. 1).

The lack of responsiveness, over-conformity to rules, and self-perpetuation of older modern organizations led Gardner (1963) to predict the eventual collapse of our 
society as a result. He states that the same flexibility and adaptiveness that we seek for society is essential for the organizations within that society. Furthermore, a society made up of arteriosclerotic organizations cannot renew itself. Other writers agree with Gardner. For instance, Argyris indicates that "organizational entropy" or "dry rot" is the rule rather than the exception in organizations today. Bennis (1968) believes that the typical bureaucratic organization with the same pyramidal structure used for two thousand years is dysfunctional in light of twentieth-century demands. Specifically, Bennis states that such organizations are unable to respond quickly to the rapid and unexpected change occurring in society or to the demands for diversity and growth facing modern organizations.

Causes of organizational entropy are built into old pyramidal structural designs, the technology, the old style leadership patterns, and administrative controls of people in power (Argyris, 1973). There are two different value systems in organizations: the bureaucratic/pyramidal value system, and the humanistic/democratic value system. Comparison of these value systems is illustrated in Table II. Adherence to bureaucratic values leads to poor, shallow, and mistrustful interpersonal relationships (Argyris, 1973). To the extent such values are held by the leaders, the following changes have been found to happen: 
TABLE II

\section{ORGANIZATIONAL VALUE SYSTEMS}

\begin{tabular}{|c|c|c|}
\hline & $\begin{array}{c}\text { Bureaucratic/Pyramidal } \\
\text { Value System }\end{array}$ & $\begin{array}{c}\text { Humanistic/Democratic } \\
\text { Value System } \\
\end{array}$ \\
\hline 1. & $\begin{array}{l}\text { Important human rela- } \\
\text { tionships, the crucial } \\
\text { ones, are those related } \\
\text { to achieving the organ- } \\
\text { ization's objectives. }\end{array}$ & $\begin{array}{l}\text { 1. The important human rela- } \\
\text { tionships are not only } \\
\text { those related to achieving } \\
\text { the organization's objec- } \\
\text { tives but those related to } \\
\text { maintaining the organiza- } \\
\text { tions internal system and } \\
\text { adapting to the environ- } \\
\text { ment as well. }\end{array}$ \\
\hline 2 . & $\begin{array}{l}\text { Effectiveness in human } \\
\text { relationships increases } \\
\text { as behavior becomes more } \\
\text { rational, logical, and } \\
\text { clearly communicated; } \\
\text { but effectiveness de- } \\
\text { creases as behavior be- } \\
\text { comes more emotional. }\end{array}$ & $\begin{array}{l}\text { 2. Human relationships in- } \\
\text { crease in effectiveness as } \\
\text { all the relevant behavior } \\
\text { becomes conscious, discus- } \\
\text { sable, and controllable. }\end{array}$ \\
\hline 3. & $\begin{array}{l}\text { Human relationships are } \\
\text { most effectively moti- } \\
\text { vated by carefully de- } \\
\text { fined direction, author- } \\
\text { ity, and control, as } \\
\text { weli as appropriate re- } \\
\text { wards and penalties that } \\
\text { emphasize rational behav- } \\
\text { ior and achievement of } \\
\text { the objective. }\end{array}$ & $\begin{array}{l}\text { 3. In addition to direction, } \\
\text { controls and rewards and } \\
\text { penalties, human relation- } \\
\text { ships are most effectively } \\
\text { influenced through authen- } \\
\text { tic relationships, internal } \\
\text { commitment, osychological } \\
\text { success, and the process of } \\
\text { confirmation. }\end{array}$ \\
\hline
\end{tabular}

first, there is a decrease in receiving and giving information about leaders' interpersonal impact on each other. Any difficulties tend to be suppressed or disguised and voiced as rational, technical, or intellectual problems. Secondly, there is a corresponding decrease in the leaders' ability to own up to their feelings, ideas, or values. Risk-taking behavior becomes less frequent, and the adage "Don't rock 
the boat" becomes the norm. Third, as a result of the first two conditions, leaders become less interpersonally competent. Conformity and distrust become more prevalent and individuals become increasingly dependent on those in power. Decision making becomes less effective, because people withhold many of their ideas. Organizational defenses, such as management by crisis and management by detail, increase. Such relationships do not permit a natural and free expression; they are non-authentic and result in decreased interpersonal competence. The lower the interpersonal competence, the less aware individuals are of relevant problems and less able they are to solve them.

- Without interpersonal competence or a psychologically safe environment, the organization is a breeding ground for mistrust, intergroup conflict, rigidity, and so on, which in turn lead to a decrease in organization success in problem solving . . (Bennis, 1968, p. 13).

Lest the reader think that holding pyramidal values is absolutely wrong, it is important to say that they are indeed a necessary part of effective human relationships. The difficulty arises when they are held to the exclusion of the humanistic values. In other words, leaders must learn to incorporate both value systems if they are to be maximally effective. The important human relationships are not only those related to achieving the organization's goals, but also those related to maintaining the internal systems. All relevant behavior, both rational and emotional, must be accepted. If this occurs, trusting, open, 
and honest relationships will develop, resulting in increased interpersonal competence, intergroup cooperation, and flexibility (Argyris, 1973).

The fact that bureaucratic values still dominate most organizations has caused the entropy noticeable in today's organizations. Argyris studied the effect of management practices on individual behavior and personal growth within organizations $(1954,1962,1965)$. He concluded that seven changes should take place in the personality of individuals if they are to develop into mature people. Calling this idea the Immaturity-Maturity theory, he postulated that these changes reside along a continuum and that the healthy personality develops along the continuum from "immaturity to maturity." The seven states are illustrated in the following way:

Immaturity

Passive

Dependence

Behave in a few ways

Erratic shallow interests Short time perspective Subordinate position

Lack of awareness of self
Maturity

Active Independence Capable of behaving in many ways Deeper and strong interests Long time perspective Equal or superordinate position Awareness and control over self

According to Argyris, keeping people immature is built into the very nature of bureaucratic organizations, in that emphasis is on goals and objectives, task specialization, chaim of command, and span of control. Power and authority 
are vested in a few individuals at the top, implying directive, task-oriented leadership where decisions about the work are made by the superior, with the workers only carrying out the decisions. These practices are incompatible with the proper development of maturity in human personality. There is an incongruity between the needs of the mature personality and practices within the formal organizations as they now exist.

Papialy accelerating change in social values has also heightened the need for innovation. As Lundberg has pointed out :

- . the present has been characterized as a truly revolutionary period, with multiple revolutions occurring in the technological, communication, political, scientific, and institutional dimensions of our society . - (1974, p. 73)

The increasing pace of these changes is having a profound effect in all aspects of society, thus an understanding of the potential impact of such changes on organizations is essential.

Toffler (1970) states that the next few decades will bring about an avalanche of change that most people and organizations are totally unprepared to handle. The following areas of rapidly accelerating change have been identified as having particular significance for organizations: the knowledge explosion, rapid product obsolescence, the changing composition of the labor force, and the growing concern over personal and social issues. These four areas 
will be discussed in some detail because of their relevance to the present study.

Because of the tremendous knowledge explosion since World War II, yesterday's science fiction becomes today's reality. Knowledge is becoming obsolete in a short time and new knowledge is scarcely around long enough to become familiar. Organizations involved in such a changing environment can also become obsolete just as quickly (Huse, 1975). One good example of organizational obsolescence is the university (and I include in this category professional schools such as dentistry, medicine, and nursing), generally considered one of the most archaic structures in modern society. Historically, the growth of universities has been more episodic, trial and error, and reactive than focused or planned. While institutions of higher learning seek to educate and to advance knowledge, they have demonstrated little interest in self-study and a somewhat limited capacity to learn from their own experiences. Their managerial and administrative styles are typically primitive and underdeveloped. For instance, the university is asked to perform conflicting missions and to do so within the framework of organizational design appropriate to its earliest mission, teaching. New functions such as research, community service, or practice have not been addressed as a rule (Perkins, 1972). In addition, there has been a lack of a tradition of valuing the administrative functions and 
administrative effectiveness coupled with an absence of formal preparation for its leaders.

Both of these factors clearly operate in the nursing profession. In the recent past, the nurse who selected nursing administration as a career choice, as opposed to clinical nursing, for example, was looked upon as "being lost" to the profession--no longer a real part of nursing. As a result of nurses' reluctance to accept administration and management as part of the profession's function, there is a "crisis in nursing leadership" (Leininger, 1973). For the foreseeable future, universities face the need for major adaptation to the rapidly changing and increasingly turbulent environment. In many cases the difficult circumstances faced by higher education today and concomitant managerial/organizational problems such as those mentioned above have resulted in increased alienation and debilitating interpersonal conflict.

Goodstein (1979) reports that the conflict is especially dysfunctional in human services organizations because many of the interactions are basically dishonest. He maintains that this is so because more often than not human service employees do not have the pressure to openly acknowledge conflict and to stick with problem solving until the conflict is resolved. Contrasting human services with industry, he states that people in industry must solve the conflict because outputs are more dependent on teamwork. 
In the public sector, administrations have become focal points for the expression of dissatisfaction. The administrative process has become even less legitimized and tenure in office of key administrators has become shorter and shorter. For example, in the case of Schools of Nursing, the average tenure for deans is two to three years.

The increasing social, technological, economic, and political pressures for change (Beckhard, 1957; Bennis, 1968; French \& Bell, 1978; Michael, 1973; Huse, 1975) and the study and practices of planned organizational change have grown. To date, however, application of theory of change in universities has been limited. While it is true that universities resemble many other complex organizations in that they have a governing board, a chief executive, a highly developed bureaucratic structure, an apparent mission, and clients, there are some major differences. Institutions of higher learning have internal organizational properties that are different from industrial organizations (Boyer \& Crockett, 1973). For example, their goals and objectives are either incompletely or poorly defined, there is great difficulty measuring the quality of their "products," there is a low degree of task interdependence among groups and between individuals which fosters fragmentation and an overly strong emphasis on departmentalization.

closely resembling the university along most of the dimensions described above are the professional schools. 
Leaders in dentistry, medicine, and nursing schools are increasingly aware of their need for help in planning the changes required by the new roles and structures of their schools and by their new relationships to the traditional university, the teaching and community hospitals, and students (Beckhard, 1974). Like other organizations, professional schools are under increasing pressure to examine their structure and their leadership methods. Unlike the university, however, increased student enrollment in the professional schools, especially nursing schools, has continued virtually unabated. At the same time, discontent is becoming more evident, not only among students in a variety of professions, but also among professional practitioners, deans of professional schools, and faculty (Argyris \& Schon, 1974).

In addition, professional roles are now undergoing radical changes. Schein argues that "the professions need innovators to improve practice and to clarify the professional's role in society" (1969, p. 32). Friedman (1973) says the professions need "successful planners" who would demonstrate skill in managing interpersonal relationships so that self-knowledge, the capacity to learn and to empathize, and the ability to live with conflict would improve. Thus, awareness of the need for creative collaboration between applied behavioral scientists and leaders in 
professional schools is growing (Rubin, Plovnick \& Fry, 1974; Beckhard, 1974).

A second factor is that as new knowledge is acquired, old products quickly become obsolete. Changes in knowledge can be expected to come about even more quickly in the future because of the increased funds being spent on research and development. Medical instrumentation and hand calculators are two examples of growing product obsolescence. As soon as one company brings out a new, complex machine, another one brings out a better one at a lower cost. Such product obsolescence requires more flexible organizations with short "turn around" time. Under such conditions, only the more adaptive and flexible organizations are likely to survive in the future.

Huse and Bowditch (1973) cited the changing composition of the labor force as having consequences for organizations. The steady migration from the farm to the city was accelerated in the early 1900s, changing the country from a predominately rural to an urban society. Whereas in 1825 about 10 percent of the American population lived in towns and cities, by the year 2000 it is estimated that 90 percent of the population will be living on 2 percent of the land area (Bell, 1973).

Increased urbanization is paralleled by a rise in educational standards, the spread of political consciousness, a rapid growth of science, and an increase in social 
mobility, all of which have great impact on organizational life (Bel1, 1973). For instance, in 1900, when Taylor did his pioneering work on Scientific Management, the majority of the workers were illiterate immigrants, a poorly educated work force accustomed to taking orders. Today, 60 percent or more of the population are engaged in some form of post-secondary school education and are less inclined to merely "take orders." In addition, the work force that was once composed mostly of laborers and semi-skilled workers now includes a greater number of managers, clericals, and professionals. Both Gardner (1963) and Bell (1973) have called the rapid growth of the professional segment of the work force one of the most striking developments in modern social organizations and state that it has played havoc with traditional bureaucracy. The professional's loyalty is typically to her/his profession rather than to the organization she/he is part of at any given point in time. Professionals tend to bring with them certain values and expectations, resulting from education and experience, that may or may not be congruent with those of the organization. For example, the professional traditionally places a high value on authority via expertise and knowledge, but places little on authority inherent in any organizational position. In addition, the professional holds universalistic professional standards rather than organizationally derived ones (Ikenberry, 1972). The increased number of professionals has 
meant that the modern organization has been infiltrated by people who give an entirely different view of their relationship to it than the typical "organization man." Professionals are not merely employed by the organization; they also help shape it.

The relative lack of rapport that exists between the professional and the organization has far-reaching consequences for how an organization will be structured and how it will function. Problems encountered in organizations with large numbers of professionals such as universities, hospitals, and professional schools, are actually precursors to those which business and industry can expect as the professional segment of society increases (Bell, 1973).

The fourth factor influenciug organizations is the public's growing concern over personal and social issues. Today's more highly educated and mobile labor force has shown an increasing desire "to do its own thing." More and more individuals are making more personal decisions regarding their lives rather than subordinating their lives to that of the organization (Huse, 1973). Workers are less interested in money per se and appear to be more concerned with opportunities for autonomy, personal choice, and freedom. The trend in management is to find new ways to balance the organization's demands on individuals and the individual's own personal needs. 
Dovetailing this change in management perspective and the change in the composition of the work force is a phenomenon which Anderson (1973) calls a "consciousness revolution" and Bennis (1968) calls a "shift in values." Both have to do with humanity's quest for self-awareness, translated today into a ". . different way of experiencing ourselves, our relation to history and to other people and to the world . . " (Anderson, 1973, p. 2).

Michael (1973) states that in recent years new formulations about human nature are reflected in the work of a diverse group of individuals. Such new statements have come from the writings of Fromm, Jung, Maslow, May, and Rogers in humaristic psychology; from the theological-politicalphilosophical writings of Buber, Cox, deChardin, Marcuse, and Watts; and from behavioral scientists involved in organizational processes and development, Argyris, Bennis, Slater, and McGregor. Michael goes on to say that the human potential philosophy has far-reaching societal implications and consequently critical implications for organizations. He describes this human potential philosophy as follows:

Human beings are part of nature, not separate from it. Persons are linked to persons and to the rest of nature in ways that transcend the conscious, rational mind. Thereby humans have access to a far wider range of being and becoming than the everyday definitions of man and the structures of our society acknowledges or rewards. These linkages and resources, if acknowledged and cultivated, encourage a drive toward compassionate and loving self-actualization, even toward transcendence, and away from exploitation of self and others; away from the compulsive need to control and manipulate; away from the canon of $\operatorname{logic}$ and science 
as the only expressions of reason; away from valuing scientific rationality over feelings and intuition; away from the excessive need for possession of material things; and away from preoccupation with greater material growth and comparative social status. For individuals and organizations the direction points toward openness, a much wider range of cognitive and effective experience and intercourse, and the shared development by responsible social evolution. (1973, pp. 288-89)

The pervasiveness of this new concept about humanity seems to be a fact that cannot be ignored. Support for the human potential image of human nature as outlined by Michael is coming from heads of corporations as well as from business schools (Lodge, 1972). In 1965, Bennis stated that the new concepts of human nature and new organization values had ". - gained wide intellectual acceptance in enlightened management quarters . ." Now, fourteen years later, Michael and others are stating that ideas based on this philosophy are beginning to be practiced:

- . among the elites of established organizations there is growing appreciation of the utility and the validity of the findings . . . fulfillment of higher human needs and aspirations is increasingly necessary for effective organizational performance . . (Michael, 1973, P. 294)

One of the more interesting spin-offs of the human potential movement has been Argyris' theory of double-loop learning, meaning learning to change underlying values and assumptions (1976). Similar to Michael's idea of conditions essential for long-range social planning, that is, learning to embrace error and live with ambiguity, double-loop learning means that the focus is on problems whose definitions 
are unclear when one begins to solve them and which may change as problem solving advances. Argyris relates double-loop learning to the beginnings of a theory of effective leadership $(197 \overline{6})$. He maintains that if we are to face the problems of organizations today, there is a need to develop leaders who are self-aware, who know how to discover the difficult questions, how to create viable problem solving, and how to channel human energy and commitment to produce the solutions.

Elsewhere Argyris and Schon (1974) talk about the "theories of action" individuals develop to guide their behavior. Unfortunately, it appears that people program themselves with theories in action that predispose them to cancel each other out when they interact and problem solve. The authors state that this is done with the aid, and indeed the coercion, of schools, churches, and other societal institutions. As a consequence, deception and diplomacy take the place of openness and honesty.

TRUST, CONCERN, AND INDIVIDDUALITY

In the 1950s, two seminal cultural developments were predicted by analysis based on trust-level theory. They were loss of confidence in our institutions and their leadership and an escalation of faith in the potential for good which characterizes the revolution of the human potential movement (Gibb, 1978). 
The theory connecting open behavior with greater individual and organizational effectiveness has been supported by organization development consultants and humanistic psychologists. Acceptance of this theory, however, is often based on subjectivity rather than on empirical testing. Advocates of this theory maintain that appropriate trust and openness improve creativity and communication, particularly in a highly dynamic environment.

In a study conáucted by Kegan and Rubenstein (1973), three main hypotheses about trust and individual effectiveness, organizational effectiveness, and organization development programs were tested. Three major companies were studied; the first was in the top one hundred of Fortune's list of the largest five hundred United States industrials, the second group was composed of all research scientists, and the third was a medium-sized company in the top three hundred of Fortune's top five hundred industrials. All levels of each organization, that is, administrators and technical support people, were included.

Results indicated a significant $(p<.01)$ relationship between individuals' trust of the focal work group and their self-actualization, and between individuals' average trust of target groups and their self-actualization. Selfactualization was taken as an indicator of individual effectiveness. Self-actualization "is present when organizational members believe their occupational role demands permit 
relatively full expression of their individual potential as well as opportunities to expand this potential" (Bonjean \& Vance, 1968, p. 300). There was also support for the second hypothesis that the higher the group members' trust of their own group, the greater the group's effectivness toward achieving its own goals. Interestingly, a sub-hypothesis that the higher the group members' trust of others with whom they interact, the greater the group's effectiveness toward the organization's goals, showed significant negative correlation, which contradicted the study hypothesis. One rival hypothesis proposed by the authors was that some raters (including the bosses) tend to rate as less effective groups that evidence greater independence and confrontation. If this interpretation is correct and these results are generalizable, then severe problems with evaluation and human potential may exist. It tends to imply that evaluators penalize assertive and confrontive individuals in spite of the possible organizational benefits of such behavior.

Trust is more than confidence. The word "trust" is derived from the German word, Trost, meaning comfort and implying ". . instinctive, unquestioning belief in and reliance upon something ..." (Gibb, 1978, p. 14). In this way, then, trust may be conceptualized as a preconscious condition permitting an individual to enter a situation with minimal defensiveness. Behaviorally, trust involves opening oneself up to a situation and exposing 
oneself to its unpredictability. Trust is further differentiated into two aspects: trust of oneself and trust of others. There is openness with respect to both receiving information and giving information. According to the theory, trust of self facilitates an individual's reality testing, adaptation, and learning. Additionally, trust of co-workers and openness with them facilitates their adaptation, learning, and effectiveness. It is believed that improved information exchange connects trust with effectiveness. This chain of relationship can be diagrammed as shown in Figure 1 .

Trust of self, then, permits openness to and awareness of the organizational environment, its goals, resources, and constraints. The non-defensive perception permits the individual to obtain a more valid conception of "reality" which promotes more effective and fully functioning participation in the organization. Non-defensive interactions help one's co-workers receive more accurate information, which in turn can lead to a more valid conception of reality and thus to more effective functioning on their part. Improved decision making and therefore improved organization effectiveness also result.

Argyris' personality organization theory (1973) also addresses the relationship of trust, concern, and individuality with competence and effectiveness. He states that conditions which are positively correlated with competence 


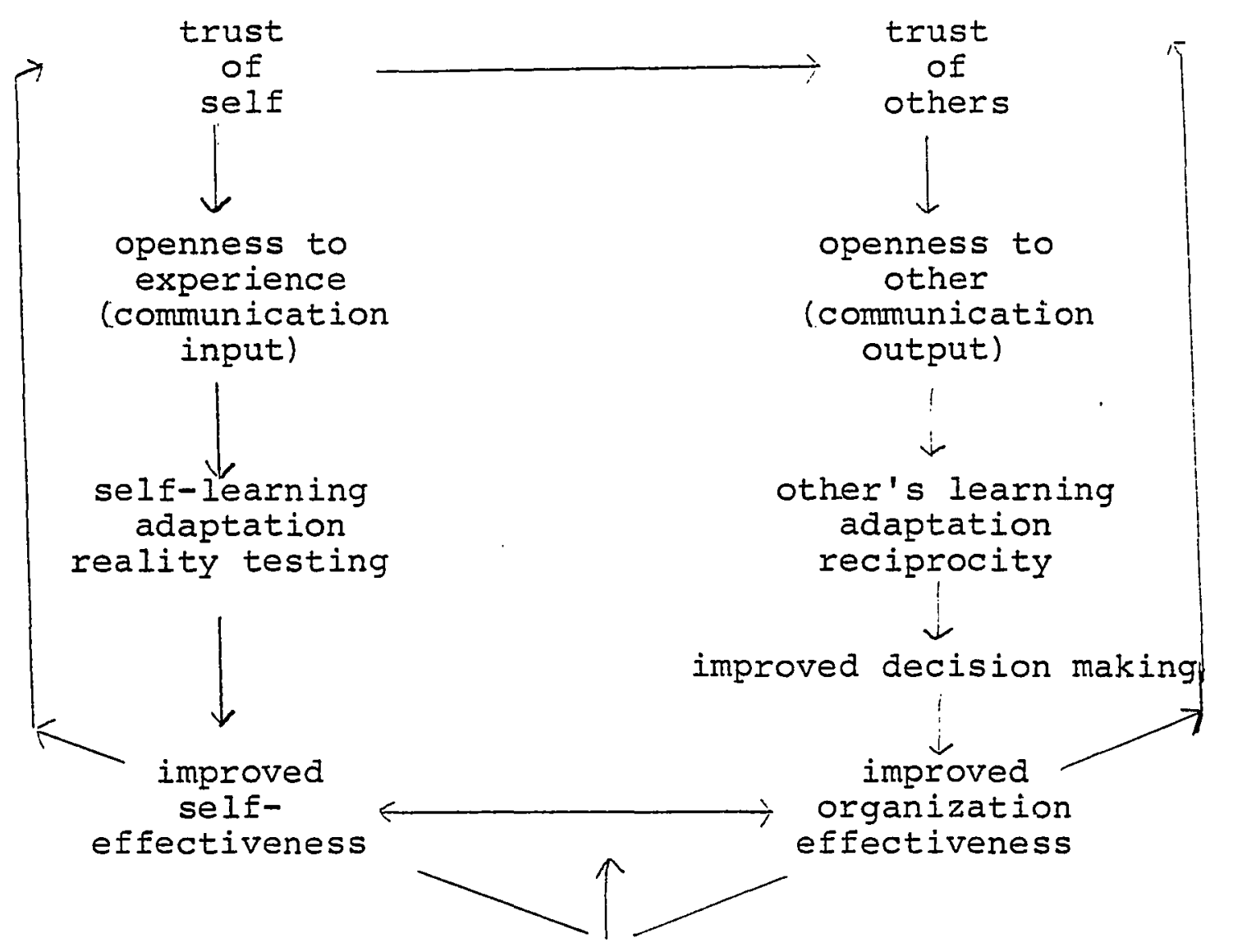

other parameters

1. (Kegan \& Rubenstein, 1974, p. 500)

Figure 1. Some relationships of trust, openness, adaptation, and effectiveness.

and effectiveness are self-acceptance, confirmation, and essentiality.

Self-acceptance refers to the degree to which individuals have confidence in and value themselves. Individuals experience a sense of confirmation when the way others experience them, i.e., their "self," are similar to the way they experience themselves. Confirmation is needed to validate one's view of and confidence in one's self. The more frequent the confirmation, the greater the confidence in 
one's potential to behave competently. The greater the sense of confidence, the greater the probability that the individual will be accepting of others. Essentiality refers to the individual's utilization of her/his central abilities and expression of needs. The more the individual is able to utilize talents and express needs, the greater will be feelings of essentiality. In turn, the greater the essentiality, the greater the commitment to the system and its effectiveness.

One of the most effective ways to increase the degree of self-acceptance, confirmation, and essentiality is to provide an organizational climate wherein individuals may achieve psychological success. Similarly, it has been suggested that specific behaviors tend to be associated with psychological success. They are individuality, expressed by owning up to or accepting responsibility for one's ideas and behaviors; concern, expressed by being open to ideas and feelings of others and those from within oneself; and trust, expressed by experimenting with new ideas and/or feelings. All of these behaviors are also expressed interpersonally; that is, helping others to own up to, be open to, and to experiment with ideas and feelings.

The specific behaviors cited above have been presented in a system of categories which can be used to observe variables related to interpersonal effectiveness and with which some useful predictions have been made and tested by Argyris 
$(1962,1964,1970,1976)$. When individuals focus on interpersonal effectiveness, a greater awareness of the relevant problems occurs and the ability to solve the problems so that they remain solved increases.

A system of categories outlining the necessary, but not necessarily sufficient, behaviors leading to three resultants as postulated by Argyris is depicted in Table III. Categories above the zero line are hypothesized to facilitate interpersonal effectiveness, while those below the zero point detract from or inhibit interpersonal effectiveness. Generally, speaking, the further away from the zero line (for the positive or plus factors), the more difficult the behavior is to perform. The further away from the zero line (for the negative or minus factors), the greater the defensiveness involved in the behavior. 
TABLE III

SYSTEM OF CATEGORIES : INTERPERSONAL EFFECTIVENESS

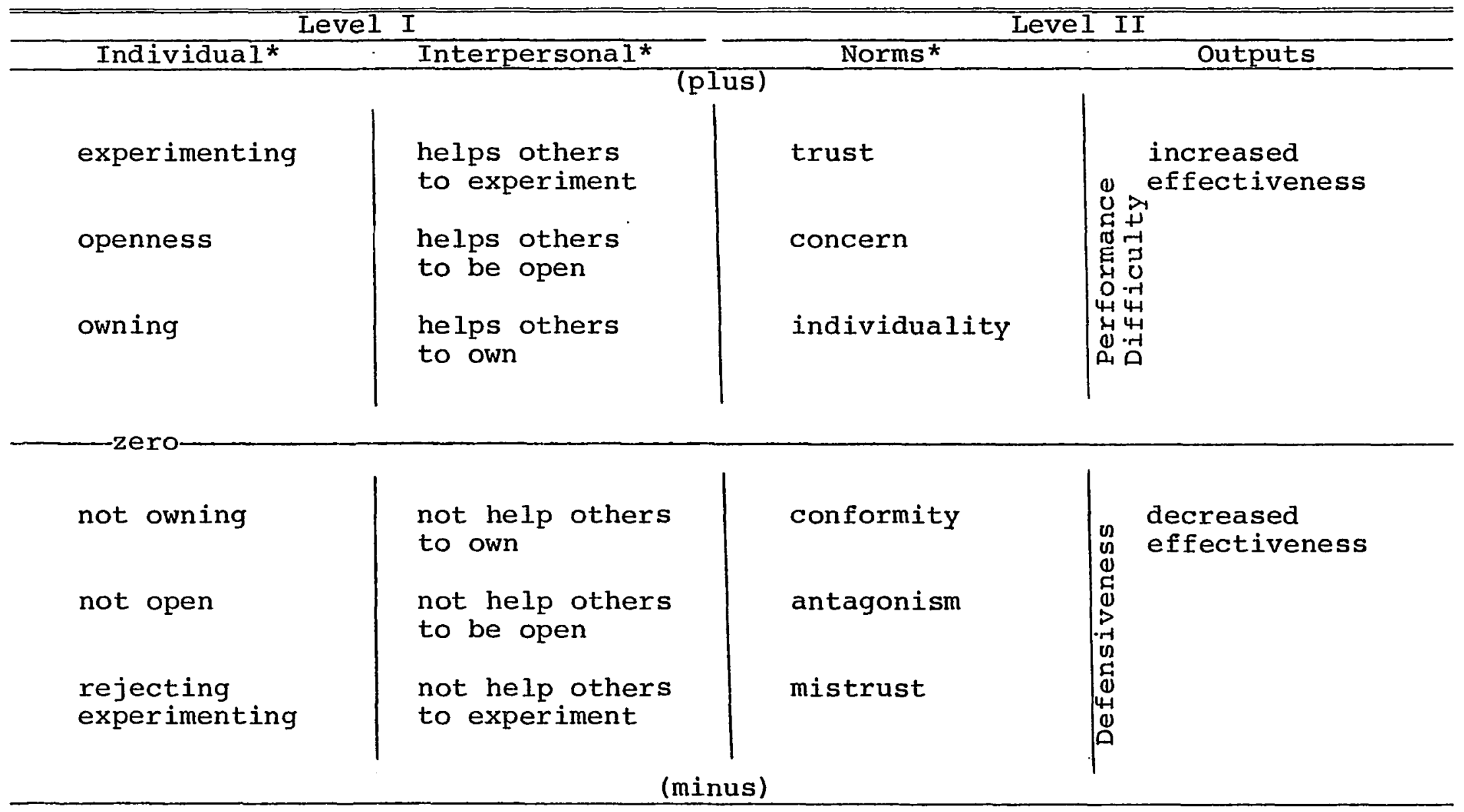

(Argyris, 1973, p. 288)

*Each category includes verbal behaviors representing "ideas" and "feelings." 


\section{CHAPTER III}

\section{METHODOLOGY}

The purpose of this research was to test the applicability of Argyris' Theory and Method model in a professional school. There were two phases to the research: the first was an assessment phase designed to obtain information about the current status of the study organization. Utilizing interviews and the University of Cincinnati departmental questionnaire, strengths and limitations of the organizational structure, support services, and the perceived emphasis placed on the four missions of the school were ascertained. The second phase was an experimental study of the impact of an OD intervention (conducted in a professional school) on organizational effectiveness.

This chapter will present the methodologies utilized in the research, the hypotheses which were tested, the treatment methods and procedures, the OD process, and the instruments used. Operational definitions and the data analysis related to each hypothesis are also described.

\section{SETTING}

Because the investigator was able to identify an organization which met Greiner's set of criteria discussed 
earlier (see pp. 27-28) indicating a state of readiness for organizational development or change, it was possible to test the effectiveness of Argyris' Intervention Theory Model. Prior to this time, Argyris' model had been applied primarily in business and industry. Its value for the academic setting had yet to be substantiated.

The study institution was a professional school in the Pacific Northwest. It has an undergraduate program leading to a Bachelor of Science degree in Nursing and a graduate program leading to a Masters of Nursing with specialization possible in Medical-Surgical Nursing, Psychiatric-Mental Health Nursing, Nursing Management and Administration, and Family-Centered-Child Nursing. There are 68 full-time faculty, 550 undergraduate students, and 110 graduate students.

\section{PARTICIPANTS}

All full-time faculty, sixty-seven female and one male, were asked to participate in the assessment phase of the study. All full-time faculty in the MedicalSurgical Nursing department (seventeen) and the PsychiatricMental Health Nursing department (twelve) were asked to participate in the second phase of the research. For this phase, the Medical-Surgical faculty comprised the experimental group and the Psychiatric-Mental Health Nursing faculty formed the control group. 


\section{METHODS : PHASE I}

This phase was designed to involve all members of the organization in the organization development program. In order to obtain information about the state of the organization regarding perceived strengths and limitations, and the emphasis given to the missions of the organization, two steps were employed: first, a series of individual and group interviews were conducted, and secondly, a departmental questionnaire was sent to each participant. Two additional steps in this phase were step 3 , which consisted of collating the data obtained in the first two steps, and Step 4, which was the feedback of data to faculty in department meetings and in a general faculty meeting.

\section{Step 1: Interviews}

Individual interviews with ten randomly selected tenured faculty, minority recruitment faculty, and the chairperson of the curriculum committee were conducted. In addition, group meetings were held with each of the four academic departments of the school, and the graduate and executive committees.

The objectives of these meetings were: (1) to obtain information about the perceived strengths and Iimitations of the organization, (2) to ascertain where faculty wanted the organization "to be" five years from now, and (3) to identify specific problem areas. 
While these interviews were essentially unstructured, answers to the following questions were sought:

1. Where do you want the organization to go in the next five to ten years?

2. What do you see in the organization currently that will get you there?

3. What kinds of specific problems are you encountering?

4. What are the organization's present strengths and limitations?

5. How do you want to be organized?

\section{Step 2: Departmental Questionnaire}

The questionnaire, designed by Bolton anả Boyer (1975), assessed the faculty's perceptions about the emphasis placed on the missions of the organization and the adequacy of support services (see Appendix A for complete questionnaire).

On the emphasis given to the missions, respondents were asked to mark each of the four missions--teaching, research and scholarly activity, community service, and clinical practice--using a Likert scale which ranged from 0 (don't know) to 5 (a very great amount). The midpoint was 3 , which indicated some emphasis was given.

On the adequacy of the support services, respondents were asked to rate the items on a Likert scale ranging from 1 (needs a great deal of improvement) to 5 (much better 
than I expected). The midpoint was 3 , which indicated that the service was satisfactory at present. Items in this part of the questionnaire included salary, academic rank, time to pursue my own interests, office space, library facilities, and the ratio of secretarial help to professors.

\section{Step 3: Data Analysis}

Information from the interviews was collated by the researcher and a task force representing the four departments and the graduate committee. Data were organized around the five questions stated earlier. On the support services and missions data, means for each participating group and a mean for the total group were calculated.

Step 4: Feedback

The researcher presented the data from the interviews and the department questionnaire to faculty in regular department meetings.

\section{METHODS: PHASE II}

This phase was designed to assess the effect of a specific $O D$ intervention on organizational effectiveness. Two research designs were employed, the pre-test/post-test control group design and the time series design. Two data collection methods were used: a questionaire, which measured the perceived effectiveness of the group; the second was nonparticipant observation of specific behaviors in 
decision-making meetings of the two departments participating in this phase. A description of each design, hypothesis, interventions, and data analysis follows.

\section{Pre-test/Post-test Control}

Group Design

This design was used to determine the : ipact of a survey feedback intervention on perceived effectiveness of the group. The survey feedback method uses the information collected by a survey to give a group information about how they perceive themselves. It is considered an excellent method for involving participants in problem identification and solution. A more detailed description of this method will be presented later in this chapter.

The pre-test/post-test control group design was used to answer the following hypotheses:

If an organization development program is conducted in a professional school,

Hypothesis I: Organizational effectiveness will be improved by increasing collaboration in decision making and problem solving by the members in the experimental group.

Hypothesis II: The effectiveness of communication vertically and horizontally in the organization will increase in the experimental group.

Hypothesis III: Organizational effectiveness of the members will be improved by more clearly understood roles in the experimental group.

The pre-test/post-test control group design can be illustrated as follows: 
$\begin{array}{lllll}\text { Experimental group } & 0_{1} & \mathrm{X} & 0_{2} \\ \text { Control } & \text { group } & 0_{1} & & 0_{2}\end{array}$

The time line for this design was twelve months between $o_{1}$ and $0_{2}$.

Data Collection Procedures and Instruments. Data for testing the first three hypotheses of this study were collected with the use of the Meetings Questionnaire, a thirtyseven-item questionnaire designed to measure group problemsolving adequacy (see Appendix A for complete questionnaire).

The instrument was developed for the Cooperative Project for Educational Development (COPED) for administration to a large number of teachers and principals in twenty-one school systems. Specific items relate to decision-making effectiveness, problem-solving adequacy, and communication. Each item describes a function usually involved in problem solving in departmental meetings which the respondent attends. Participants were instructed to respond on the following Likert scale:

This is very typical of this meeting; it happens repeatedly.

This is quite typical of this meeting; it happens quite often.

This is more typical than not, but it doesn't happen a lot.

This is more untypical than typical, though it does happen sometimes.

This is quite untypical; it rarely happens.

This is not typical at all; it never happens.

Items were rated on this six-point scale from 0 to 5 . A rating of 0 meant that the behavior never occurred; a rating 
of 1 meant that the behavior was quite untypical; and so forth. An example of a typical item is, "When problems come up in the meeting, they are thoroughly explored until everyone understands what the problem is" (Miles, 1970).

One month prior to collection of baseline observational data, the questionnaires were delivered to the participants by placing them in the faculty mail boxes. Return envelopes were provided and anonymity was insured by not requiring a signature. Six months after the intervention phase, the questionnaires were redistributed in the same manner to collect post-treatment data.

According to Lake, Miles, and Earle (1973), the testretest studies have demonstrated a reliability of .60 and: . . construct validity of the instrument was explored through the use of four separate factor analyses... the criterion for including an item in a factor was that it must have a .50 or better loading . . (p. 38) Scoring of the Meetings Questionnaire is done by item to assess the combined scores of all respondents in the group to that particular item.

Based on factor analysis, three major scales were developed by Lake, Miles, and Earle (1973). They are collaboration, communication, and role clarity.

Time Series Design

This design was employed to determine the effect of intervention on specific targeted behaviors over time. The regular meetings of the Medical-Surgical Nursing department, 
the experimental group, and the Psychiatric-Mental Health Nursing department, the control group, were observed and targeted behaviors were counted using Argyris' system of categories.

Baseline data were collected for one month in both groups, and then pre-treatment observations were made for three weeks. During weeks 4,5 , and 6 the experimental group received the treatment, while the control group was merely observed to remove the effect of no visit. The design can be illustrated as follows:

$$
\begin{aligned}
& \text { Experimental } \quad 0_{1} 0_{2} 0_{3} \quad x_{1} x_{2} \quad x_{3} \quad 0_{4} 0_{5} 0_{6} \\
& \text { Control } \quad 0_{1} O_{2} O_{3} \quad 0_{4} 0_{5} 0_{6}
\end{aligned}
$$

The time line for this design is nine weeks.

With this design the following hypotheses were tested:

If an organization development is conducted in a professional school:

Hypothesis IV: Organizational effectiveness of the members will be improved by an increase in individuality behaviors in the experimental group.

Hypothesis V: Organizational effectiveness of the members will be improved by an increase in concern behaviors in the experimental group.

Hypothesis VI: Organizational effectiveness of the members will be improved by an increase in trust behaviors in the experimental group.

As will be recalled from the earlier discussion, the observational schedule used in the research consists of a 
system of categories derived from Argyris (1973) that tap individual and interpersonal factors and norms of the behavioral system. In using this system, there are two assumptions regarding behavior which should be made explicit: first, all behavior that can be classified within the categories is considered relevant and any behavior that cannot be classified according to the categories is assumed to be irrelevant. Second, all behavior is classified as idea or intellectual and/or feeling or emotional.

There are two levels in Argyris' system: Level I with two sub-parts, the individual and interpersonal; and Level II, the norms. The definition of each of the categories given in the following section are those used by Argyris (1962).

Level I (Individual)

1. Owning up to: ideas or feeling behaviors which indicate the individual is aware of and accepts responsibility for the behavior being manifested.

Examples: "I believe," "In my opinion," "I don't agree"

2. Not owning up to: idea or feeling behavior which indicates inability to be aware of, identify, and own up to one's actions.

Examples: "I am not upset" (although obviously flustered), "I don't mind" (when face and body language indicate otherwise) 
3. Openness: behavior which enlarges the individual's scope, increases awareness, and permits reception of new information.

Examples: "Please tell me more," "I'm not sure I understand"

4. Not open: behavior which constricts boundaries of awareness, person discourages receiving new information.

Examples: "I'm not interested in what you have to say," "I'm sure that I'm correct"

5. Experimenting: behavior which represents some risk for the individual; for example, generating new information on the feeling or idea level.

Examples: "Let's try it and see what happens," "I'm willing to give it a try," "I've never said this to anyone, but now I realize. . ."

6. Rejecting experimenting: not examining feelings or ideas, not willing to subject ideas or feelings to a test.

Examples: "This is nonsense," "There's no sense continuing"

\section{Level I (Interpersonal)}

1. Helping others to own: behavior is similar to owning on the individual level except it is designed to help others to own. 
Examples: "May I try to help you clarify?" "If I understand you correctly, you are suggesting . . " "Beth has a point"

2. Not helping others to own: influencing others to not own.

Examples: cutting person speaking off and saying, "Let me tell them what you're saying," "I know a better example." Saying to a person who is upset and who has just denied it, "O.K., if you can say you're not upset, that's enough for me"

3. Helping others to be open: focused on helping others to be open.

Examples: "May I help you explore that further?" "Would it help to consider the following ideas?" "Since you asked for clarification on the point, let me try"

4. Not helping others to be open: preventing others from being open.

Examples: "In my opinion, you'd be a fool to listen to her," "Why do you spend time raising these issues?" "Enough of this, let's get back to the facts we have"

5. Helping others to experiment: focused on encouraging exploration of new ideas or expression of feelings.

Examples: "I sense this is a difficult topic for you; I appreciate you discussing it," "I'd like to do everything I can to help you" 
6. Not helping others to experiment: behaviors which inhibit the free expression of ideas or feelings. Examples: "This is a crazy idea. You'd be a fool to continue," "This subject is obviously going to upset you; let's get off it"

Level II Norms. In Argyris' system of categories, norms are the sum of the individual and interpersonal behaviors observed. For example, if sixteen observed behaviors are coded "owning-ideas" and ten behaviors are coded "helping others to own-ideas," the result would be twenty-six behaviors on the norm "Individuality-ideas." The same would be done for the feeling category.

Operational definitions of the six norms in the system follow.

1. Individuality ( $i$ or $f$ ): emphasizes the appropriateness of the expression of individual ideas or feelings. It is good to say what she believes. To behave in a way that is congruent with internal feelings and ideas.

2. Conformity ( $i$ or $f$ ): behavior that leads to no choice, cuts down alternatives as speaker demands, requires dependence. Behaving in accordance with what one believes to be congruent with someone else's desires. 3. Concern ( $i$ or $f$ ): emphasizes, in addition to the expression of individuality, the appropriateness of manifesting interest in, involvement with, ideas and 
feelings of self and others, as well as with topics at hand. Unconditional regard, non-evaluative feedback, and confirmation.

4. Antagonism ( $i$ or $f$ ): not mindful of, concerned about self and others. Hostility toward self and others. Little regard or conditional reward. Evaluative feedback.

5. Trust ( $i$ or $f$ ): to think in ways, or express feelings that mean the individual takes risks. To risk one's self-esteem in a relationship.

6. Mistrust ( $i$ or $f$ ): fear of risking one's self in a relationship.

Reliability. The reliability problem inherent in any observational research was solved by training two raters in the use of Argyris' system. An observational data sheet was developed by the researcher. Two raters were taught operational definitions of the categories in the system and were given examples of verbal behavior for each category.

After mastering the system, the raters simultaneously observed two meetings over a two-week period of time. Each meeting was two hours long. These meetings were also audiotaped. From the data sheets, the researcher computed inter-rater reliability between the two raters. Using a percent agreement formula, agreement/agreement+ disagreements, suggested by Johnson and Bolston (1974), the interrater agreement ranged from 75 percent to 83 percent with a 
mean agreement of 77 percent. Thus, the previously established criterion agreement rate of 75 percent was attained. In addition, one fifteen-minute segment of an audio-taped meeting was coded by the investigator and an inter-rater agreement computed. An 80 percent agreement was found.

In order to reduce rater decay over time, the raters were told that a high percentage of the observations would also be rated by the investigator and an inter-rater agreement computed.

Data Collection. A rater present in the room during meetings collected baseline data for three weeks in the experimental and control groups. One rater was assigned to each group for the duration of the research. During weeks 4,5 , and 6 , while the experimental group received the treatment, the control group was observed in the usual manner so as to remove the effect of no visit. Observations were made in both groups during meetings in weeks 7,8 , and 9 .

Dependent and Independent

Variables

In traditional research terminology, the organization development program itself could be called the independent variable (IV), or the treatment or cause; that is, it is presumed to cause variation in the dependent variable (DV) of effect. There has been considerable disagreement on the correctness of this conceptualization, however. For 
example, Pate, Nielsen, and Bacon (1976) state:

Some researchers regarded OD itself to be an independent variable. However, in our view, OD does not generally constitute the independent variable, but is only instrumental in its manipulation. For example, one might expect introduction of participation decision making (OD intervention) to facilitate worker awareness of the rationale for organizational actions (independent variable), which in turn may increase support for and commitment to those actions (dependent variable). (pp. 389, 392)

Furthermore, it is not really known in most cases what "causes" the effects of an OD intervention; it is only known in a general sense that something within the overall activity caused some change. French and Bell (1978) state that:

- . in the strictest sense, the cause [of a change] is the independent variable, and since that is usually not identified in OD research, we will loosely refer to the OD intervention ... as a "treatment" that contains some independent variables having an impact on dependent variables of interest. (p. 227)

In light of the previous discussion, the decision to identify or not to identify the dependent and independent variables of the present research is a matter of personal conviction. The present researcher elected to identify the variables as follows.

Dependent Variable. The dependent variable of this research was organizational effectiveness, defined as the positive change in (a) collaboration, (b) communication, (c) role clarity, and (d) level of concern, individuality, and trust behaviors. 
Independent Variables. The independent variables were survey feedback, process consultation, and coaching/ modeling.

Intervention

The present study used three OD interventions: survey feedback, process consultation, and coaching or modeling. While these techniques are used widely in organization development programs, the specifics of intervention methodology relate solely to the study organization. Even though the techniques are used in other programs, because of the nature of OD work organization development practitioners cannot talk about replication of an OD study in the same way traditional researchers can. For instance, while the same kind of organization could be used in several studies and the same techniques, how these techniques are implemented would be different in each case. The specifics of intervention would be tailored to the dynamics of the group involved. A general discussion of the technisues employed in the present study follows and some examples of specific interventions will be given.

Survey Feedback. Survey feedback involves summarizing the results of survey questionnaires and presenting them to the participants. This feedback is ordinarily given in group meetings of organizational "families," i.e., departments, sub-groups, etc. The purpose of these feedback meetings is to allow the group to discuss their responses 
and sometimes to compare them with other groups' responses. Such feedback discussion contributes to eliciting new information, learning new behaviors, and may also contribute to constructive action to remedy problems which have been identified.

Process Consultation. Interactive skills are difficult to acquire on a didactic basis. A better alternative is to intervene directly in a group, inter-group, or total organization, using their problems as material for intervention. By the researcher/consultant asking pertinent questions, information can be generated to be studied and insights derived about group process. This is a process consultation strategy. The same process can be used after a group has been given information about how they have been functioning or how they have responded to a questionnaire. Process consultation involves the members of an organization and the consultant/researcher in a period of close interaction. In addition, it focuses on the improvement of the client's ability to ascertain strengths and problems in the group. It is a key assumption of process consultation that clients must learn to see the problem themselves to share in the diagnosis of what is going on in the group, and to be actively involved in generating a remedy. The goal is to focus members' attention on studying their own situation so they are in a better position to 
consolidate aspects that are desirable and to change what is unwanted.

Coaching/Modeling. Another strategy in process consultation is modeling, where the researcher uses her/his own behavior to set an example of how others might behave in order to improve the effectiveness of the group. The client may change by imitation, following the researcher's example in such matters as personal openness, giving feedback, and exhibiting concern for others. This aspect of change may never be explicitly pointed out, as the mechanism may work best when it is not deliberate and calculated.

The interactive processes that are most crucial to organizational effectiveness and therefore relevant to the present study are: collaboration in problem solving and decision making, communication, role clarity, and the norms of each group. Each of these was discussed during the three-week intervention period. A brief description of the three intervention meetings follows.

Week 1 of Intervention. The first half of this twohour intervention period was devoted to presenting the data from the Meetings Questionnaire and the observational data, and the last half was the regular department meeting. Using the three weeks of baseline observational data, the frequency of each category occurring during the meetings was arrayed on flip charts. Examples of verbal behavior included in each category were explained and questions 
answered. Questions were encouraged regarding both the system of categories and the Meetings Questionnaire results. The implications of the behaviors for the effectiveness of the group were also discussed. An overview of the consequences of adhering to the problem behaviors was presented and questions answered.

The frequency individual members of the group spoke at each meeting was also presented. At this point the content of the communication was not addressed. A general and brief discussion on how members could incorporate the behaviors identified as facilitative ensued. The researcher served as facilitator and process consultant. To give one example of facilitation, the following vignette is presented:

The department chairperson had asked for volunteers to give sophomore challenge exams. After a brief silence (and no volunteers), she turned to faculty $A$ and asked: "Can you help us out?" Faculty A replied, "No," and went on to state how busy (and overworked) she was. Before she completed her somewhat lengthy statement, faculty $B$ said (sharply and with reddened face): "We're all busy," and turning to the department chairperson, said, "I'll do it." Not waiting for any statement from either faculty $A$ or the chairperson, faculty $B$ brought up another agenda item.

The intervention consisted of stating to faculty $A$ : "I'm wondering how you are feeling right now." The response was, "I'm feeling embarrassed and put down." The researcher then asked faculty A to "say more" and facilitated an open discussion between faculty $A$ and $B$. At this point, the consultant was modeling the behavior "helping others to 
be open to and owning feelings" and coaching the faculty in the use of facilitative communication.

Weeks 2 and 3 of Intervention. During regular department meetings, process consultation, coaching, and modeling expressions of feelings, owning and helping others to experiment continued. In these two meetings, the researcher continued to assist the group to shift from review of results of baseline data to a recognition and understanding of what was occurring in the group now. Progress was stimulated by exploration of one's immediate thoughts and feelings. An example of one intervention follows:

(Researcher speaking) I'd like to state my understanding of what we have been doing as a group so far. We began by exploring the data from three meetings and identifying the most common inter-personal behaviors. When we did this, however, we were immediately confronted with trust issues. It was as if we couldn't really expose our differences until we felt safe with one another and until we talked at a low risk level about what we have in common. At least this is my understanding of why we have been so much in agreement. Soon I suspect that some of you will begin risking more by making statements which express your differences.

After several minutes of silence, one faculty spoke about how she felt about a curriculum issue, a feeling she had not expressed before. A lively discussion of differences soon emerged.

In summary, the intervention period consisted of three two-hour regular department meetings. During the first week, approximately one hour was devoted to survey and observation feeedback of pre-test and baseline data. 
The remaining hour in week $I$ and two hours in weeks 2 and 3 , the department conducted a regular meeting with the researcher serving as a process consultant.

\section{DATA ANALYSIS}

In order to determine whether there was a significant statistical difference between the pre- and post-treatment data for hypotheses I, II, and III, the te test for uncorrelated samples was computed; the level of significance was set at .05 . Since there were multiple items in each of the factors (collaboration, communication, and role), it was decided that 50 percent or more of the items would have to be significant in order for the factor as a whole to be considered significant. This decision is supported by other researchers who have used the Meetings Questionnaire (Morrison, 1978; Boyer, 1974).

Analysis of the observational data involved a frequency count of the target behaviors and a calculation of the percentage of the total meeting time each behavior represented. These percentages were then graphed for the three-week baseline period and the three-week post-treatment period. The pattern and direction of the data over time were then examined. In order to evaluate changes in the data, two characteristics were noted: change in level and/or change in slope. A change in level refers to a difference at the height at which the targeted behaviors are 
represented on the graph on post-treatment measures. A change in slope refers to a change in trend between phases. A "significant" change in the data across phases was considered as either a change in level or slope. 
CHAPTER IV

\section{RESUITS AND DISCUSSION: PHASE I}

This chapter will present the data gathered in the first phase of the research. Individual and group interviews were used to assess the strengths and Iimitations of the organization and the emphasis given to the four missions of the school.

\section{INDIVIDUAL AND GROUP INTERVIEWS}

This information will be presented in an outline format ranked ordered from most frequently mentioned to least frequently mentioned. Number 1 will represent those items most frequently mentioned and number 5 will represent those items least frequently mentioned. The midpoint of 3 will indicate that the item was mentioned an "average" number of times compared to others.

\section{Question I}

Where do you want the organization "to go" in the next five to ten years?

1. Strengthen the graduate program by:

- offering majors in community health, gerontology, and maternal child nursing 
- explore feasibility of beginning a doctoral program either here or through a collaborative inter/institutional arrangement

- increase the number of doctorally prepared faculty

1. Create and fill positions for research and teaching assistants.

1. Make additional support services available for such activities as grant writing and research proposals.

2. Obtain additional joint appointments for faculty.

3. Decrease enrollment in the generic baccalaureate program.

4. Increase the enrollment in the baccalaureate program for registered nurses.

5. Explore the possibility and practicality of a $2+2$ program.

5. Establish fee-for-services nursing clinics.

Question II

What do you see in the organization currently that will get you there?

1. Dedicated faculty and administrators.

The comment must be made that this was the answer given by every faculty interviewed. 
Question III.

What kinds of specific problems are you encountering?

1. Anatogonistic organizational structure with parameter (sophomore, junior, senior) curriculum organization and the departmental structure.

1. Parameter coordinators having no authority and yet are asked to assume responsibility. Coordinator position is not legitimate.

1. Faculty do not know where to go to settle curriculum problems or to change the curriculum.

1. Role of parameter coordinator and departmental chairperson dysfunctionally overlapping and illdefined.

2. Unpredictable student loads in clinical courses.

2. Students ill-prepared in mathematics, biological sciences, and physical sciences.

2. Theory not integrated with clinical work of students.

3. Core courses are repetitive and boring.

3. "Group process" inappropriately substituted for "content" in courses.

4. Faculty are not adequately prepared to teach some "content."

4. Differing academic calendars for the three professional schools cause scheduling problems for students and faculty. 
5. Classification of our graduate students as "nondegree" by Portland State University often prevents them from taking certain courses they want/ need to fulfill requirements for their minor.

Question IV

What are organization's present strengths and limitations?

Strengths.

1. Clinical experiences for students are good, i.e., there are a variety of settings.

2. Faculty preparation is generally good.

1. The school is now an independent entity on a par with other two professional schools.

1. Dedicated faculty.

Limitations.

1. Chronic under-funding.

1. Budgetary constraints lead to high student/faculty ratios which leaves little time for research and other scholarly activity.

1. No career development plans.

4. Rigid and redundant curriculum.

5. Poor scheduling of classes.

Question V

How do you want to be organized? 
of the five questions, this one generated the most discussion. Faculty, without exception, commented that the current organizational structure presented numerous problems. The faculty expressed that they felt that there should be a strong, decentralized departmental structure and these departments should be renamed so that faculty could be assigned according to their interests and expertise.

Because of the overwhelming concern expressed by faculty and their expressed desire to spend considerable time of this question, the researcher suggested that faculty submit the organizational structure they felt would be more reflective of their wishes. The following models were submitted to the researcher. To provide a comparison, the extant organizational structure will be presented (see Figure 2). The models presented in the following section were submitted by individual faculty members.

Figure 3 depicts a proposed organizational structure with five departments, four assistant deans, and the dean. The curriculum problems identified by the faculty would be handled by the assistant dean for curriculum who would also be supervising the curriculum coordinators for the sophomore, junior, and senior years. This model would have twice as many administrators as the current organizational structure shown in Figure 2. It also identifies administrative responsibility for faculty, students, and support services. Figure 4 is a model which has three clinical departments 


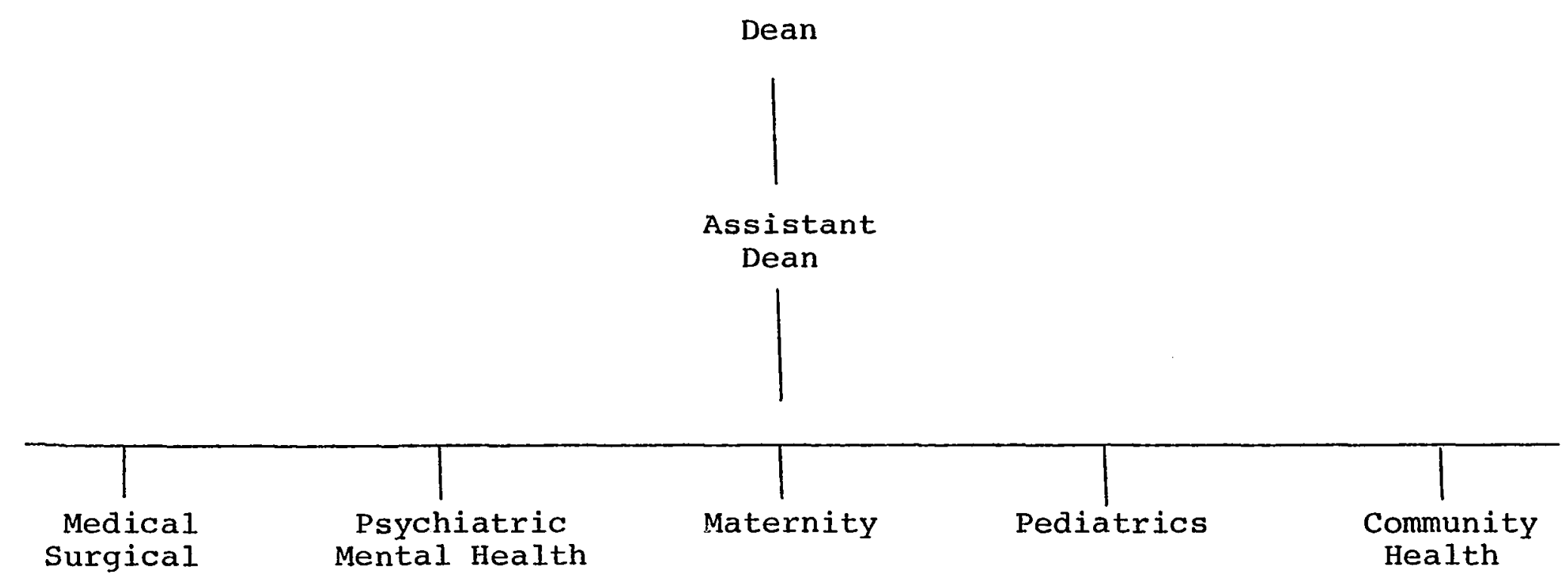

Figure 2. Current organizational structure, 1977. 
whose department heads are at the assistant dean level and one assistant dean responsible for the faculty and student organizations, the learning resources center, and the continuing education. As in Model $A$, additional positions at the Assistant Dean level would be required. Both Model A and $B$ would cost additional money because of the additional dean positions. Model $C$, illustrated in Figure 5, the school would be organized around the levels of instruction. There would be assistant deans in charge of each of the four years (sophomore, junior, senior, and graduate) and one for student and faculty. Similar to the preceding models, this is an administratively top-heavy one and therefore more costly in terms of salaries. Figure 6 illustrates Model $D$, which is also an administrative and hierarchical structure. Unlike the previous three models, however, there is an emphasis on such support services as grant writing and research. Additionally, the department chairpersons would report directly to an Assistant Dean for programs rather than to the Dean. This organizational structure is administratively top-heavy.

Model E, depicted in Figure 7, represents an entirely different organizational arrangement. It is adapted from the Southern Regional Education Board's (SREB) Proposed System for Nursing (1976). Looking at the role structure in nursing and the various kinds and levels of practice, the 


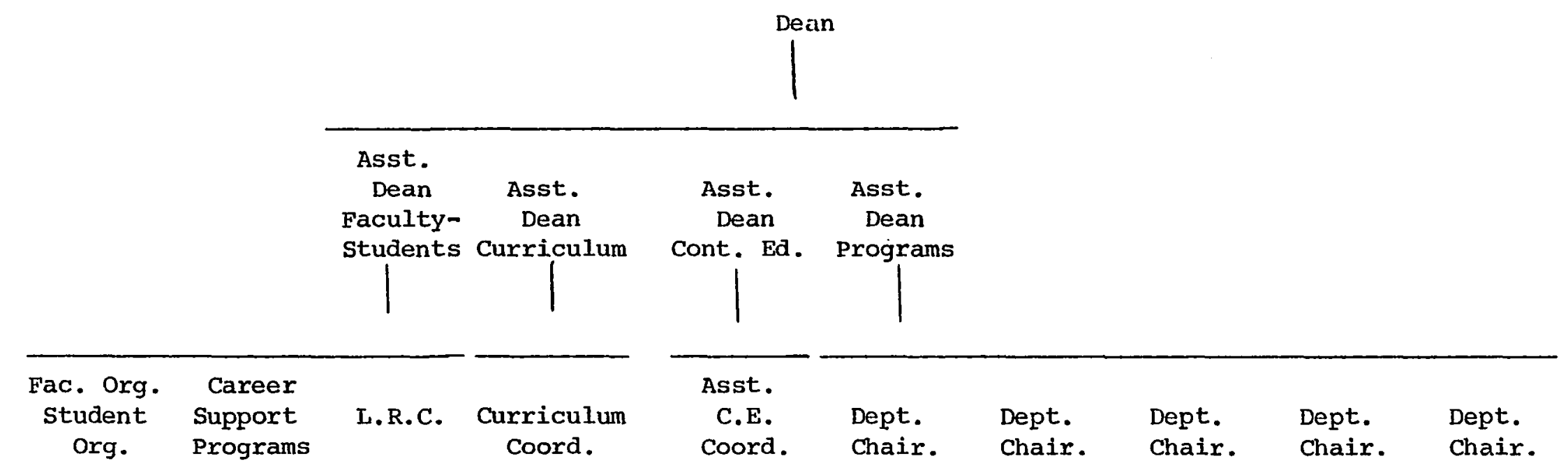

Figure 3. Model A. 


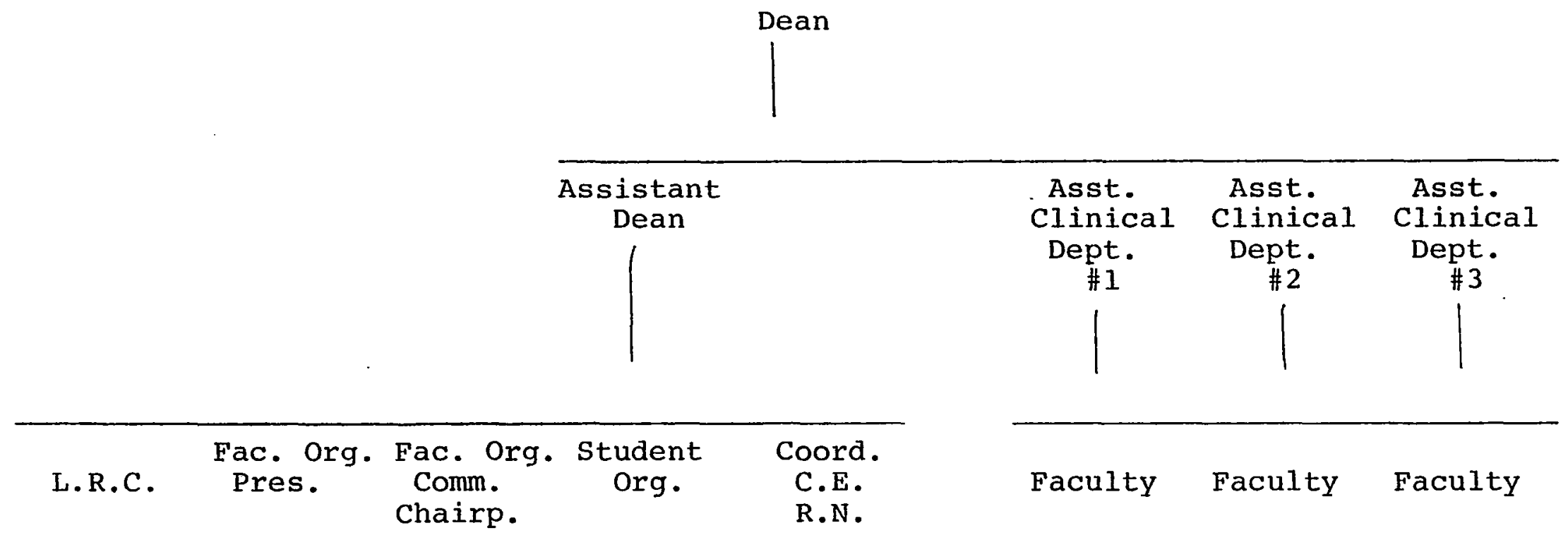

Asst.

Coord.

Figure 4. Model B. 


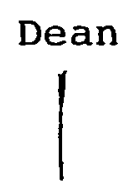

\begin{tabular}{|c|c|c|c|c|c|c|}
\hline $\begin{array}{l}\text { Asst. Dean } \\
\text { Soph. } \\
\text { Level }\end{array}$ & $\begin{array}{l}\text { Asst. Dean } \\
\text { Junior } \\
\text { Level }\end{array}$ & $\begin{array}{l}\text { Asst. Dean } \\
\text { Senior } \\
\text { Level }\end{array}$ & $\begin{array}{l}\text { Asst. Dean } \\
\text { Grad. } \\
\text { Level }\end{array}$ & $\begin{array}{l}\text { Asst. Dean } \\
\text { Dean } \\
\text { Fac.-Stud. }\end{array}$ & & \\
\hline Faculty & Faculty & Faculty & Faculty & C.E. & L.R.C. & $\begin{array}{l}\text { Fac.- } \\
\text { Stud. } \\
\text { Org. }\end{array}$ \\
\hline
\end{tabular}

Figure 5. Model C. 


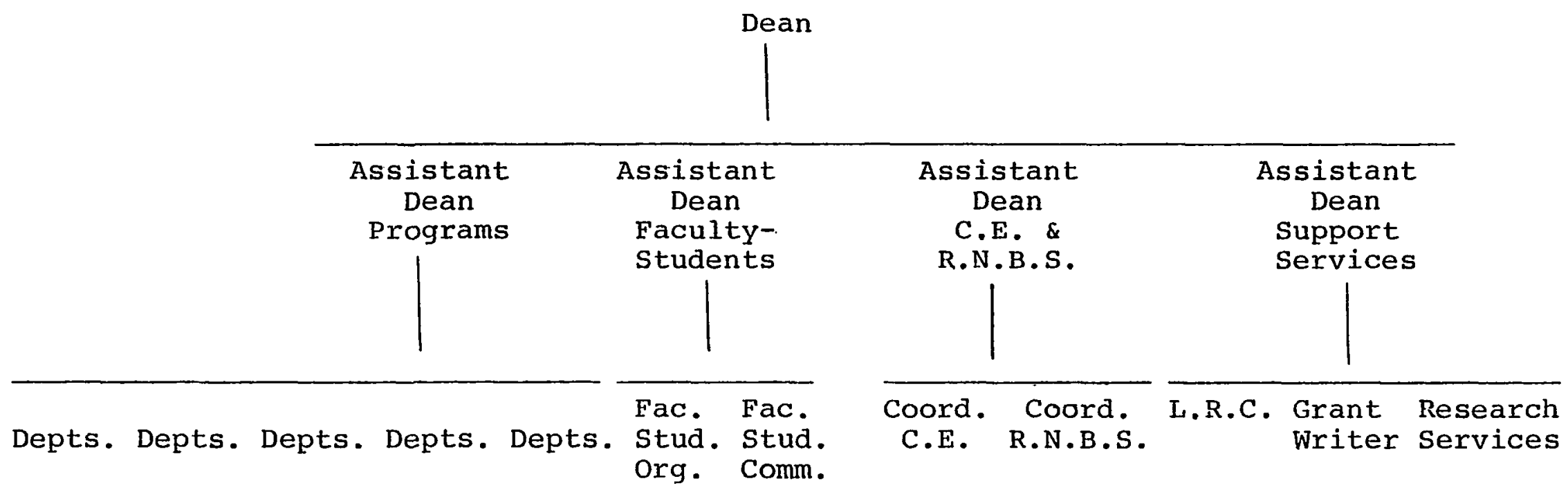

Figure 6. Model D. 
SREB task force conceptualized nursing practice into primary care, secondary care, and tertiary care.

The department of primary care would include faculty whose practice is directed toward providing services for health maintenance and health promotion. Secondary care faculty would be those whose practice takes place in the traditional setting, i.e., hospitals. Tertiary care was defined by the SREB task force as associated with large hospitals and/or health sciences centers. Like secondary care, it was seen as dealing with a single episode of illness, but with rare and more complex illnesses.

The department of core would have faculty whose interests resided in the basic knowledges underlying nursing practice.

Despite, and quite possibly because of, the innovativeness of Model $E$, faculty rejected it. It was this writer's perception that faculty felt a major curriculum revision would be necessary before the organizational structure suggested by this model could be implemented.

Model F, illustrated in Figure 8, was finally selected by faculty as the organizational structure. As can be seen, two Associate Dean positions were suggested, one for academic affairs and one for administration. The model suggested two minor changes in the existing structure: the graduate committee became a department and the two small 


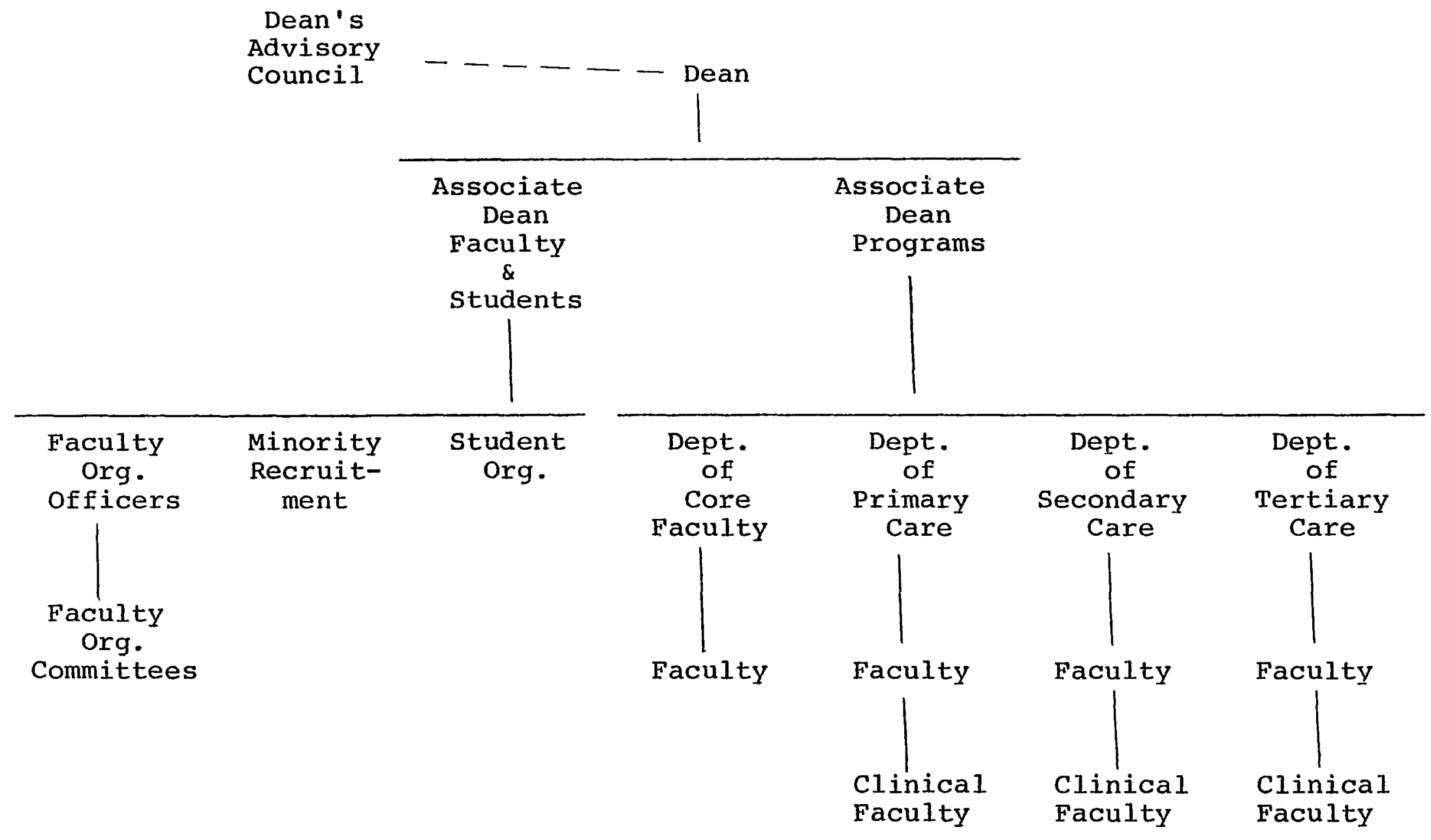

Figure 7. Model E. 
maternity and pediatric departments became the parentchild department.

\section{MISSIONS OF THE SCHOOL}

Next, information about the perceived emphasis on the missions of the school, teaching, community service, research, and practice will be presented. The mean scores for the total group and for each of the departments are presented in Table IV.

TABLE IV

MEAN RESPONSES: PERCEIVED EMPHASIS ON MISSIONS OF THE SCHOOI

\begin{tabular}{lcccccc}
\hline & & \multicolumn{5}{c}{ Departmental Faculty Mean } \\
\cline { 3 - 7 } Missions & $\begin{array}{c}\text { Grand } \\
\text { Mean }\end{array}$ & $\begin{array}{c}\text { Community } \\
\text { Fealth } \\
(n=4)\end{array}$ & $\begin{array}{c}\text { Graduate } \\
(n=9)\end{array}$ & $\begin{array}{c}\text { Medical- } \\
\text { Surgical } \\
(n=17)\end{array}$ & $\begin{array}{c}\text { Parent- } \\
\text { Child } \\
(n=4)\end{array}$ & $\begin{array}{c}\text { Mentric- } \\
\text { Health } \\
(n=12)\end{array}$ \\
\hline Teaching & 4.8 & 5.0 & 5.0 & 4.8 & 4.9 & 4.6 \\
Community & 2.0 & 2.5 & 2.5 & 1.5 & 2.5 & 2.0 \\
Service & 2.8 & 2.6 & 2.7 & 3.0 & 2.5 & 3.5 \\
Research & 2.0 & 2.5 & 2.0 & 1.5 & 1.5 & 2.5 \\
Practice & 2.0 & & & & & \\
\hline
\end{tabular}

Teaching

As can be seen in Table IV, the mean score for all departments on emphasis on teaching was 4.8 .

Community Service

Again, mean responses for perceived emphasis on community service ranged from 1.5 (little or no emphasis) 


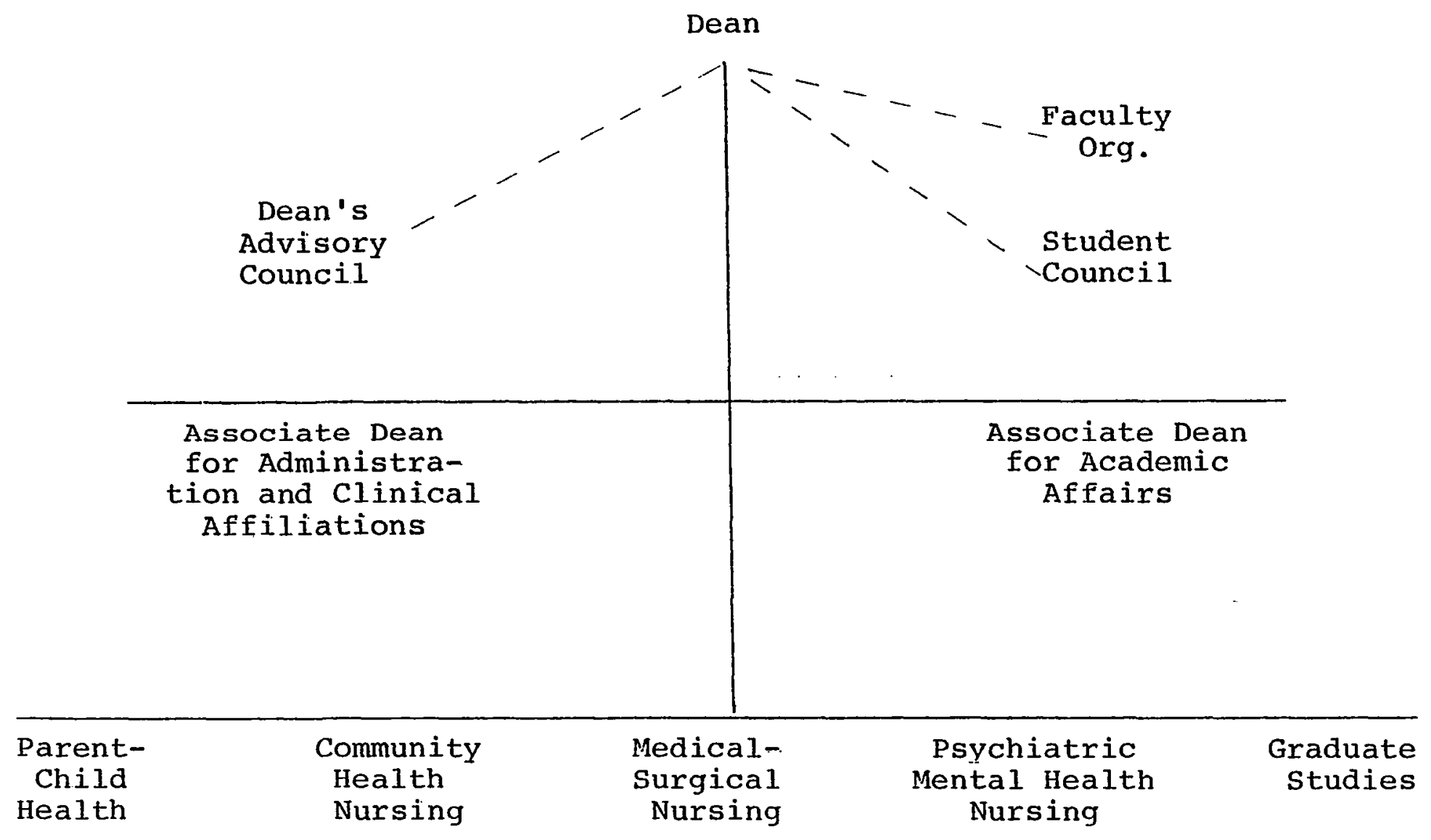

Figure 8. Model F. 
in the Medical-Surgical department to a 2.5 (moderate emphasis) in the Graduate Studies, Community Health, and ParentChild departments. The Psychiatric-Mental Health department faculty responses fell in the 2.0 rating, a slight amount of perceived emphasis.

\section{Research}

A consistently low emphasis was perceived by all respondents in all the departments. There was a range from little emphasis (2) to some emphasis (3), Parent-Child department and Medical-Surgical department respectively. It can be noted that there was a considerably higher perceived emphasis on this mission than on community service and on the next mission, practice.

\section{Practice}

Similar to teaching, but in reverse, virtually all respondents perceived little or no emphasis on clinical practice being given in the school.

\section{Summary}

It is clear from the information gathered from the perceived emphasis on the Missions of the School that only one mission is being given any attention, that of teaching. The lowest emphasis is given to community Service, the next is Practice, and then Research. 
SUPPORT SERVICES

The final data from Phase $I$ is the perceived adequacy of the support services, library facilities, office space, and the ratio of secretary to faculty. In addition, the adequacy of salary, academic rnak, time available to pursue own interests, and chances for promotion will also be reviewed. Mean responses for all the departments will be presented in Table V.

TABLE V

MEAN RESPONSES: PERCEIVED ADEQUACY OF SUPPORT SERVICES

\begin{tabular}{|c|c|c|c|c|c|c|}
\hline \multirow[b]{2}{*}{ Item } & \multirow[b]{2}{*}{$\begin{array}{r}\text { Grand } \\
\text { Mean }\end{array}$} & \multicolumn{5}{|c|}{ Departmental Faculty Mean } \\
\hline & & $\begin{array}{c}\text { Community } \\
\text { Health } \\
(n=4)\end{array}$ & $\begin{array}{l}\text { Graduate } \\
(n=9)\end{array}$ & $\begin{array}{c}\text { Medical- } \\
\text { Surgical } \\
(n=17)\end{array}$ & $\begin{array}{c}\text { Parent- } \\
\text { Child } \\
(n=4)\end{array}$ & $\begin{array}{l}\text { Psychi- } \\
\text { atric- } \\
\text { Mental } \\
\text { Health } \\
(n=12)\end{array}$ \\
\hline Salary & 2.0 & 2.5 & 2.0 & 1.9 & 1.5 & 2.2 \\
\hline $\begin{array}{l}\text { Time to } \\
\text { Pursue Own }\end{array}$ & & & & & & \\
\hline Interest & 2.3 & 2.7 & 2.2 & 2.5 & 2.0 & 2.3 \\
\hline $\begin{array}{l}\text { Chances } \\
\text { Promotion }\end{array}$ & 2.1 & 3.0 & 2.3 & 2.3 & 2.0 & 1.0 \\
\hline $\begin{array}{l}\text { Office } \\
\text { Space }\end{array}$ & 2.2 & 3.2 & 2.2 & 2.0 & 1.7 & 1.9 \\
\hline Iibrary & 1.2 & 1.0 & 1.0 & 1.0 & 2.0 & 1.0 \\
\hline $\begin{array}{l}\text { Ratio of } \\
\text { Secretarial } \\
\text { Help to } \\
\text { Professors }\end{array}$ & 2.0 & 3.0 & 1.5 & 2.0 & 2.0 & 1.6 \\
\hline
\end{tabular}

As can be seen in Table $V$, all faculty rated the library facilities as "needing a great deal of improvement." Salary, time to pursue my own interests, and chances for 
promotion were also seen as "needing a great deal of improvement" or "needing some improvement" by all departments.

Summary

It is evident that satisfaction with salary was well below the satisfactory point for all departments and that this low satisfaction was also evident with the chances for promotion and in some cases for the opportunity to "pursue my own interests." In the category "chance for promotion," the Psychiatric-Mental Health faculty rated this as a 1.0, "needs a great deal of improvement," the lowest rating given by any of the departments. office space, secretary/faculty ratio, and library facilities were also rated as in need of a great deal of improvement. Quality of office space was rated higher by Medical-Surgical faculty. 


\section{CHAPTER V}

\section{RESULTS AND DISCUSSION: PHASE II}

The methodology for this part of the research was designed to conduct and assess the impact of an $O D$ process utilizing a control group design which included two measures: the Meetings Questionnaire and nonparticipant observation. Six hypotheses were posed which predicted that, as a result of the $O D$, collaboration in the experimental group would increase, communication would improve, roles would become clearer, and there would be an increase in trust, concern, and individuality behaviors.

The purpose of this chapter is to present the data generated by the research and to analyze the data associated with each of the six hypotheses. The format of this chapter is as follows: each hypothesis will be stated. The data pertaining to each hypothesis will then follow. Finally, a discussion and analysis of the data will be presented.

As will be recalled, the Meetings Questionaire consisted of thirty-seven items to which the respondent is asked to indicate the frequency of occurrence of specific behaviors on a six-point scale ranging from "always occurs" to "never occurs." 


\section{HYPOTHESIS I}

If organization development is conducted in a professional school, organizational effectiveness will be improved by increased collaboration in decision making and problem solving by the members of the experimental group.

In order to determine whether organization development does increase collaboration, the Meetings Questionnaire was administered pre- and post-treatment to both the MedicalSurgical group and the Psychiatric-Mental Health group. As collaboration in decision making and problem solving increases, members of the experimental group would participate more actively and equally in decision making and problem solving. Individuals would have input in determining content for the meetings and in policy recommendations and resolutions to problems. With increased collaboration, members of the experimental group would be apt to disagree more freely, to manage conflict more constructively, to be more honest with each other, and to be more committed to the outcomes of decision making and problem solving in the group. As a result, members would express greater satisfaction and be more positive about the group problem-solving and decision-making efforts.

There are nineteen items on the Meetings Questionnaire which deal with collaboration. They are: $1,2,5,7,8$, $9,12,16,20,22,23,24,28,30,32,34,35,36$, and 37 (see Appendix B). If an individual responded that it was typical that "the average person in the meeting feels that 
her/his ideas have gotten into the discussion," this implies that there is considerable participation in the meeting. If the hypothesis is confirmed, 50 percent or more of the nineteen items in the category must be significantly different on post-test.

As can be seen in Table VI, there was a significant change in the experimental groups' scores from the pre-test to the post-test on four items: numbers $22,28,30$, and 37. Therefore, it can be concluded that following the OD process, members of the experimental group perceived that during meetings it was more typical that people became more involved with the meeting (22), that the results of the group's work was worthwhile (28), that people feel very committed to carrying out the solutions arrived at by the group (30), and, finally, that "people feel satisfied or positive" during the meeting (37).

TABLE VI

PRE-TEST AND POST-TEST MEAN RESPONSES OF EXPERIMENTAI AND CONTROT GROUPS TO THE MEETINGS QUESTIONNAIRE-COLIABORATION

\begin{tabular}{|c|c|c|c|c|c|c|c|}
\hline & \multirow[b]{3}{*}{ statement } & \multicolumn{6}{|c|}{ Group } \\
\hline & & \multicolumn{3}{|c|}{$\begin{array}{l}\text { Experimenta1 } \\
(n=16)\end{array}$} & \multicolumn{3}{|c|}{$\begin{array}{l}\text { Control } \\
(n=12)\end{array}$} \\
\hline & & Pre & $\frac{\text { Post }}{x^{a}}$ & $t^{b}$ & Pre & Post & $t^{b}$ \\
\hline \multirow[t]{2}{*}{1.} & $\begin{array}{l}\text { When problems come up in the meet- } \\
\text { ings they are thoroughly explored } \\
\text { until everyone understands what the }\end{array}$ & & & & & & \\
\hline & problem is. & 4.5 & 4.7 & .07 & 4.3 & 4.0 & .10 \\
\hline 2. & $\begin{array}{l}\text { The first solution proposed is } \\
\text { often accepted by the group }\end{array}$ & 2.0 & 1.9 & .19 & 2.3 & 2.1 & .04 \\
\hline
\end{tabular}


TABLE VI--Continued

\begin{tabular}{|c|c|c|c|c|c|c|c|}
\hline \multirow{3}{*}{\multicolumn{2}{|c|}{ Statement }} & \multicolumn{6}{|c|}{ Group } \\
\hline & & \multicolumn{3}{|c|}{$\begin{array}{l}\text { Experimental } \\
(n=16)\end{array}$} & \multicolumn{3}{|c|}{$\begin{array}{r}\text { Control } \\
(n=12)\end{array}$} \\
\hline & & Pre & Post & $t^{b}$ & Pre & Post & $t^{b}$ \\
\hline 7. & $\begin{array}{l}\text { There are many problems which } \\
\text { people are concerned about which } \\
\text { may never get on the agenda. } \\
\text { The group discusses the pros and } \\
\text { cons of several different alter- } \\
\text { native solutions to a problem. }\end{array}$ & 3.0 & 2.0 & .13 & 3.0 & 2.1 & $2.69 *$ \\
\hline 8. & $\begin{array}{l}\text { People bring up extraneous or ir- } \\
\text { relevant matters. }\end{array}$ & 2.9 & 1.9 & .75 & 1.7 & 2.7 & .46 \\
\hline 9. & $\begin{array}{l}\text { The average person in the meeting } \\
\text { feels that his ideas have gotten } \\
\text { into the discussion. }\end{array}$ & 4.3 & 4.3 & .00 & 4.3 & 4.6 & .09 \\
\hline 12. & $\begin{array}{l}\text { Either before the meeting or at } \\
\text { its beginning, any group member } \\
\text { can easily get items on the } \\
\text { agenda. }\end{array}$ & 3.6 & 2.9 & .12 & 4.8 & 5.0 & .03 \\
\hline 16 . & $\begin{array}{l}\text { The same few people seem to do } \\
\text { most of the talking during the } \\
\text { meeting. }\end{array}$ & 3.2 & 3.2 & .00 & 2.2 & 2.1 & .10 \\
\hline 20 & $\begin{array}{l}\text { From time to time in the meet- } \\
\text { ing, people openly discuss the } \\
\text { feelings and working relation- } \\
\text { ships in the group. }\end{array}$ & 2.7 & 2.0 & .12 & 4.3 & 3.1 & .28 \\
\hline 22 . & $\begin{array}{l}\text { People don't seem to care about } \\
\text { the meeting or want to get in- } \\
\text { volved with it. }\end{array}$ & 2.5 & 1.0 & $2.24 *$ & 2.4 & 2.7 & .24 \\
\hline 23 & $\begin{array}{l}\text { When the group is thinking about } \\
\text { a problem, at least two or three } \\
\text { different solutions are suggested. }\end{array}$ & 4.6 & 4.9 & .05 & 4.9 & 4.7 & .04 \\
\hline 25 . & $\begin{array}{l}\text { Some very creative solutions come } \\
\text { out of the group. }\end{array}$ & 3.6 & 4.0 & .19 & 3.9 & 3.5 & .05 \\
\hline 28. & $\begin{array}{l}\text { The results of this group's work } \\
\text { are not worth the time it takes. }\end{array}$ & 3.7 & 1.5 & $2.14 *$ & 1.2 & 2.9 & .12 \\
\hline 30 . & $\begin{array}{l}\text { People feel very committed to } \\
\text { carrying out the solutions ar- } \\
\text { rived at by the group. }\end{array}$ & 3.0 & 4.6 & $2.38 *$ & 4.0 & 4.3 & .08 \\
\hline 32. & $\begin{array}{l}\text { People feel antagonistic or } \\
\text { negative during the meeting. }\end{array}$ & 2.8 & 1.0 & .45 & 2.9 & 1.3 & .25 \\
\hline
\end{tabular}


TABLE VI--Continued

\begin{tabular}{|c|c|c|c|c|c|c|c|}
\hline \multirow{3}{*}{\multicolumn{2}{|c|}{ statement }} & \multicolumn{6}{|c|}{ Group } \\
\hline & & \multicolumn{3}{|c|}{$\begin{array}{c}\begin{array}{c}\text { Experimental } \\
(n=16)\end{array} \\
\end{array}$} & \multicolumn{3}{|c|}{$\begin{array}{c}\text { Control } \\
(n=12)\end{array}$} \\
\hline & & Pre & Post & $t^{b}$ & Pre & Post & $t^{b}$ \\
\hline 34. & $\begin{array}{l}\text { Solutions and decisions are in } \\
\text { accord with the chairperson's } \\
\text { point of view, but not necessarily } \\
\text { with the members'. }\end{array}$ & 1.6 & 1.0 & .13 & 1.4 & 1.1 & .24 \\
\hline 35 . & $\begin{array}{l}\text { There are splits or deadlocks be- } \\
\text { tween factions or subgroups. }\end{array}$ & 1.8 & 1.5 & .13 & 1.3 & 1.5 & .55 \\
\hline 36. & $\begin{array}{l}\text { The discussion goes on and on } \\
\text { without any decision being reached. }\end{array}$ & 1.0 & 2.9 & .20 & 2.6 & 1.7 & .13 \\
\hline 37. & $\begin{array}{l}\text { People feel satisfied or positive } \\
\text { auring the meeting. }\end{array}$ & 2.5 & 4.2 & $2.83 *$ & 3.2 & 4.5 & .21 \\
\hline
\end{tabular}

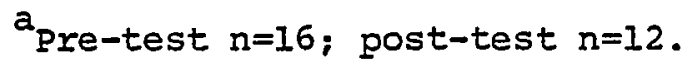

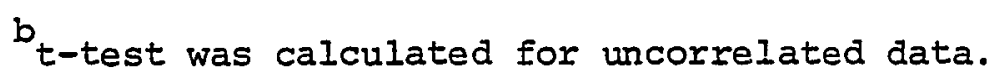

*

* Significant at or beyond .05 .

On the pre-test it can be noted that behaviors which were fairly typical of the meetings of the experimental group were: problems being thoroughly explored (\#1), discussion of the pros and cons of several alternate solutions (\#7), average person getting his ideas into the discussion (\#9), and any person can get items on the agenda (\#12). These item means ranged from 4.2 to 4.7 , indicating that the group's effectiveness was fairly high prior to the OD effort. On the other hand, there was a fairly consistent finding that there were many problems that were of concern to people that never got on the agenda (\#5) and that it was more untypical than typical for feelings and working 
relations within the group to be discussed (\#20). While there was not a significant difference in the post-test scores on these two items, an improvement was noted in item \#20. The post-test score indicated that there was "some" discussion of feelings and relationships.

Similar to the experimental group, the control group pre-test mean scores were high on item \#1, "Problems are throughly explored in the meetings," indicating that in the control group respondents also felt that this was a typical behavior. They also felt that the average person "was able to get his ideas into the discussion" and that it was very typical for "any group member to be able to get items on the agenda either before the meeting or at the beginning." In both the experimental group and the control group, there was a decrease in the mean score on item \#8, "People bring up extraneous or irrelevant matters," indicating a trend toward greater collaboration.

It can also be seen from Table VI that in both groups, the following pre-test behaviors were perceived as being more untypical: the first solution being accepted (\#2), splits or deadlocks in the group (\#35), and the solutions being in accord with the chairperson's view (\#34). The mean scores on these items ranged from 1.3 to 2.0 , indicating a high degree of collaboration.

Because of the previously established decision rule that a significant difference in pre-test and post-test 
scores on 50 percent of the items was required in order to accept a hypothesis as significant, Hypothesis I was rejected.

\section{HYPOTHESIS II}

If organization development is conducted in a professional school, the effectiveness of communication vertically and horizontally in the organization will increase in the experimental group.

Once again, the Meetings Questionnaire was used to determine an increase in effective communication. Participants responded to questions about information sharing, openness, communication flow, and conflict management. If communication in the experimental group becomes more effective, the following behaviors would occur: problems would be carefully discussed by the group, alternative solutions and their potential consequences will be explored. Furthermore, once decisions were made, it would be clearer what they were and who would implement them. Disagreements would be voiced more frequently and conflict would be worked through more often. Individuals would feel free to openly share their points of view and feel satisfied with the level of their own verbal participation. In addition, there would be follow-up of decisions to evaluate the impact of these decisions.

The quality and quantity of communication are measured by sixteen items on the Meetings Questionnaire: $3,4,6$, $10,13,14,15,17,19,21,24,26,27,29,31$, and 33 (see 
Appendix B). If the effectiveness of communication increased, responses should show that it was more "untypical" that "People are afraid to be openly critical or make good objections." Confirmation of Hypothesis II was accepted if there was a significant change in 50 percent of the sixteen items in the category on post-test.

As can be seen in Table VII, group mean scores of the experimental group revealed significant change on two items: $\# 3$ and \#4. Following the OD process, the members of the experimental group reported that it was more untypical for people to come to the meeeting not knowing what was to be presented or discussed and that it was quite typical for people to ask why the problem existed and what the cause(s) of the problem was.

TABIJE VII

PRE-TEST AND POST-TEST MEAN RESPONSES OF EXPERIMENTAL AND CONTROL GROUP TO THE MEETINGS QUESTIONNAIRE--COMMUNICATION

\begin{tabular}{|c|c|c|c|c|c|c|c|}
\hline & \multirow[b]{3}{*}{ statement } & \multicolumn{6}{|c|}{ Group } \\
\hline & & \multicolumn{3}{|c|}{$\begin{array}{l}\text { Experimental } \\
(n=16)\end{array}$} & \multicolumn{3}{|c|}{$\begin{array}{c}\text { Control } \\
(\Omega=12)\end{array}$} \\
\hline & & Pre & Post & $t$ & Pre & Post & $t$ \\
\hline 3. & $\begin{array}{l}\text { People come to the meeting not } \\
\text { knowing what is to be presented } \\
\text { or discussed. }\end{array}$ & 2.9 & 1.1 & 1.7 * & 2.8 & 1.8 & 1.09 \\
\hline & $\begin{array}{l}\text { People ask why the problem exists, } \\
\text { what the causes are. }\end{array}$ & 2.2 & 4.6 & $2.9 *$ & 5.0 & 5.0 & .00 \\
\hline 6. & $\begin{array}{l}\text { There is a tendency to propose } \\
\text { answers without really having } \\
\text { thought the problem and its } \\
\text { causes through carefully. }\end{array}$ & 1.9 & 1.6 & .09 & 1.4 & 1.0 & .13 \\
\hline 10. & $\begin{array}{l}\text { Someone summarizes progress from } \\
\text { time to time }\end{array}$ & 3.7 & 4.2 & .29 & 4.6 & 4.0 & .09 \\
\hline
\end{tabular}


TABIE VII--Continued

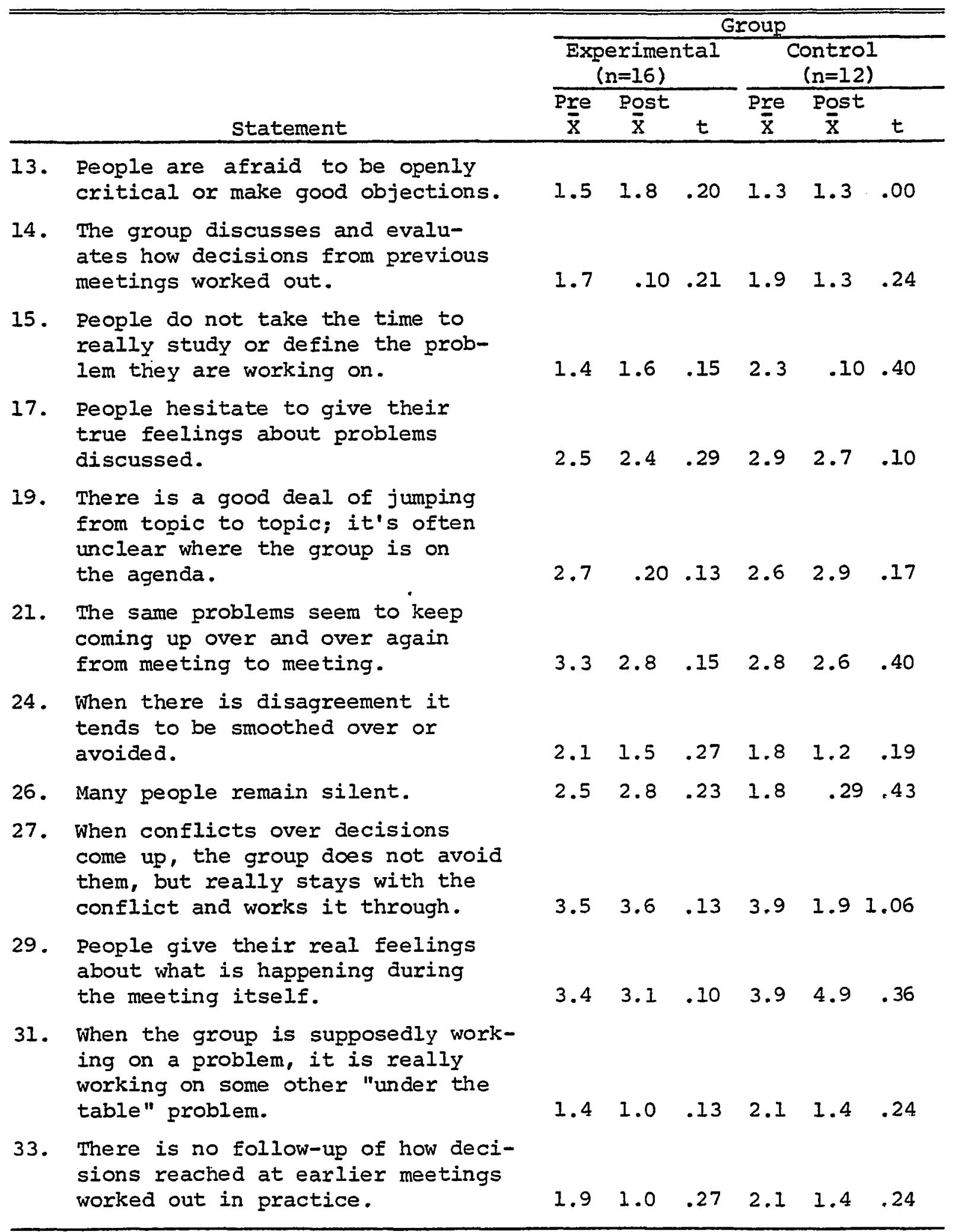

*Significant at or beyond .05 . 
On the pre-test, the experimental group felt that it was fairly typical for someone to summarize progress from time to time, for people to give their real feelings about what is happening during the meeting itself, and for the group not to avoid conflict. The mean scores on these items, however, was 3.5, indicating that there was room for improvement. The post-test scores on the first of these items, "Someone summarizes progress," increased whereas there was a slight decrease on the item, "People give their true feelings."

Additionally, it was untypical for people to fear being critical (\#13), to smooth over disagreements (\#24), to have "hidden agendas" (\#31), or to fail to follow up on. how decisions reached in earlier meetings worked out in practice. The relatively high scores on item \#26 on pretest and post-test, that it is "more typical than not for many people to remain silent during meetings" is an indication that there is considerable room for improvement. The control group had pre-test and post-test scores, reflecting that it was more untypical for this to occur. The control group scores on both pre- and post-test also reveal that it was very typical for people to ask why the problem existed and the causes for it. Besides these two differences, the pre-test scores for both the experimental and the control group were very similar. 
Since only two items of the sixteen concerning communication were significantly different, Hypothesis II was rejected.

\section{HYPOTHESIS III}

If organization development is conducted in a professional school, organizational effectiveness of the members will be improved by more clearly understood roles in the experimental group.

This hypothesis predicts that organizational effectiveness would be improved if the members understand their roles and the roles of others. In order to determine whether roles were clarified as a result of the $O D$ intervention, the Meetings Questionnaire dealing with clarity of responsibility for implementing decisions made in the meetings was examined. These items were \#11 and \#18.

As can be seen in Table VIII, the pre-test and posttest scores on item \#11 are the same in both the experimental and the control group. The score on the pre-test indicates that it is more typical for decisions and the person responsible for carrying out the decision to be clear. Both post-test scores were lower, indicating that it is "untypical" for decisions to be left vague, indicating greater role clarity. On the second item, there was an unexplainable decrease in the experimental group's mean score on post-test. Scores on neither item was significantly higher on post-test, and therefore Hypothesis III was rejected. 
TABLE VIII

PRE-TEST AND POST-TEST MEAN RESPONSES OF EXPERIMENTAL AND CONTROI GROUP TO THE MEETINGS QUESTIONNAIRE--ROLE CLARITY

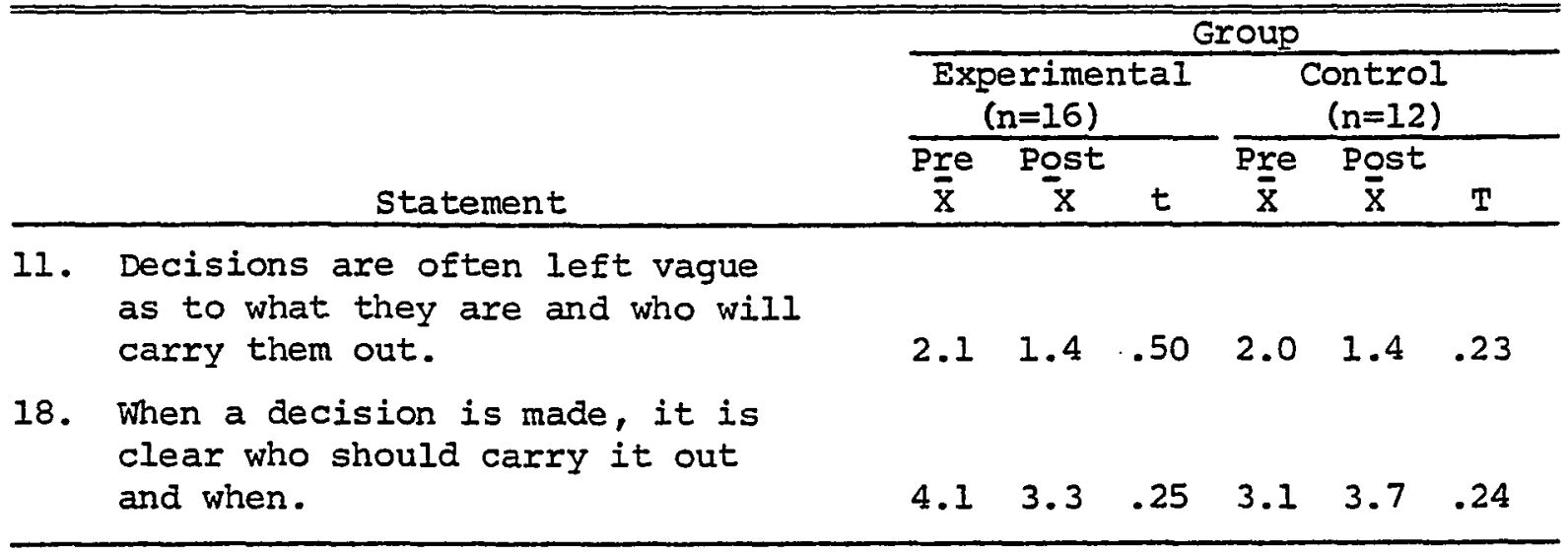

HYPOTHESES IV, V, AND VI

If organization development is conducted in a professional school, organizational effectiveness of the members will be improved by an increase in trust behaviors in the experimental group.

If organization development is conducted in a professional school, organizational effectiveness of the members will be improved by an increase in concern behaviors in the experimental group.

If organization development is conducted in a professional school, organizational effectiveness of the members will be improved by an increase in individuality behaviors in the experimental group.

Data for this part of the research were collected by observing the behavior of participants during actual decision-making meetings using Argyris' system of categories. Six meetings were observed in both the experimental and the control groups. A sumary table outlining the frequency of behaviors manifested during each of the six meetings will be presented along with a discussion of the data. 
Percentage of total meeting time each behavior represented will be graphed and examined for changes in level and/or slope.

Effective problem solving involves three criteria, according to Argyris: a high level of awareness of factors having a positive or negative effect on the organization, problems are solved in such a way that they remain solved, and the problem-solving process and the environment are positive. If these three criteria are met, the individual will have to verbalize her/his awareness of feelings, to be able to "own up" to them, to accept responsibility for them, and to risk expressing them. Additionally, participants will have to strive to be "open" to new factors and to "experiment" with new options. Such behavior leads to the creations of norms of individuality, concern, and trust.

As will be recalled from an earlier discussion, Level II behaviors are the norms of the group and are a composite of both individual and interpersonal behaviors. For example, individuality is the combination of "owning" and "helping others to own" and trust is the combination of "experimenting" and "helping others to experiment." Conformity, antagonism, and mistrust are the negative aspects of each of the above categories.

In Table IX, data for meetings 1 through 3 are pretreatment, and 4 through 6 are post-treatment for the experimental group. As can be seen, the frequency of 
behavior in the "idea" category far exceeds that of behavior in the "feeling" category. Concern for "ideas" ranked first in meeting $I$ and individuality "ideas" ranked first in both meetings 2 and 3 . It will be recalled that according to Argyris' research findings, concern for ideas is high when group members are attempting to obtain information, when they want to learn the viewpoint of a supervisor, or when they need clarification of a point. It is obvious, then, that the frequency of "idea" and/or feeling could be dependent on the agenda of the meeting being observed. If such a meeting was designed to give information to the participants, the likelihood of observing a preponderance of "idea" behaviors is much higher than it would be in a meeting where the agenda was different. Given the potential impact of agenda differences, the finding in the present study should be interpreted with caution. It is helpful, however, to discuss what the literature states in a general way about such results. Argyris believes that to the extent people are rewarded primarily for contributing ideas to the achievement of an organization's objectives and are controlled through scarce rewards and competition, a high incidence of "owning ideas" (individuality) will be seen. People will be attempting to sell their point of view in order to maximize the possible rewards and minimize the possible penalties (Argyris, 1964). When people are intent on 
selling their own ideas, contributions made by others will often not be heard.

TABLE IX

FREQUENCY AND PERCENTAGE OF NORMS OBSERVED

IN EXPERIMENTAL GROUP MEETINGS

\begin{tabular}{|c|c|c|c|c|c|c|c|c|c|c|c|c|}
\hline \multirow[b]{2}{*}{ Norms } & \multicolumn{2}{|c|}{$\begin{array}{c}1 \\
n=97\end{array}$} & \multicolumn{2}{|c|}{$\begin{array}{c}2 \\
n=133\end{array}$} & \multicolumn{2}{|c|}{$\begin{array}{c}3 \\
n=129\end{array}$} & \multicolumn{2}{|c|}{$\begin{array}{c}4 \\
n=84\end{array}$} & \multicolumn{2}{|c|}{$\begin{array}{c}5 \\
n=175\end{array}$} & \multicolumn{2}{|c|}{$\begin{array}{c}6 \\
n=166\end{array}$} \\
\hline & I & $\frac{q}{8}$ & $\mathrm{f}$ & $\%$ & $\mathrm{E}$ & $q$ & $\underline{f}$ & 8 & $\mathbf{f}$ & $\%$ & $\mathrm{f}$ & so \\
\hline \multicolumn{13}{|c|}{ Individuality } \\
\hline Ideas & 6 & 6 & 51 & 38 & 48 & 37 & 33 & 39 & 37 & 21 & 41 & 25 \\
\hline Feelings & 3 & 3 & & & & & 4 & 5 & 1 & 1 & 5 & 3 \\
\hline \multicolumn{13}{|l|}{ Concern } \\
\hline Ideas & 44 & 45 & 36 & 27 & 31 & 25 & 23 & 27 & 60 & 34 & 35 & 21 \\
\hline Feelings & 3 & 3 & & & 1 & $<1$ & 1 & 1 & 16 & 9 & 10 & 6 \\
\hline \multicolumn{13}{|l|}{ Trust } \\
\hline $\begin{array}{l}\text { Ideas } \\
\text { Feelings }\end{array}$ & $\begin{array}{r}31 \\
1\end{array}$ & $\begin{array}{r}32 \\
1\end{array}$ & 32 & 24 & 34 & 26 & $\begin{array}{r}14 \\
1\end{array}$ & $\begin{array}{r}17 \\
1\end{array}$ & 54 & 31 & $\begin{array}{l}45 \\
14\end{array}$ & $\begin{array}{r}27 \\
8\end{array}$ \\
\hline \multicolumn{13}{|l|}{ Conformity } \\
\hline Ideas & 2 & 2 & & & & & & & & & & \\
\hline Feelings & 1 & 1 & & & 1 & $<1$ & & & & & & \\
\hline \multicolumn{13}{|l|}{ Mistrust } \\
\hline Ideas & 3 & 3 & 14 & 11 & 13 & 10 & 7 & 8 & 7 & 4 & 9 & 5 \\
\hline Teelings & 3 & 3 & & & & & 1 & $I$ & & & 7 & 4 \\
\hline \multicolumn{13}{|l|}{ Antagonism } \\
\hline Ideas & & & & & 2 & 1 & & & & & & \\
\hline Feelings & 1 & 1 & & & & & & & & & & \\
\hline
\end{tabular}

The preponderance of "idea" behavior in all the meetings of the control group suggests that rationality is the accepted and rewarded way of behaving. On the other hand, this finding supports Boyer and Crockett's contention that participants in higher education tend to value ideas, thoughts, and concepts over feelings. Even so, Argyris believes that when "idea" behavior is valued over "feeling" behavior, people will tend to "play it safe" and be overly 
cautious rather than to take risks related to topics considered emotional. People will also tend to be prepared to defend their own position and viewpoint rather than to explore either openly. In the present research, "trust" scores are relatively low in the "idea" category and virtually nonexistent in the "feeling" behavior. With similar findings in public sector settings, Argyris has stated that the only safe way for people to express feelings is to create crises where emotionality is permitted (1973) and that these crises are typically created by those with power because only they can violate the norm against emotionality. It is impossible to make such emphatic statements on the basis of the data in the present research. However, a prudent consultant/researcher continuing to do follow-up with the study organization would be alert to any signs of such behavior.

The pattern of behavior illustrated in Table IX is that which is evidenced in most bureaucratic organizations because of the implied values underlying bureaucracy as a concept. That is to say, there is a basic belief in rationality, low emotionality, and rules and regulations. According to Argyris' theoretical viewpoint, this pattern tends to lead to low interpersonal competence and lowered system effectiveness. Few interpersonal problems are solved effectively, resulting in a deterioration of the problemsolving process. It will be recalled that in the 
pre-treatment questionnaire responses, over half of the Medical-Surgical faculty felt that the same problems were brought up repeatedly. Furthermore, many of the faculty felt that conflicts were typically not worked through. Individuality "ideas," concern "ideas," and trust "ideas" ranked first in both frequency and percentage of the total behavior manifested in meetings 4 through 6 respectively. Although there continued to be a norm of rationality even after intervention, the increase in trust "ideas" behavior in meeting 5 and the fact that it ranked first in meeting 6 gives some indication that individuals were willing to present their ideas for review and open discussion. This is encouraging despite the fact that individuality "ideas" ranked a close second in meeting 6 . In addition, trust "feelings" in this meeting occupied 8 percent of the interactions, more than at any other meeting.

In summary, the following conclusions, based on the number of times each ranked first, can be drawn:

1. The most clearly demonstrated norm in the six meetings was that of individuality (owning) ideas.

2. Concern for ideas (openness) was the second ranked norm.

3. Trust for ideas (experimenting) ranked third. The control group was very similar to the experimental group in terms of frequency and percentage of time spent in 
behaviors defined as "idea" behaviors. As can be seen in Table $\mathrm{x}$, individuality "ideas" have the highest frequency and percentage of responses in all six meetings with concern "ideas" ranking second. The norm of individuality emphasizes the importance of the individual's expressing her/his own ideas or feelings. Based on the data, the control group behaves in a way that implies that it is good for a person to say what she/he believes and to exercise personal independence. In addition, the individual takes responsibility for her/his ideas and is unafraid to state beliefs. With the exception of the "concern" category, the "feeling" behaviors are much higher than in the experimental group, indicating a greater willingness to express emotionality. This result is hardly surprising considering that the control group was comprised of psychiatric faculty whose education and clinical expertise involves dealing with the psychological aspects of living. If one is to believe Argyris, this group would be more humanistic and emotional in their orientation than the experimental group.

We can conclude that as a group, the PsychiatricMental Health faculty demonstrated a high degree of individuality, holding "individuality-ideas" as the most important in the group with "individuality-feelings" second. Both groups are similar in the following ways: 
TABLE X

FREQUENCY AND PERCENTAGE OF NORMS OBSERVED IN CONTROL GROUP MEETINGS

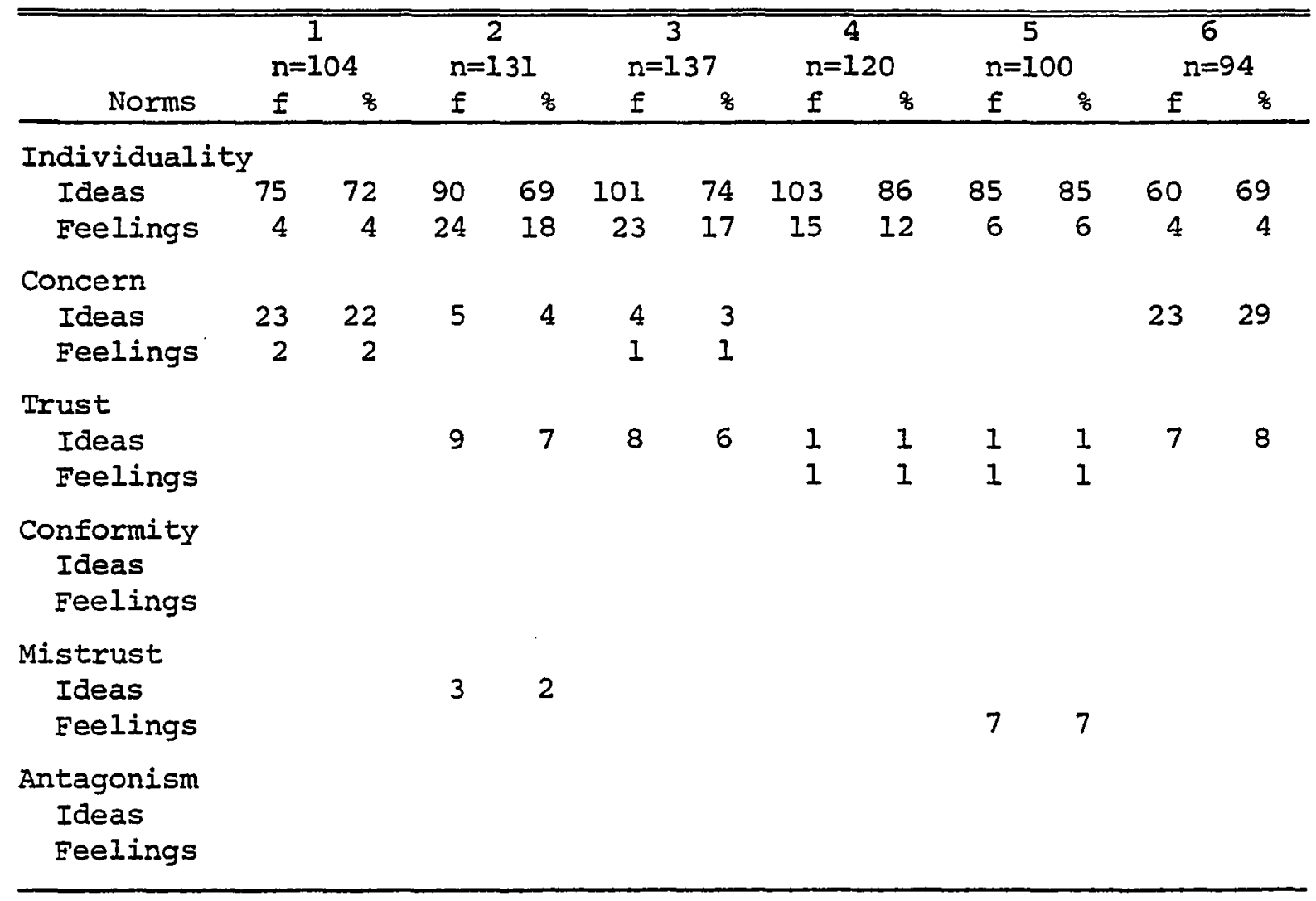

1. Antagonism to ideas or feelings is low. Members seldom show discomfort (and never anger) toward each other.

2. On the interpersonal level, "not helping others" in any category is as infrequent as "helping others." Both are almost at the bottom in terms of frequency of occurrence.

3. Behaviors that were rarely observed were:
a. Risk taking
b. Trust in the control group 
c. Conformity

d. The expression of either positive or negative feelings

e. Overtly refusing to give one's point of view or overtly refusing to listen to someone else's point of view

f. Encouraging silent members to participate To this point, the analysis has focused on comparing observations of the groups with Argyris' model of values and behavior in task-oriented meetings. The data were looked at in a global way. The analysis of the specific hypotheses will be concerned with the effects of the organization development effort over a six-week period of time. The pattern and direction of the data wi 1 be discusse noting two characteristics: change in levi and change in slope. It will be recalled that a change in level refers to a change at the point at which the intervention is made whereas a change in slope refers to a change in trend across time. A "significant" change in the data across time will be reflected either as a change in level or a change in slope or both. For example, a very gradual change in behavior after the intervention might be detected as a change in slope but no change in level. Each hypothesis has two components, "ideas" and "feelings," which will be presented in separate graphs. 
Hypothesis IV

If organization development is conducted in a professional school, organizational effectiveness of the members will be improved by an increase in individuality behaviors in the experimental group.

It will be recalled that the norm individuality indicates that a group considers experession of individual ideas and feelings as appropriate. It also reflects the appropriateness of taking responsibility for owning up to and taking responsibility for one's own ideas and feelings. It is further characterized by verbal statements such as "in my opinion," "I feel," "I don't agree with . . .," and "I would like to discuss."

Reviewing the data illustrated in Figure 9, it is immediately apparent that the level for the control group "individuality, ideas" was higher than that of the experimental group in the baseline data. The slope for both groups was also different during the baseline period. In the post-treatment weeks, the level for both groups increased and there was a downward trend in the slope for both groups as well. For the experimental group, however, there was a sharper downward slope. At week 7, the department head for the control group was hospitalized and a member of the department conducted the meeting. While this event introduced a confounding variable into the control group, it had no impact on the experimental group. Since the experimental group was the group of interest, the research was continued. 


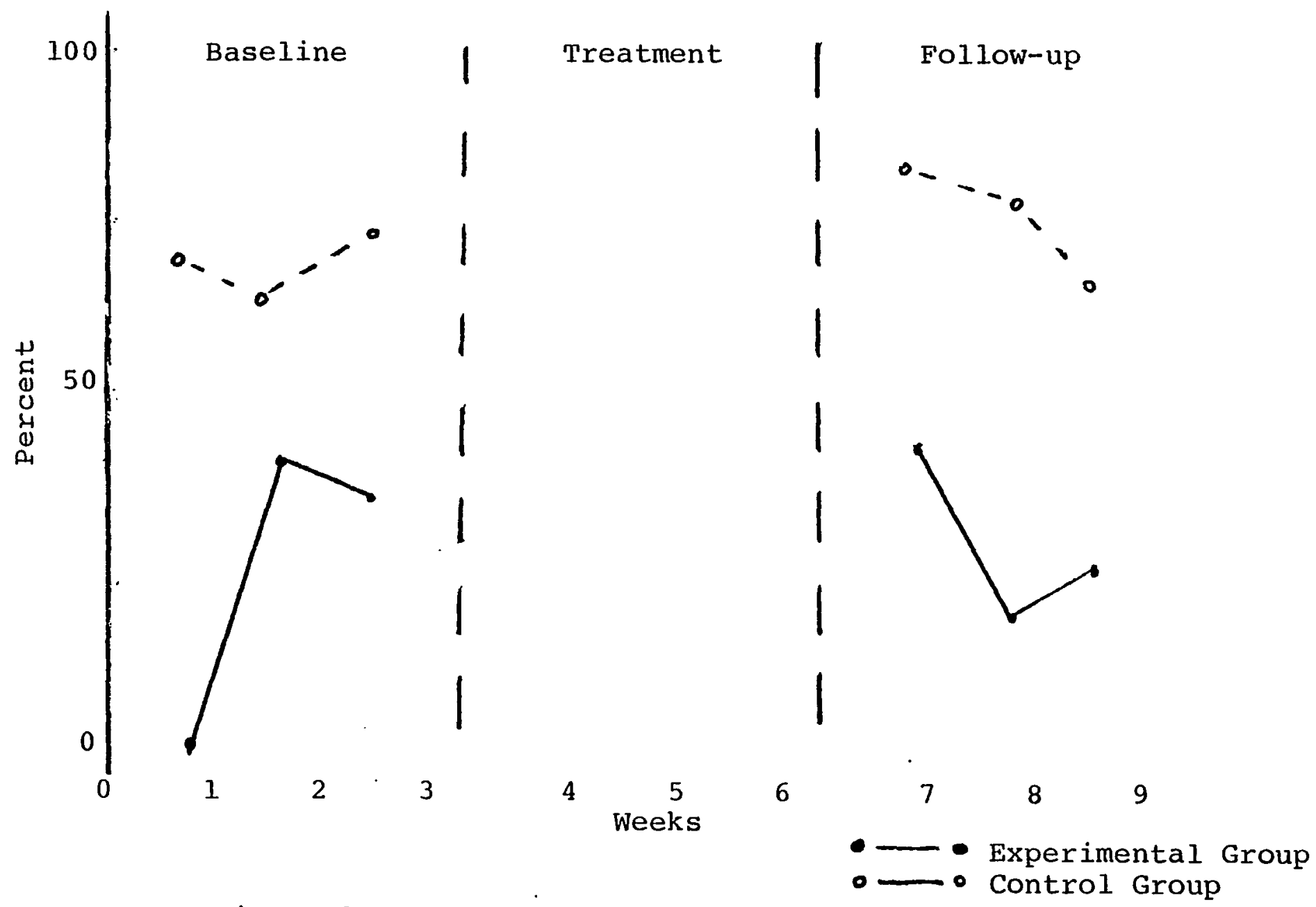

Figure 9. Frequency of Individuality: Ideas. 
Data for "individuality, feelings" are presented in Figure 10. It is obvious that the level of feeling behaviors was low for both groups. While the slope for the experimental group remained fairly unchanged over time, the control group data reflect an upward slope in week 2 and a downward trend in both level and slope for weeks 7,8 , and 9.

From the pattern of data just presented, it can be concluded that there was not a greater increase in "individuality, ideas" or "individuality, feelings" for the experimental group. Because there was no change in either dimension, Hypothesis IV was rejected.

Hypothesis V

If organization development is conducted in a professional school, organizational effectiveness of the members will be improved by an increase in concern behaviors in the experimental group.

The norm, concern, emphasizes the appropriateness of manifesting interest in and involvement with the ideas and feelings of others and oneself. It acts to influence members to help protect and develop the uniqueness of other persons' ideas and feelings. There is a general unconditional regard, non-evaluative feedback, and confirmation of others. There is a readiness to receive new ideas and questions are asked to receive information. Individuals strive to hear people the way they wish to be heard. Verbal behaviors characteristic of this norm include: "Please 


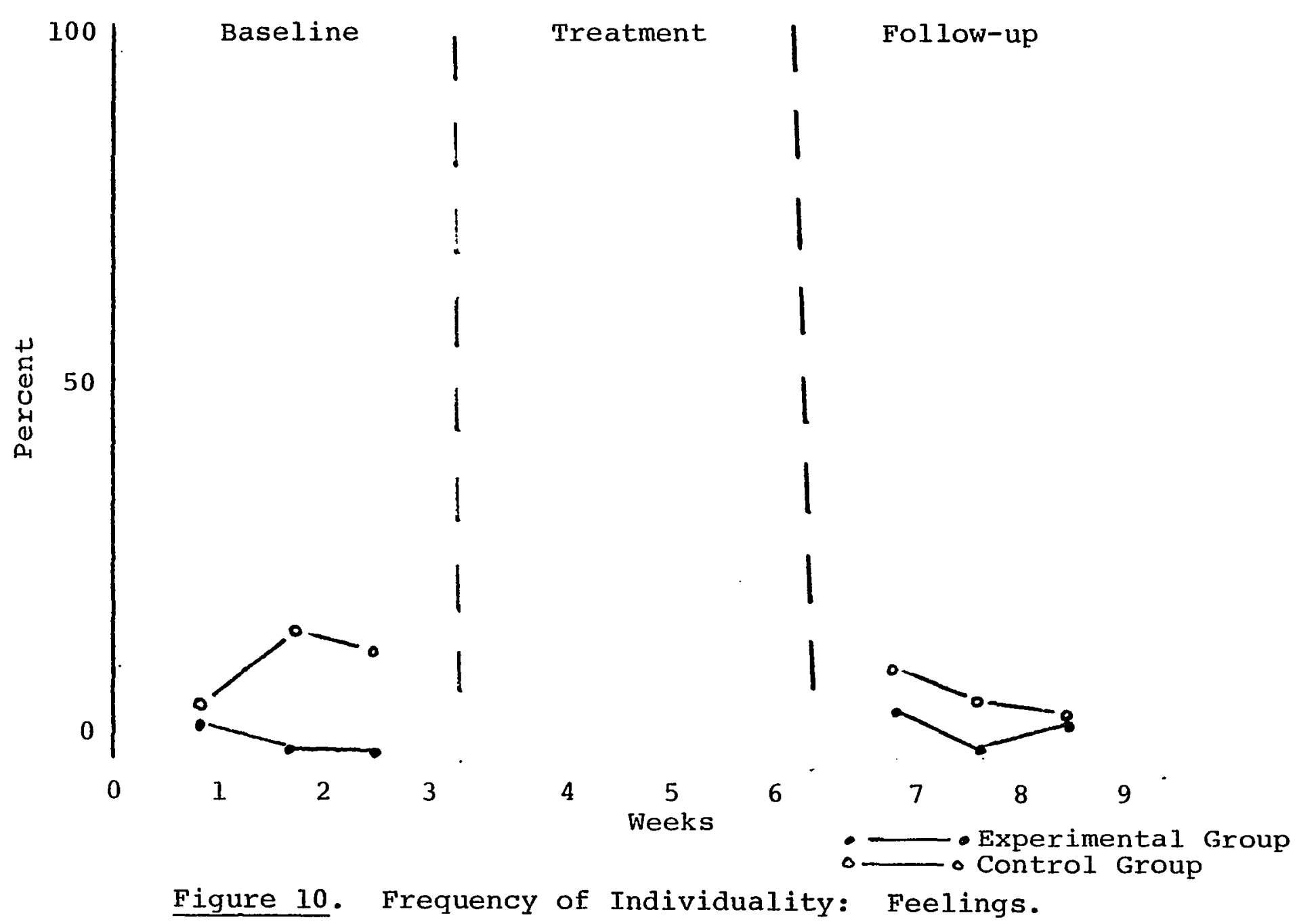


tell me more," "What do you mean?" and "I wonder why I haven't seen that before."

The data for "concern, ideas" are presented in Figure 11 and those for "concern, feelings" in Figure 12. As can be seen in Figure 11, once again the level is markedly different for the two groups, and the slope is different. Results plotted in Figure 11 indicate an initial downward trend in the slope for both groups at weeks 2 and 3 . At week 8 , there is a sharp increase in level for the control group but only a slight increase for the experimental group. Proceeding further, if one examines the experimental group data, there seems to be a slight increase initially in the level of "concern" for ideas behavior at week 7 with another slight increase at week 8. This increase, however, is not sustained, and by week 9 the level is below baseline. The contributory cause for this finding is mere speculation, but one suggestion would be that the energy required to sustain the behavior was too great and the time in which to practice the behavior too short to make any great impact on the members of the group.

Turning now to Figure 12, where data for "concern" for feelings are illustrated, it can be seen that both the baseline level and slope are the same for the two groups. At week 8 , the level and slope for the experimental group increases slightly and remains higher than baseline in week 9 . The control group, on the other hand, remains consistent 


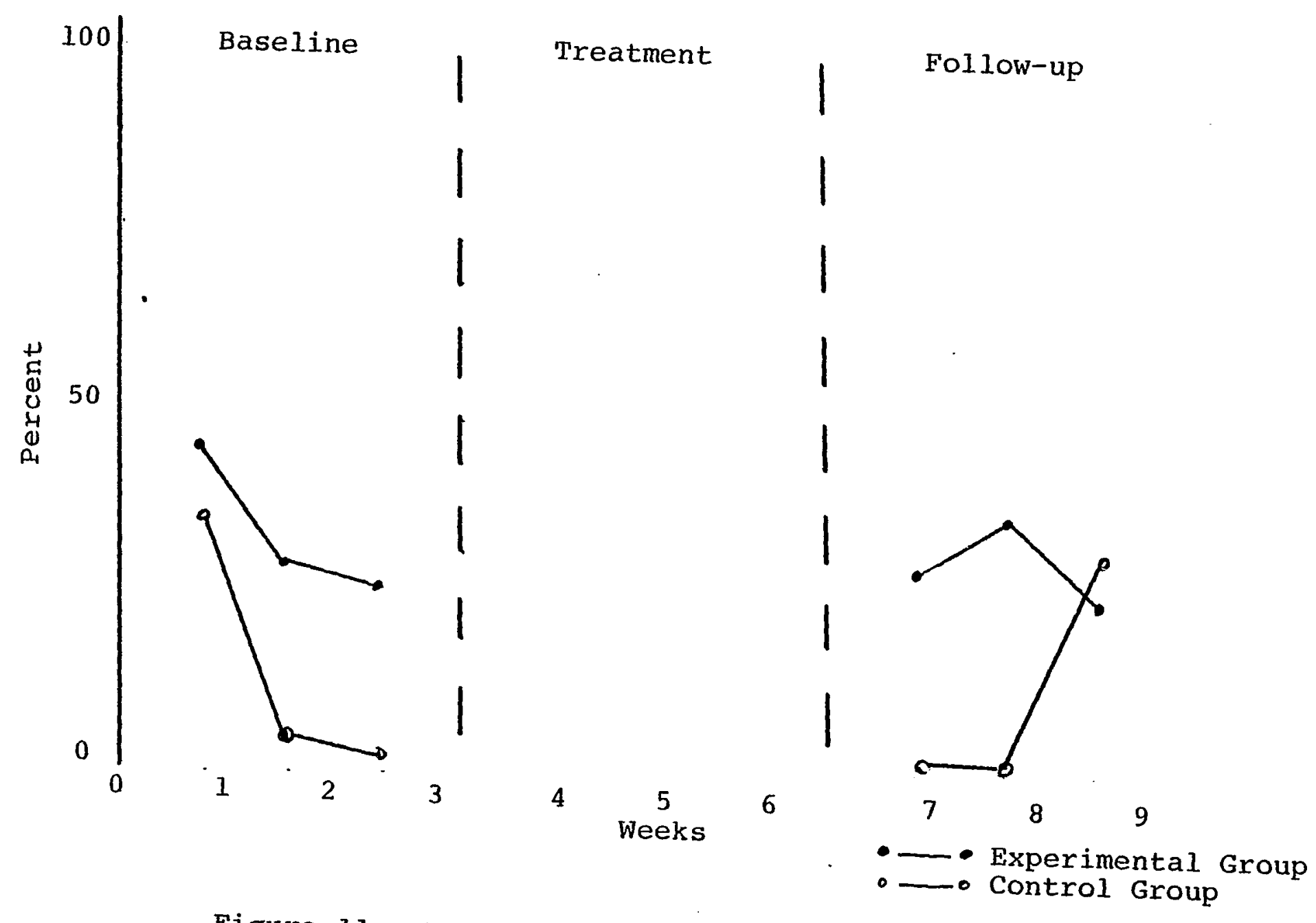

Figure 11. Frequency of Concern: Ideas. 


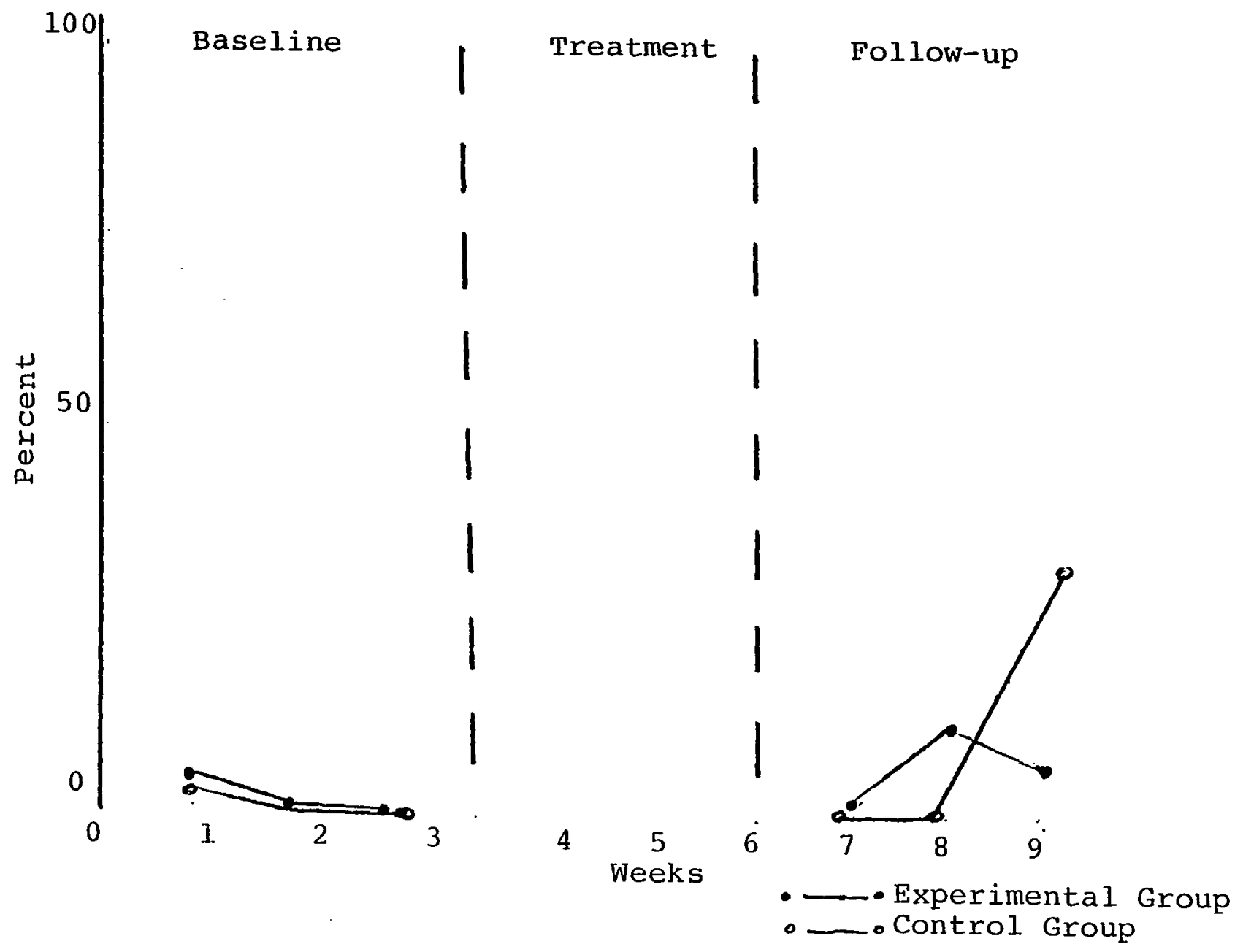

Figure 12. Frequency of Concern: Feelings. 
throughout. From the data presented above, it can be concluded that support for the hypothesis did not follow from the data and therefore it is rejected.

Hypothes is VI

If organization development is conducted in a professional school, organizational effectiveness of the members will be improved by an increase in trust behaviors in the experimental group.

The final variable to be considered in this chapter is trust. The norm of trust does not necessarily mean in relationships, but rather means that individuals take risks about their sense of self-esteem and are willing to examine their ideas and feelings for the purpose of disclosing new aspects of the self. Verbal behaviors exemplifying this category are as follows: "Let's try it and see how it works," "I'm a little afraid to try it, but I will," "I've never said this before. . .," and "I'll go along with it." The results of observations of these behaviors appear in Figures 13 and 14. From the data presented in the first figure, it can be determined that the baseline level for "trust, ideas" in the experimental group was higher than for the control group, even with the downward slope at week 2 . Both level and slope for the control group remained consistent over time. Despite the fact that the level for the experimental group at week 7 was lower than at baseline, there was an increase in level and a sharp upward slope at week 8 , followed by a slight decline in level for the 
experimental group. This decline, however, approached the higher baseline level for the group. There was also a downward trend in slope at week 9. The lack of change in either level or slope for data illustrated in Figure 14 leads the researcher to reject the hypothesis.

Observations of the behavior in six meetings of the Medical-Surgical and Psychiatric-Mental Health departments revealed some marked similarities but some differences as well. Both departments held individuality ideas (owning) as their highest norm. Whereas the Medical-surgical participants held concern for ideas as their second norm, the Psychiatric-Mental Health participants held individuality feelings second. According to Argyris, the PsychiatricMental Health faculty would be considered less tied to pyramidal values and would be more humanistic in outlook. He suggests that in an organization where rationality is uppermost, such a group might be seen as "trouble makers" who are always holding up accomplishing the "task."

There was an increase in behaviors demonstrating individuality ideas, concern ideas and feelings, and trust ideas and feelings in the Medical-Surgical group in the post-treatment weeks, but a decay in trust behaviors was noted at week 9, indicating that the limited OD intervention was insufficient to maintain new behaviors. 


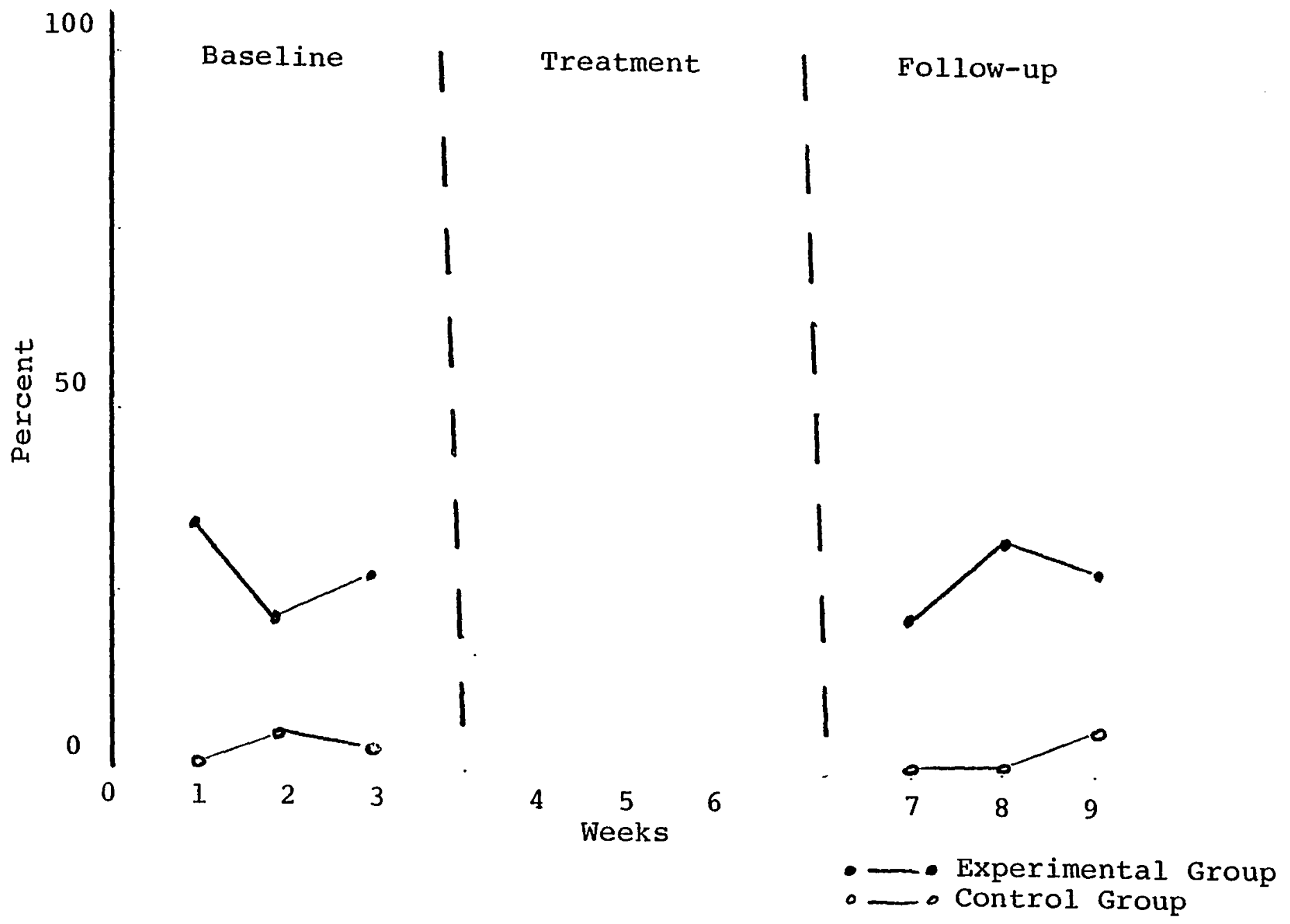

Figure 13. Frequency of Trust: Ideas. 


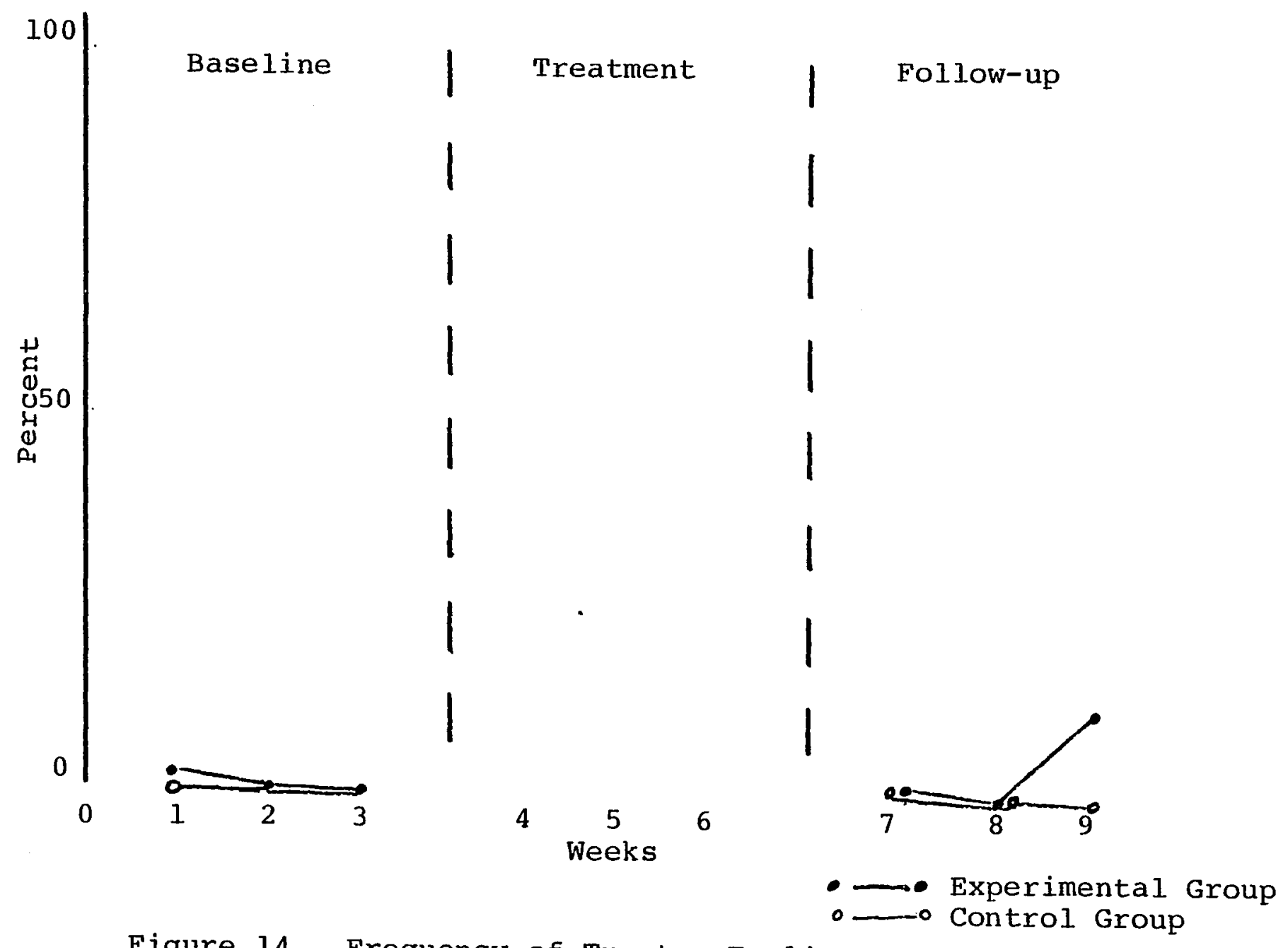

Figure 14. Frequency of Trust: Feelings. 
SUMMARY

This chapter has provided a presentation and analysis of the data collected to test six hypotheses. The six hypotheses predicted that as a result of the OD conducted with the experimental group in a professional school: (a) their collaboration would increase, (b) their communication would improve, (c) their roles would become clearer, and (d) there would be an increase in trust, concern, and individuality behaviors.

Even though the six hypotheses were rejected, there was a trend toward greater collaboration seen in the posttest scores of the control group. Based on these results, it can be stated that the OD did not result in more effectiveness of communication, collaboration, or role clarity, or an increase in trust, concern, and individuality behaviors. 
CHAPTER VI

SUMMARY, CONCLUSIONS, AND RECOMMENDATIONS

The purpose of this chapter is to present a summary of the research and conclusions. Recommendations for further research are also made.

\section{INTRODUCTION}

The purpose of this research was to test the applicability of Argyris' Theory and Method model to a professional school. In order to accomplish this, the research was designed to include two major phases: first, an assessment phase; and second, an organization development phase. Data for the first phase were collected by individual and group interviews and departmental questionnaire. Data for the second phase were generated by the Meetings Questionnaire and nonparticipant observations of six departmental meetings --three baseline and three post-treatment. For the purposes of this research, organization development was defined as the process of diagnosis, data collection, data feedback and exploration, action, and evaluation. 


\section{SUMMARY OF PHASE I}

The individual and group interviews, while basically unstructured, were designed to accomplish the following objectives: (I) to get input about the perceived strengths and limitations of the organization, (2) to ascertain where faculty would like the organization "to be" five years from now, (3) to identify specific problem areas, and (4) to ascertain the perceived need for change.

Information from these sessions was reviewed by a Steering Committee made up of representatives of the various departments and levels of the organization and the researcher. This group collated and analyzed the information and developed an integrated picture relative to the four objectives.

The interviews indicated that, as a rule, faculty felt that one of the strengths of the organization was its educational program; that is, clinical experiences for students were varied and excellent and faculty preparation and commitment were good. Another frequently cited strength was the fact that the school was now an independent part of the Health Sciences Center rather than under the administrative control of the School of Medicine.

Limitations were easier than strengths for most faculty to name. The budgetary constraints were named by the majority of the faculty as the top limitation. Among other effects of low budget, the high student/faculty ratio was 
ranked number one. The faculty felt that the heavy teaching and clinical supervision work load caused by this high ratio virtually precluded time for scholarly activity and professional career development. In addition, opportunities for clinical practice and continuing education for faculty were seen as severely curtailed.

In response to the query, "How do you want to be organized?" the majority of the faculty wanted a strong, decentralized departmental structure. In a series of meetings, several organizational structures were presented and reviewed. The model finally accepted by the faculty is shown in Figure 15.

This model represented three major changes from the current one, namely:

1. The small Maternity Nursing and the Pediatric Nursing departments were merged to form a larger Parent-Child department

2. The Graduate Committee was given departmental status

3. A second Associate Dean for Administration position was added

After a great deal of discussion, this model was approved by faculty as the intermediate organizational format until 1981. At this time, the model will be reviewed and discussion of possible changes will take place. It was recommended that discussions around possible changes, such as 


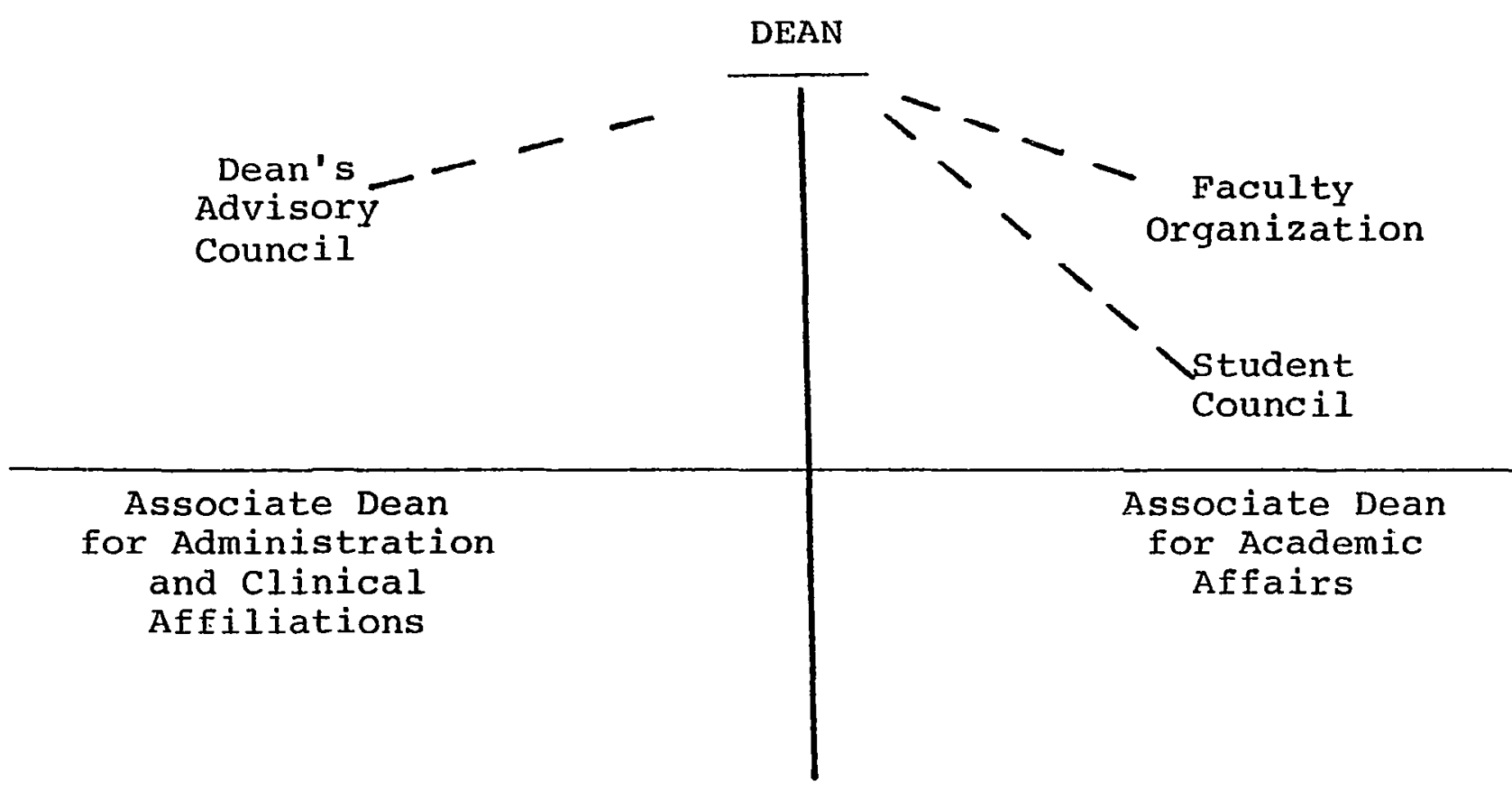

\begin{tabular}{cccc}
\hline Parent- & Community & Medical- & Psychiatric- \\
Child & Health & Surgical & Mental Health \\
Nursing & Nursing & Nursing & Sursing
\end{tabular}

Figure 15. Intermediate Model--1978-1981. 
elimination of the Graduate Studies department, begin in the 1979-1980 academic year.

In evaluating the participants' perceived emphasis on the four missions of the school, it was found that almost without exception they saw a great deal of emphasis placed on teaching, some on community service, and little or none on scholarly activities such as research and publication.

Participants were also asked to rate the adequacy of support services and personnel policies. Faculty satisfaction with salary, academic rank, and opportunities for advancement was low. Many felt that there were too many faculty holding lower ranks and that with opportunities for professional growth severely curtailed by low budgets, the chance for promotion was slim. Secretary/faculty ratio was also clearly perceived as needing a great deal of improvement. The library was rated by almost 100 percent of the participants as in need of a great deal of improvement.

SUMMARY OF PHASE II

The second phase of the research was to measure the impact of an organization development on effectiveness. Effectiveness was defined as an increase in collaboration, improved communication vertically and horizontally, clearer roles, and increase in trust, concern, and individuality behaviors. The two larger departments of the organization were the target groups; one served as the control group, 
the other as the experimental group. Data were collected to test six hypotheses designed to determine the degree to which the organization development program improved collaboration, communication, role clarity, and trust, concern, and individuality behaviors in the experimental group. None of the hypotheses was accepted. There was, however, a trend toward improved collaboration with four of the nineteen items measuring this variable significantly higher on posttest in the experimental group. Iittle change was noted in either the communication or role clarity variables.

Nonparticipant observations of six departmental meetings indicated that organization development had little impact on increasing trust, concern, and individuality behaviors.

\section{CONCLUSIONS}

The contribution of organization development to and the applicability of Argyris' model for the professional. school was not clearly demonstrated by results of the present research. Whereas this research was needed to fill the gap in the literature regarding evaluation of OD strategies in the public sector and the applicability of Argyris' model for professional schools, the results raise more questions than they answer. The conclusions are similar to those reported in Miorrison's study (1978) in that OD was found to 
have a relatively mild impact on the effectiveness of a large public organization.

While this research used a control group design, thus limiting the influence of variables other than the treatment variable, it must be noted that other factors could have influenced the measures. For example, there was a great deal of activity at the administrative level of the school which created an unusually turbulent environment. These activities included a long-range planning group, accreditation review, an ongoing curriculum evaluation, and a change in the president's office.

Even though the research design provided for greater control than most studies reported in the literature, there were definite weaknesses. The first one is that much of the instrumentation used to assess $O D$ impact is not well enough tested for reliability and validity. In addition, the instruments may not evaluate as adequately as desired the variety and intensity of changes which are associated with behavior change. As in the case of the present research, the change in frequency of certain targeted behaviors was greater than others, but the fact that they represented only a smali percentage of total behavior in any given two-hour meeting meant that the hypothesis of a significant change had to be rejected. The question of how much change would be sufficient is left unanswered by the present research. 
Another limitation of the present research was the time frame involved. The twelve-month period between the pre- and post-test measure on the Meetings Questionnaire left considerable room for other factors to influence the outcome measure. The relatively mild degree of change measured in the targeted behaviors may be attributed to the relative mildness of the OD treatment applied. The researcher spent a total of six hours in intervention.

The instrument used to measure the impact of the $O D$ effort may lack the precision needed to detect changes. It must also be stated that the goals of any OD effort are determined by the client group and typically involve the process of the work rather than the output. This fact necessarily limits the measurement of change, especially in such settings as a professional school and other public service settings. In such settings the measurement of improved communication and collaboration are not as easily accomplished as those of reduced costs, improved profits, or increased sales in the private sector.

In summary, analysis of the data indicated that in the present research there were no significant improvements in the post-test measures related to increased collaboration, improved communication, clearer roles, and increased individuality, concern, and trust behaviors. Consequently, the applicability of Argyris' model for the professional 
school setting was not supported. Conclusions drawn from the findings of the research are:

1. Organization development had little impact on improving organizational effectiveness. None of the six hypotheses was supported.

2. The time actually spent on the oD intervention may have been too little to sustain behaviors.

3. It may not be possible for $O D$ to have a great impact on public sector organizations because of their constantly changing environment.

4. Where an organization development intervention is mild, only a mild impact can be expected. In the present research, little time was spent in the actual intervention. It may be that there is an optimal time for the intervention.

5. The fact that none of the hypotheses was supported does not necessarily mean that organization development has no value for the professional school, but rather may be due to the inadequacy of the instruments, the duration of the intervention, the mild application of the intervention, and the lack of long-term reinforcement for new behaviors.

6. The OD program reported here was conducted with a group which perceived itself as functioning fairly effectively. The degree to which the $O D$ will make a difference is dependent in part on the level of 
organizational effectiveness already present when the OD is applied. Organization development tends to make less difference in areas where the organization is already functioning effectively and a greater difference in areas where the organization is functioning less effectively.

7. Evaluation of $O D$ outcomes may also be imprecise because the objectives are fluid and change as the OD process evolves.

Finally, the essentially negative findings of this research can be taken by others in the field as a very positive outcome. That is, it should now be somewhat more apparent to those engaged in similar endeavors exactly what the pitfalls are and what elements should be stressed as we begin to understand the potential effectiveness of organization development in the public sector.

\section{RECOMMENDATIONS FOR FUTURE RESEARCH}

1. Exploration of the impact of time on the success or failure of an OD effort should be undertaken.

2. A follow-up study of the organization in the present study to assess changes should be done.

3. A more intensive $O D$ intervention should be designed to ircrease trust, concern, and individuality behaviors. Such an intervention might include workshops designed to allow practice of these behaviors. 
4. An attempt should be made to develop more precise measurement tools for evaluation of $O D$.

5. An experimental design should be developed with the agenda content controlled; that is, an agenda dealing with information, one dealing with personnel problems, and one unstructured agenda, to test the effect of agenda on trust, concern, and individuality behaviors. 


\section{REFERENCES}


Aiken, C. and P. Hage. Organizational Structure. San Francisco, California: Jossey-Bass Co., 1968.

Alderfer, C. P. Change processes in organizations. In M. Dunnette (Ed.), Handbook of Industrial and Organizational Psychology. Chicago, Illinois: Rand McNally, 1975.

and $R$. Ferriss. Understanding the impact of survey feedback. In W. W. Burke and H. A. Hoenstein (Eds.), The Social Technology of Organizational Development. New York: McGraw-Hill, 1979 .

and J. Holbrook. A new design for survey feedback, Education and Urban Society, 1973, 5, 437-464.

Anderson, w. Politics and the New Humanism. Pacific Palisades, California: Goodyear Publ. Co., 1973.

Argyris, c. Integrating the Individual and the Organization. New York: John Wiley \& Co., 1954.

- Conditions for Competence Acquisition and Therapy. Journal of Applied Behavioral Science, 1968, $\underline{4}(2), 147-178$.

- Interpersonal Competence and Organizational Effectiveness. Homewood, Illinois: Dorsey Press, 1962.

- Organization and Innovation. Homewood, Illinois: Dorsey Press, 1965.

- Intervention Theory and Method. Reading, Massachusetts: Addison-Wesley, 1973 and 1970.

and D. Schon. Theory in Practice: Increasing Professional Effectiveness. San Francisco, California: Jossey-Bass Co., 1974.

- T-Groups for Organizational Effectiveness. Harvard Business Review, 1964, 52, 60-74.

- Increasing Leadership Effectiveness. New York: John Wiley \& Sons, 1976.

Beckhard, R. ABS in health care systems: who needs it? Journal of Apjlie' Behavioral Science, 1974, 10 (1), 93-106. 
Beckhard, R. The confrontation meeting. Harvard Business Review, 1957, 46 (2), 149-155.

- Organization Development: Strategies and Models. Reading, Massachusetts: Addison-Wesley, 1969.

Be11, D. The Coming of the Post-Industrial Society. New York: Basic Books, Inc., 1973.

Bennis, W. G. The Temporary Society. New York: HarperRow Co., 1968 .

- Changing Organizations. New York: McGraw Hill Co. , 1965 .

Blake, R. R. and J. S. Mouton. Consultation. Menlo Park, California: Addison-Wesley Publ. Co., 1976.

Blau, P. and W. R. Scott. Formal Organizations: A Comparative Approach. San Francisco, California: Chandler Publ. Co., 1962 .

and R. Schoenherr. Organizations: Structure and Process. San Francisco, California: Jossey-Bass Co., 1971.

Bonjean, C. M. and G. G. Vance. A short-form measure of self-actualization. Journal of Applied Behavioral Science, 1968, $\underline{4}$ (3), $299-312$.

Bowers, D. G. O.D. Techniques and their results in 23 organizations. The Michigan ICL Study. Journal of Applied Behavioral Science, 1973, 9 (1), 21-43.

- Perspectives in Organizational Development. Technical Report to the Office of Naval Research, 1970 .

and J. I. Franklin. Survey--Guided Development I: Data Based Organizational Change. La Jolla, California: University Associates, 1977.

Boyer, R. K. New Applications in O.D.: The University. Paper presented at the meeting of the Organization Development Division, Academy of Management, Seattle, Washington, 1974.

- Organization Development approaches to improving teaching. Paper presented at the National Conference of the American Association of Higher Education, Chicago, Illinois, 1975. 
Boyer, R. K. and C. Crockett. O.D. in higher education. Journal of Higher Education, 1973, 44 (5), 339-350.

Campbel1, D. T. and J. C. Stanley. Experimental and QuasiExperimental Designs for Research. Chicago: Rand McNaliy, 1963.

Campbell, J. P. Personnel training and development. Annual Review Psychology, 1979, 22, 291-306.

- Structures for organizational effectiveness and their implications. Paper presented at the American Psychological Association National Convention, Washington, D.C., September 1976.

and M. Dunnett. Effectiveness of T-Group experience in managerial training and development. Psychological Bulletin, 1968, 70, 73-104.

Champion, D. J. The Sociology of Organizations. New York: McGraw-Hill Co., 1975 .

Chesler, M. A. and M. Flanders. Resistance to research and research utilization: the death and life of a feedback attempt. J.Appl. Beh. Sc., 1967, 3, 469-487.

Chin, R. and $K$. Benne. General strategies for effecting changes in human systems. In W. Bennis, K. Benne, R. Chin and T. Corey (Eds.), The Planning of Change. New York: Holt, Rinehart \& Winston Co., 1976.

Etzioni, A. Modern Organizations. Englewood Cliffs, New Jersey: Prentice Hall, 1964 .

French, W. Organization development: objectives, assumptions and strategies. California Management Review, $1969,12(2), 23-24$.

and C. Bell. Organization Development: Behavioral Science Interventions for Organization Improvement. Englewood Cliffs, New Jersey: Prentice-Hall, 1978.

Friedlander, F. and L. D. Brown. Organization development. Annual Review Psychology, 1974, 24, 219-341.

Friedman, G. The Anatomy of Work. Glencoe; Illinois: Free Press, 1961 .

Gardner, J. Self-Renewal: The Individual and the Innovative Society. New York: Harper \& Row Publ. Co., 1963. 
Gibb, J. Trust: A New View of Personal and Organizational Development. Los Angeles, California: The Guild of Tutors Press, 1978.

Glazer, M. The Research Adventure. New York: Random House, 1972 .

Goodstein, I. Personal Communication, June 7, 1979.

- Consulting with Human Services. Reading, Massachusetts: Addison-Wesley, 1978.

Gouldner, A. Organizational Analysis. In R. K. Merton (Ed.), Sociology Today. New York: Basic Books, 1954.

Greenfield, T. B. Organizations as social inventions: rethinking assumptions about change. Journal of Applied Behavioral Science, 1973, 9 (5), 551-573.

Greiner, I. Patterns of organizational change. Harvard Business Review, 1967, 45, 119-128.

Haas, J. E. and T. E. Drabek. Complex Organizations: A Sociological Perspective. New York: The Macmillan Co., 1973.

Hill, P. Toward a New Philosophy of Management. New York: Barnes and Noble, 1971.

Huse, E. F. O.D. and Change. San Francisco, California: West Publishing Co., I973.

and $J$. Bowditch. Behavior in Organizations: A Systems Approach to Management. Reading, Massachusetts: Addison-Wesley Co., 1973.

Ikenberry, S. O. The organizational dilemma. Journal of Higher Education, 1972, 43 (1), 23-24.

Johnson, S. M. and O. D. Bolston. Methodological Issues in Naturalistic Observation: Some Problems and Solutions for Field Research. In I. A. Hamerlynck, L. C. Handy, and E. J. Mash (eds.), Behavior Change: Methodology, Concepts, and Practice. Champaign, Illinois: Research Press, 1974. 
Kegan, D. and A. Rubenstein. Trust, effectiveness and organizational development: A field study in $R \& D$. Journal of Applied Behavioral Science, 1974, 9 , 498-513.

Kerlinger, F. Foundations of Behavioral Research. New York: Holt, Rinehart \& Winston, 1973.

Kuhn, T. The Structure of Scientific Revolutions. Chicago, Illinois: The University of Chicago Press, 1970.

Lake, D. G.; M. G. Miles; and R. B. Earle. Measuring Human Behavior. New York: Teachers College Press, 1973.

Leavitt, H. J. Applied organizational change in industry: structure, technology and humanistic approaches. In J. G. March (Ed.), Handbook of Organizations.

Leininger, M. The crisis in leadership. The American Nurse, 1973.

Lippitt, R., J. Watson and B. Westley. The Dynamics of Planned Change. New York: Harcourt, Brace \& World, 1955 .

Lodge, G. C. In R. Martin. Be Kind to Your Plants or You Could Cause a Violet to Shrink. Wall Street Journal, February 2, 1972 .

Lundberg, C. O.D.: Current Perspectives and Future Issues. Paper presented to Southeast Chapter of American Institute for Decision Sciences, 1974.

Michael, D. On Learning to Plan and Planning to Learn. San Francisco, California: Jossey-Bass Publishing Co., 1973.

Miles, M. G. Final Report, Appenaix, Cooperative Project for Educational Development. U.S. Office of Education, Washington, D.C., 1970 .

Morrison, P. Evaluation of OD: A review and assessment. Journal of Group and Organization Studies, 1978, 3 , 42-70. 
Pate, L. E., W. R. Nielsen and P. C. Bacon. Advances in research on organization development: Toward a beginning. In R. L. Taylor, M. J. O'Connell, R. A. Zawacki, and D. D. Warrick (Eds.), Academy of Management Proceedings 176 (Proceedings of the 36 th Annual Meeting of the Academy of Management, Kansas City, Mo., August 11-14, 1976), pp. 389-394.

Perkins, J. O.D. in health care settings. Journal of Applied Behavioral Sciences, 1972, 8 (1), 36-42.

Raia, A. O.D.: Some issues and challenges. California Management Review, 1972, 14 (4), 13-20.

Rubin, I., M. Plovnik and R. Fry. Initiating planned change in health care systems. Journal of Applied Behavioral Sciences, 1974, 10, 107-1 $\overline{24}$.

Sashkin, M. Models and roles of change agents. In J. W. Pfeiffer and J. E. Jones (Eds.), Organization Development: Selected Readings. La Jolla, California: University Associates, 1977.

Schein, E. H. Process Consultation: Its Role in Organization Development. Reading, Massachusetts: AddisonWesleY, 1969 .

Schmuck, R. A. and M. B. Miles. Improving schools through OD: An overview. In R. A. Schmuck and M. B. Miles (Eds.), Organization Development in Schools. Palo Alto, California: National Press Books, 1971.

Simon, H. On the Concept of Organizational Goal. Administrative Science Quarterly, 1964, 9 (1), 19-30.

Toffler, A. Future Shock. New York: Random House, 1970.

Varney, G. H. Organization Development for Managers. Menlo Park, California: Addison-Wesley Publishing Co., 1977. 
APPENDICES 
APPENDIX A

DEPARTMENTAI ANALYSIS QUESTIONNAIRE

Department

1. What is your present rank? Mark one.

Professor

Associate Professor

Assistant Professor

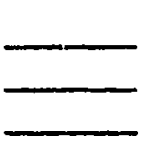

Instructor

Lecturer

Other

2. How long have you been in this department? Mark one.

0-3 Years

9-15 Years

4-8 Years

Over 15 Years

3. Do you hold a joint appointment? Mark one.

Yes

No

4. Within your depart-

ment how much emphasis is placed on each of the following? Mark one on each line.

A Very A

Great Great

Amount Amount some
A

slight at

Amount AIl
a. Instruction of Undergraduate
b. Instruction of graduate stu- dents
c. Community service
d. Research and publication
e. Practice 
5. The following are a number of areas which individuals usually consider as being important when thinking about their involvement in a department. Please indicate your thoughts about each of the areas below:

$\begin{array}{cc}\begin{array}{c}\text { Much } \\ \text { Somewhat }\end{array} & \begin{array}{c}\text { Needs a good } \\ \text { deal of }\end{array} \\ \text { better than better than Satisfactory Needs some } \\ \text { I expect I expect at present improvement improvement }\end{array}$

a. Salary

b. Time available to pursue my own interests

c. Chances for promotion

d. Office space

e. Library facilities

f. Ratio of secretarial help to professors 


\section{APPENDIX B}

\section{STAFF MEETINGS}

The philosopher Martin Buber once said, "All life is meeting." No matter how that statement makes you feel, you will probably agree that university personnel hold a lot of meetings, and that much depends on their quality. We are thinking specifically of either meetings in which the entire faculty of your department meets or meetings in which only a part of the faculty meets (committee meetings).

Name of the meeting you are considering

How often does it usually meet?

length of typical meeting

Now please consider what usually or typically happens in this meeting. Beside each of the items below, put one of the following numbers.

5 This is very typical of this meeting; it happens repeatediy.

4 This is fairly typical of this meeting; it happens quite often.

3 This is more typical than not, but it doesn't happen a lot.

2 This is more untypical than typical, though it does happen some.

1 This is quite untypical; it rarely happens.

0 This is not typical at all; it never happens.

1. When problems come up in the meeting, they are thoroughly explored until everyone understands what the problem is.

2. The first solution proposed is often accepted by the group.

3. People come to the meeting not knowing what is to be presented or discussed.

4. People ask why the problem exists, what the causes are. 
5. There are many problems which people are concerned about which never get on the agenda.

6. There is a tendency to propose answers without really having thought the problem and its causes through carefully.

7. The group discusses the pros and cons of several different alternate solutions to a problem.

8. People bring up extraneous or irrelevant matters.

9. The average person in the meeting feels that his ideas have gotten into the discussion.

10. Someone summarizes progress from time to time.

11. Decisions are often left vague--as to what they are, and who will carry them out.

12 . Either before the meeting or at its beginning, any group member can easily get items onto the agenda.

13. People are afraid to be openly critical or make good objections.

14. The group discusses and evaluates how decisions from previous meetings worked out.

15 . People do not take the time to really study or define the problem they are working on.

16. The same few people seem to do most of the talking during the meeting.

17. People hesitate to give their true feelings about problems which are discussed.

18. When a decision is made, it is clear who should carry it out, and when.

19. There is a good deal of jumping from topic to topic-it's often unclear where the group is on the agenda.

20. From time to time in the meeting, people openly discuss the feelings and working relationships in the group. 
21.

22.

23.

24.

25.

26.

27.

28.

29.

30.

31.

32.

33.

34.

35.

36.

37.

The same problems seem to keep coming up over and over again from meeting to meeting.

People don't seem to care about the meeting, or want to get involved in it.

When the group is thinking about a problem, at least two or three different solutions are suggested.

When there is a disagreement, it tends to be smoothed over or avoided.

Some very creative solutions come out of this group.

Many people remain silent.

When conflicts over decisions come up, the group does not avoid them, but really stays with the conflict and works it through.

The results of the group's work are not worth the time it takes.

People give their real feelings about what is happening during the meeting itself.

People feel very committed to carrying out the solutions arrived at by the group.

When the group is supposedly working on a problem, it is really working on some other "under the table" problem.

People feel antagonistic or negative during the meeting.

There is no follow-up of how decisions reached at earlier meeting worked out in practice.

Solutions and decisions are in accord with the chairman's or leader's point of view, but not necessarily with the members'.

There are splits or deadlocks between factions or sub-groups.

The discussion goes on and on without any decision being reached.

People feel satisfied or positive during the meeting. 